\title{
Supporting information for \\ Repurposing an aldolase for the chemoenzymatic synthesis of substituted quinolines
}

\author{
Douglas J. Fansher, Richard Granger, Satinderpal Kaur, and David R. J. Palmer* \\ Department of Chemistry, University of Saskatchewan, Saskatoon, SK, Canada S7N 5C9
}

*to whom correspondence should be addressed.dave.palmer@usask.ca

\section{Table of contents}





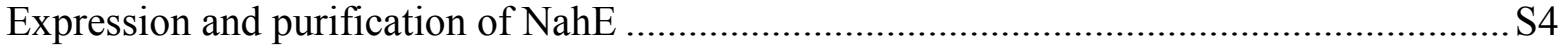

HPLC Monitoring of NahE-Catalyzed Quinaldic Acid Formation........................................S5

NMR Monitoring of NahE-Catalyzed Quinaldic Acid Formation...........................................S5

General procedure for the synthesis of 2-nitrobenzaldehydes from 2-nitrobenzoic acids .....S6

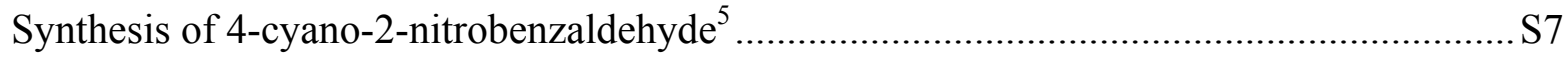

General procedure for Chemo-Enzymatic Synthesis of Quinaldic Acids ..............................S8



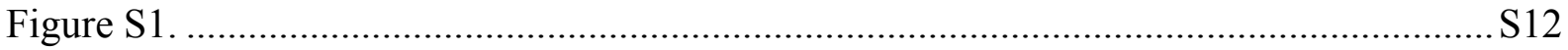

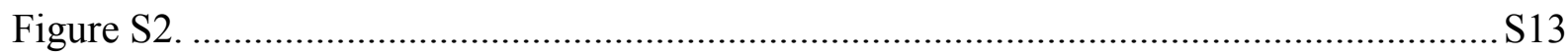

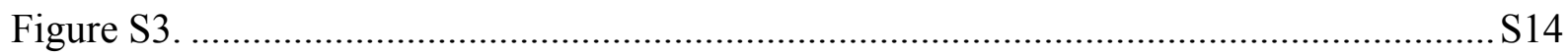

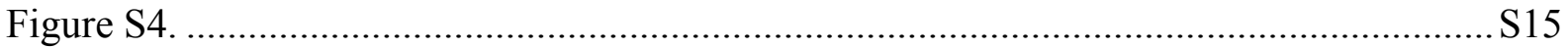

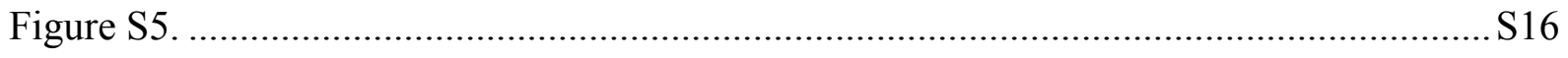

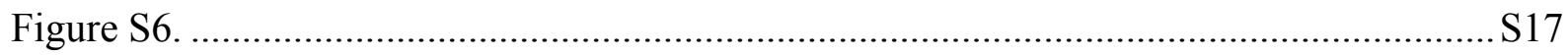

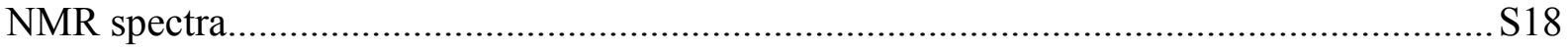




\section{General procedures}

2-Aminobenzaldehydes were prepared immediately prior to use in large scale enzymatic reactions. 2-Aminobenzaldehyde (2-AB) used in HPLC and kinetic assays were aliquoted and frozen at $-20{ }^{\circ} \mathrm{C}$ for future use. Commercially available 2-nitroaldehydes and 2-nitrobenzoic acids were purchased from AK Scientific, Sigma-Aldrich or Alpha Aesar. Thin layer chromatography was conducted using silica gel $60 \mathrm{~F}_{254}$ aluminum plates with visualization using by UV lamp $(254 \mathrm{~nm})$. NMR spectra were obtained on a Bruker $500 \mathrm{MHz}$ spectrometer, with chemical shift downfield from TMS assigned based upon residual protiated solvent peaks. High resolution mass spectrometry was performed using an Applied Biosystems/MDS Sciex Qstar X1 LC/MS/MS. NMR and MS instruments are part of Saskatchewan Structural Sciences Centre. 


\section{The nahE gene}

The gene encoding NahE, matching the sequence reported by Howard, et al., 2016 was obtained from GeneScript. ${ }^{1}$ The synthetic gene was ordered already cloned into pET-28a-TEV and contains an N-terminal hexa-histidine tag for affinity column protein purification. The resulting plasmid was transformed into E. coli BL21 Gold (DE3).

\section{Gene sequence:}

atgctgaacaaagtgattaaaaccaccegectgaccgcggaagatattaacggcgcgtggaccattatgccgacccegagcaccceggat gcgagcgattggcgcagcaccaacaccgtggatctggatgaaaccgcgcgcattgtggaagaactgattgcggcgggcgtgaacggcat tctgagcatgggcacctttggegaatgcgegaccetgacctgggaagaaaaacgcgattatgtgagcaccgtggtggaaaccattcgegg ccgcgtgccgtatttttgcggcaccaccgcgctgaacacccgcgaagtgattcgccagacccgcgaactgattgatattggcgegaacggc accatgctgggcgtgccgatgtgggtgaaaatggatctgccgaccgcggtgcagttttatcgcgatgtggegggcgcggtgccggaagcg gcgattgcgatttatgcgaacccggaagcgtttaaatttgattttccgcgeccgttttgggeggaaatgagcaaaattccgcaggtggtgaccg cgaaatatctgggcattggcatgctggatctggatctgaaactggcgccgaacattcgctttctgccgcatgaagatgattattatgcggcggc gcgcattaacccggaacgcattaccgcgttttggagcagcggcgcgatgtgcggcceggcgaccgcgattatgctgcgegatgaagtgga acgcgcgaaaagcaccggcgattggattaaagcgaaagcgattagcgatgatatgcgegcggeggatagcaccetgtttccgcgeggeg attttagcgaatttagcaaatataacattggectggaaaaagcgcgcatggatgcggegggetggctgaaagcgggcecgtgcegccegc cgtataacctggtgccggaagattatctggtgggegcgcagaaaagcggcaaagcgtgggcggcgctgcatgcgaaatatagcaaataa

Protein sequence (with His-tag and TEV cleavage site underlined): MGSSHHHHHHSSGENLYFQGHMLNKVIKTTRLTAEDINGAWTIMPTPSTPDASDWRSTN TVDLDETARIVEELIAAGVNGILSMGTFGECATLTWEEKRDYVSTVVETIRGRVPYFCGT TALNTREVIRQTRELIDIGANGTMLGVPMWVKMDLPTAVQFYRDVAGAVPEAAIAIYAN PEAFKFDFPRPFWAEMSKIPQVVTAKYLGIGMLDLDLKLAPNIRFLPHEDDYYAAARINP ERITAFWSSGAMCGPATAIMLRDEVERAKSTGDWIKAKAISDDMRAADSTLFPRGDFSE FSKYNIGLEKARMDAAGWLKAGPCRPPYNLVPEDYLVGAQKSGKAWAALHAKYSK UniProtKB: Q51947 


\section{Expression and purification of NahE}

For expression of NahE, cells harboring the plasmid were incubated with shaking ( 250 rpm) overnight at $37{ }^{\circ} \mathrm{C}$ in LB media $(10 \mathrm{~g} / \mathrm{L}$ tryptone, $5 \mathrm{~g} / \mathrm{L}$ yeast extract and $10 \mathrm{~g} / \mathrm{L}$ sodium chloride) supplemented with $50 \mu \mathrm{g} / \mathrm{mL}$ kanamycin. This starter culture was then used to inoculate $1 \mathrm{~L}$ of LB media. Cells were grown to an $\mathrm{OD}_{600}$ of 0.6 at $37^{\circ} \mathrm{C}$ with shaking $(250 \mathrm{rpm}$ ) after which cells in media were cooled to $15{ }^{\circ} \mathrm{C}$ and IPTG was added to a final concentration of 1.0 $\mathrm{mM}$. Cells were shaken for 36 hours and harvested by centrifugation $(10,000 \mathrm{~g}$ for 10 minutes at $4{ }^{\circ} \mathrm{C}$ ) and stored for later use. Frozen pellet from $1 \mathrm{~L}$ of culture was thawed on ice and suspended in lysis buffer (50 mM Tris- $\mathrm{HCl}, 300 \mathrm{mM} \mathrm{NaCl}$ and $20 \mathrm{mM}$ imidazole) and sonicated using a Branson Digital Sonfier 250 (3 minutes total run time at 55\% amplitude cycling between $10 \mathrm{sec}$ on and $20 \mathrm{sec}$ off). Cell debris was removed by centrifugation at $20,000 \mathrm{~g}$ for 45 minutes at $4{ }^{\circ} \mathrm{C}$. Supernatant was loaded onto a pre-equilibrated nickel chelating Sepharose column (GE Healthcare). The column was subsequently washed with 15 column volumes of lysis buffer and then the protein was eluted with $5 \mathrm{~mL}$ of elution buffer $(50 \mathrm{mM}$ Tris- $\mathrm{HCl}, 300 \mathrm{mM} \mathrm{NaCl}$ and 500 $\mathrm{mM}$ imidazole). The eluted protein was dialyzed using $25 \mathrm{kDa}$ dialysis tubing (Spectrum Labs) against 200 volumes storage buffer ( $25 \mathrm{mM}$ Tris- $\mathrm{HCl}, 300 \mathrm{mM} \mathrm{NaCl}$ and $30 \% \mathrm{v} / \mathrm{v}$ glycerol). Protein purification was assessed by Coomassie Blue-stained SDS-PAGE electrophoresis. Protein concentration was quantified by UV absorbance (NanoDrop) based upon an extinction coefficient of $67,630 \mathrm{M}^{-1} \mathrm{~cm}^{-1}$ calculated using Expasy ProtParam Tool. Aliquots were frozen in liquid nitrogen for long term storage at $-80^{\circ} \mathrm{C}$.

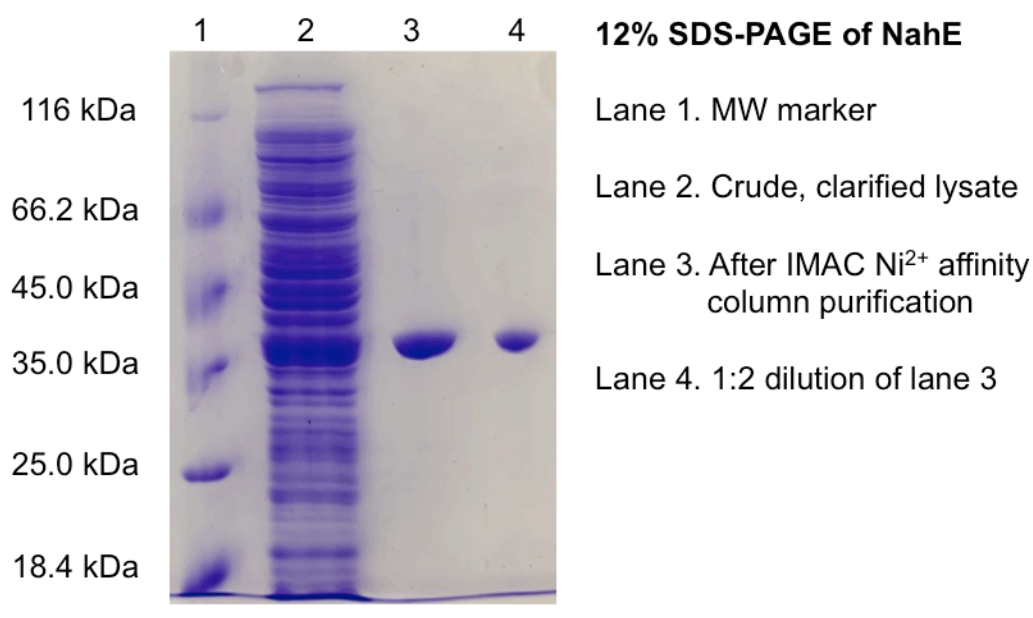




\section{HPLC Monitoring of NahE-Catalyzed Quinaldic Acid Formation}

2-AB $(1.67 \mathrm{mg}, 13.8 \mu \mathrm{mol}, 13.8 \mathrm{mM})$ in DMSO $(50 \mu \mathrm{L})$ was added to $100 \mathrm{mM} \mathrm{KPO}_{4}(\mathrm{pH}$ 6.5, $947 \mu \mathrm{L})$ containing sodium pyruvate $(2.20 \mathrm{mg}, 20.0 \mu \mathrm{mol}, 20 \mathrm{mM})$. NahE $(3 \mu \mathrm{L}, 20.5 \mu \mathrm{g})$ was added to bring the final volume to $1 \mathrm{~mL}$, as well as to initiate the reaction. The reaction was mixed at room temperature and aliquots were taken at 5, 20,40,60, 80, 100, 120, 140 and 300 minutes for characterization by HPLC. For each measurement, a $50-\mu \mathrm{L}$ aliquot of the reaction mixture was diluted 20 -fold using $100 \mathrm{mM} \mathrm{KPO}_{4}(\mathrm{pH} 6.5,950 \mu \mathrm{L})$ and resolved on a Hamilton PRP-X100 Anion Exchange column at a pump speed of $1 \mathrm{~mL} /$ minute using a mobile phase of $100 \%$ methanol for a total runtime of 15 minutes, monitored at $300 \mathrm{~nm}, 320 \mathrm{~nm}$, and $368 \mathrm{~nm}$.

\section{NMR Monitoring of NahE-Catalyzed Quinaldic Acid Formation}

A master reaction was prepared according to the procedure for synthesis of quinaldic acids. Upon addition of the NahE, aliquots $(2 \times 750 \mu \mathrm{L})$ were removed after various time points $(0.083,0.25,0.75,2.33,4.33,10$ and $1440 \mathrm{~min})$ and quenched with an equal volume of methanol. Samples were placed in Speed-Vac $\left(65^{\circ} \mathrm{C}\right)$ and the solvent removed under vacuum. The samples for each time point were combined and reconstituted with $\mathrm{D}_{2} \mathrm{O}(1 \mathrm{~mL})$ and characterized with ${ }^{1} \mathrm{H}$ NMR. Integrals of 2-aminobenzaldehyde (singlet at $9.7 \mathrm{ppm}$ ), 2-QA (doublet at 8.37 and 8.03 $\mathrm{ppm}$ ) and 2-aminobenzylidenepyruvate (doublet at $6.78 \mathrm{ppm}$ ) were taken in reference to glycerol $\mathrm{C}-\mathrm{H}$ proton $(3.73 \mathrm{ppm})$ which was set to an integration of 1 . Integrations for each compound were divided by the sum of integrations for the three species in solution (chemical shifts listed above). These $\%$ compositions were plotted against time to estimate percentage of each species in solution. Notes: Glycerol is a component of the enzyme storage buffer and is endogenous to the reaction; 2-QA integrations used correspond to proton at $\mathrm{C} 3$ and $\mathrm{C} 4$; the average of the two 2-QA peaks $(\mathrm{C} 3-\mathrm{H}$ and $\mathrm{C} 4-\mathrm{H})$ was used to determine its relative abundance. In some cases, half of the trans-alkene doublet could not be resolved (0.083-2.33 minutes) so the integration of half the peak was taken instead (and multiplied by two) to get relative abundance of 2 aminobenzylidenepyruvate. 


\section{General procedure for the synthesis of 2-nitrobenzaldehydes from 2-nitrobenzoic acids}

Synthesis of 2-nitrobenzaldehydes was adapted from Roberts et al., 2004. ${ }^{2}$ In brief, carboxylic acid derivatives were converted to the corresponding Weinreb amide and reduced at $80{ }^{\circ} \mathrm{C}$ using DIBAL. Carboxylic acid $(1.5 \mathrm{mmol})$ was dissolved in DCM $(25 \mathrm{~mL})$ containing triethylamine (1.1 eq, $1.68 \mathrm{mmol})$. PyBOP•PF $6(1.1 \mathrm{eq}, 1.68 \mathrm{mmol})$ was added and the reaction was stirred at room temperature for $5 \mathrm{~min}$. $\mathrm{N}, \mathrm{O}$-dimethyl hydroxylamine $\bullet \mathrm{HCl}$ salt $(1.15 \mathrm{eq}, 1.75$ mmol) was added followed immediately by triethylamine (1.1 eq, $1.68 \mathrm{mmol})$. The reaction was stirred at room temperature overnight upon which starting material was consumed as shown by TLC. Reaction mixture was washed with $1 \mathrm{M} \mathrm{HCl}$ solution $(3 \times 10 \mathrm{~mL}), \mathrm{H}_{2} \mathrm{O}(1 \times 10 \mathrm{~mL}), 1 \mathrm{M}$ $\mathrm{NaHCO}_{3}(3 \times 10 \mathrm{~mL}), \mathrm{H}_{2} \mathrm{O}(1 \times 10 \mathrm{~mL})$, brine $(1 \times 10 \mathrm{~mL})$ and dried with $\mathrm{Na}_{2} \mathrm{SO}_{4}$. Solvent was removed under vacuum to given crude Weinreb amide followed by column chromatography to yield pure Weinreb Amide. Reduction of Weinreb amide to aldehyde was conducted according to Roberts et al., $2004^{2}$ with the exception that anhydrous DCM was used rather than THF for solubility reasons.

\section{4-Chloro-2-Nitrobenzoic acid $N$-methoxy- $N$-methylamide}

${ }^{1} \mathrm{H}$ NMR (500 MHz, $\left.\mathrm{CDCl}_{3}\right): \delta 8.12(\mathrm{~d}, \mathrm{~J}=1.94 \mathrm{~Hz}, 1 \mathrm{H}), 7.70(\mathrm{dd}, \mathrm{J}=8.15$ and $2.02 \mathrm{~Hz}, 1 \mathrm{H})$, $7.49(\mathrm{~d}, \mathrm{~J}=8.12 \mathrm{~Hz}, 1 \mathrm{H}), 3.35(\mathrm{~s}, 3 \mathrm{H})$ and $3.34(\mathrm{~s}, 3 \mathrm{H}) .{ }^{13} \mathrm{C} \mathrm{NMR}\left(125 \mathrm{MHz}, \mathrm{CDCl}_{3}\right): \delta 167.7$, $146.4,136.0,134.1,129.8,129.7,124.2,61.5$ and 33.4.

\section{4-Chloro-2-Nitrobenzaldehyde ${ }^{3}$}

${ }^{1} \mathrm{H}$ NMR (500 MHz, $\left.\mathrm{CDCl}_{3}\right): \delta 10.39(\mathrm{~s}, 1 \mathrm{H}), 8.12(\mathrm{~d}, \mathrm{~J}=1.94 \mathrm{~Hz}, 1 \mathrm{H}), 7.96(\mathrm{~d}, \mathrm{~J}=8.32 \mathrm{~Hz}, 1 \mathrm{H})$ and $7.79(\mathrm{dd}, \mathrm{J}=8.26$ and $1.62 \mathrm{~Hz}, 1 \mathrm{H})$.

\section{3-Chloro-2-Nitrobenzoic acid $N$-methoxy- $N$-methylamide}

${ }^{1} \mathrm{H}$ NMR $\left(500 \mathrm{MHz}, \mathrm{CDCl}_{3}\right): \delta 7.61(\mathrm{dd}, \mathrm{J}=8.05$ and $1.06 \mathrm{~Hz}, 1 \mathrm{H}), 7.54(\mathrm{t}, \mathrm{J}=7.56,1 \mathrm{H}), 7.49$ $(\mathrm{d}, \mathrm{J}=8.42 \mathrm{~Hz}, 1 \mathrm{H}), 8.53(\mathrm{~s}, 1 \mathrm{H})$ and $3.34(\mathrm{~s}, 1 \mathrm{H}) .{ }^{13} \mathrm{C} \mathrm{NMR}\left(125 \mathrm{MHz}, \mathrm{CDCl}_{3}\right): \delta$ 146.6, 132.4, $131.8,131.7,127.2,126.6,61.6$ and 32.9.

\section{3-Chloro-2-Nitrobenzaldehyde ${ }^{4}$}

${ }^{1} \mathrm{H}$ NMR $\left(500 \mathrm{MHz}, \mathrm{CDCl}_{3}\right): \delta 9.91(\mathrm{~s}, 1 \mathrm{H}), 7.89(\mathrm{dd}, \mathrm{J}=7.63$ and $1.15 \mathrm{~Hz}, 1 \mathrm{H}), 7.78(\mathrm{dd}, \mathrm{J}=$ 8.14 and $1.13 \mathrm{~Hz}, 1 \mathrm{H})$ and $7.67(\mathrm{t}, \mathrm{J}=7.90,1 \mathrm{H}) .{ }^{13} \mathrm{C} \mathrm{NMR}\left(125 \mathrm{MHz}, \mathrm{CDCl}_{3}\right): \delta 185.9,136.0$, $131.7,130.03,128.5$ and 126.6. 


\section{Synthesis of 4-cyano-2-nitrobenzaldehyde ${ }^{5}$}

Step 1: 3-Nitro-4-[(2- $N, N$-dimethylamino)ethenyl]benzonitrile

4-Cyano-2-nitro-toluene (1.00 g, $6.2 \mathrm{mmol})$ was refluxed with dimethylformamidedimethylacetal (DMF-MA) (1 eq, $6.2 \mathrm{mmol})$ and dimethylformamide $(3.75 \mathrm{~mL})$ overnight. Reaction mixture was washed with $\mathrm{H}_{2} \mathrm{O}(3 \times 30 \mathrm{~mL})$, and $1 \mathrm{M} \mathrm{NaHCO}_{3}(3 \times 30 \mathrm{~mL})$, dried with $\mathrm{Na}_{2} \mathrm{SO}_{4}$. Solvent was removed under vacuum and gave a red solid $(1.34 \mathrm{~g}, 100 \%)$ that was used without further purification.

${ }^{1} \mathrm{H}$ NMR $\left(500 \mathrm{MHz}, \mathrm{CDCl}_{3}\right): \delta 8.08(\mathrm{~d}, \mathrm{~J}=1.28 \mathrm{~Hz}, 1 \mathrm{H}), 7.46(\mathrm{~d}, \mathrm{~J}=8.67 \mathrm{~Hz}, 1 \mathrm{H}), 7.39(\mathrm{~d}, \mathrm{~J}=$ $8.61 \mathrm{~Hz}, 1 \mathrm{H}), 7.21(\mathrm{~d}, \mathrm{~J}=13.24 \mathrm{~Hz}, 1 \mathrm{H}), 5.92(\mathrm{~d}, \mathrm{~J}=13.19 \mathrm{~Hz}, 1 \mathrm{H})$ and $3.00(\mathrm{~s}, 6 \mathrm{H}) .{ }^{13} \mathrm{C}$ NMR $\left(125 \mathrm{MHz}, \mathrm{CDCl}_{3}\right): \delta$ 148.0, 143.0, 140.6, 134.0, 130.5, 123.9, 118.2, 103.3, 89.9 and 34.8.

Step 2: 4-Cyano-2-nitrobenzaldehyde

3-Nitro-4-[(2- $N, N$-dimethylamino)ethenyl]benzonitrile $(0.500 \mathrm{~g}, 2.3 \mathrm{mmol})$ was added to 50:50 THF: $\mathrm{H}_{2} \mathrm{O}$ solution $\left(8.3 \mathrm{~mL}\right.$ each) containing $\mathrm{NaIO}_{4}(1.55 \mathrm{~g}, 7.23 \mathrm{mmol}, 3.1 \mathrm{eq})$. The reaction mixture was stirred for approximately 3 hours or until disappearance of starting material was indicated by TLC. Product was purified by column chromatography using 50:50 EtOAC:Hex to give 4-cyano-2-nitrobenzaldehyde (313 mg, 77.2\%).

${ }^{1} \mathrm{H}$ NMR (500 MHz, $\mathrm{CD}_{3} \mathrm{CN}$ ): $\delta 10.33$ (), $8.51(\mathrm{~d}, \mathrm{~J}=1.38 \mathrm{~Hz}, 1 \mathrm{H}), 8.20(\mathrm{dd}, \mathrm{J}=7.96$ and 1.20 $\mathrm{Hz}, 1 \mathrm{H})$ and $(\mathrm{d}, \mathrm{J}=7.95 \mathrm{~Hz}, 1 \mathrm{H}) .{ }^{13} \mathrm{C} \mathrm{NMR}\left(125 \mathrm{MHz}, \mathrm{CD}_{3} \mathrm{CN}\right): \delta 188.3,137.9,134.3,130.6$, $128.4,116.8$ and 116.2 . 


\section{General procedure for Chemo-Enzymatic Synthesis of Quinaldic Acids}

Synthesis of substituted 2-aminobenzaldehydes was adapted from Deidrich et al., 2008. ${ }^{6}$ In short, iron powder (626 mg, $10.8 \mathrm{mmol}, 10 \mathrm{eq}$ ) was added to a solution containing 2nitrobenzaldehyde (163.6 mg, $1.08 \mathrm{mmol})$ in $25 \mathrm{~mL}$ ethanol and $7.5 \mathrm{~mL}$ water. $\mathrm{HCl}(200 \mu \mathrm{L}$, catalytic) was added and the reaction heated at $80{ }^{\circ} \mathrm{C}$ for approximately 1 hour, or until thin-layer chromatography (TLC) showed complete consumption of starting materials. Reaction mixture was quenched with ethyl acetate $(50 \mathrm{~mL})$, dried with $\mathrm{Na}_{2} \mathrm{SO}_{4}$ and filtered. Important Note: prior to solvent removal DMSO $(5 \mathrm{~mL})$ was added to improve stability of the aminoaldehyde.

Freshly prepared aminoaldehyde $(1.08 \mathrm{mmol})$ in DMSO $(5 \mathrm{~mL})$ was added to $100 \mathrm{mM}$ $\mathrm{KPO}_{4}$ ( $\mathrm{pH}$ 6.5, final volume $50 \mathrm{~mL}$ ) containing sodium pyruvate $(357 \mathrm{mg}, 3.24 \mathrm{mmol}$ ). NahE (7.93 mg, $0.02 \mathrm{~mol} \%$ ) was added to initiate the reaction and mixed at room temperature for 16 hours. Residual aldehyde was extracted with ethyl acetate $(2 \times 20 \mathrm{~mL})$ and aqueous phase was acidified to $\mathrm{pH} 2$ and extracted with ethyl acetate $(3 \times 20 \mathrm{~mL})$. The organic layer was washed with water $(3 \times 30 \mathrm{~mL})$, brine $(2 \times 30 \mathrm{~mL})$ and dried with sodium sulfate. Solvent was removed under vacuum to give corresponding substituted 2-quinolinecarboxylic acid. In some cases further washing of the product was required to remove pyruvic acid.

For compound 1n, extraction of the final product into an organic phase was not possible, and was instead isolated as the methyl ester by the following procedure. Residual aldehyde was removed from the enzymatic reaction as described above, and the aqueous fraction was lyophilized followed by addition of dried methanol $(20 \mathrm{~mL})$. The solution was cooled to $0{ }^{\circ} \mathrm{C}$ followed by dropwise addition of $\mathrm{SOCl}_{2}(630 \mu \mathrm{L}, 8.6 \mathrm{mmol})$. The reaction was then warmed to room temperature and stirred overnight. The mixture was cooled to $0{ }^{\circ} \mathrm{C}$ and made alkaline with saturated $\mathrm{NaHCO}_{3}$. This mixture was extracted with EtOAc $(3 \times 20 \mathrm{~mL})$, and the combined organic layers were washed with water $(3 \times 30 \mathrm{~mL})$, brine $(2 \times 30 \mathrm{~mL})$ and dried with sodium sulfate. Solvent was removed under vacuum to reveal a crude product which was purified by column chromatography using EtOAc (100\%) to give $\mathbf{1 n}$. 


\section{Characterization of products}

\section{Quinaldic Acid}

${ }^{1} \mathrm{H}$ NMR (500 MHz, DMSO): $\delta$ 1345. (s, $\left.1 \mathrm{H}\right), 8.56(\mathrm{~d}, \mathrm{~J}=8.44 \mathrm{~Hz}, 1 \mathrm{H}), 8.17$, (d, J = $8.46 \mathrm{~Hz}$, $1 \mathrm{H}), 8.13(\mathrm{~d}, \mathrm{~J}=8.46 \mathrm{~Hz}, 1 \mathrm{H}), 8.09(\mathrm{~d}, \mathrm{~J}=8.26 \mathrm{~Hz}, 1 \mathrm{H}), 7.88(\mathrm{t}, \mathrm{J}=7.22 \mathrm{~Hz}, 1 \mathrm{H})$ and $7.75(\mathrm{t}, \mathrm{J}=$ 7.56 1H). ${ }^{13} \mathrm{C}$ NMR (125 MHz, DMSO): $\delta$ 166.9, 149.1, 147.2, 138.1, 131.0, 130.2, 129.3, 129.0, 128.5 and 121.2. HRMS: Calc'd for $\mathrm{C}_{7} \mathrm{H}_{10} \mathrm{NO}_{2}$ 173.04768, found 173.04783.

\section{5-Chloro-2-quinaldic Acid (1a)}

${ }^{1} \mathrm{H}$ NMR (500 MHz, DMSO): $\delta 13.67$ (s, 1H), 8.67 (d, J = 8.90 Hz, 1H), 8.22 (d, J = $8.78 \mathrm{~Hz}$, 1H), $8.14(\mathrm{~d}, \mathrm{~J}=8.34 \mathrm{~Hz}, 1 \mathrm{H}), 7.89(\mathrm{dd}, 7.58$ and $0.96 \mathrm{~Hz}, 1 \mathrm{H})$ and $7.83(\mathrm{~m}, 1 \mathrm{H}) .{ }^{13} \mathrm{C}$ NMR $(125$ MHz, DMSO): $\delta$ 166.4, 150.0, 147.9, 134.4, 131.1, 130.7, 129.9, 129.1, 126.8 and 122.5. HRMS: Calc'd for $\mathrm{C}_{10} \mathrm{H}_{6} \mathrm{ClNO}_{2}$ 207.00871, found 207.00967.

\section{6-Chloro-2-quinaldic Acid (1b) ${ }^{7}$}

${ }^{1} \mathrm{H}$ NMR (500 MHz, DMSO): $\delta 13.55$ (s, 1H), 8.55 (d, J = 8.52 Hz, 1H), 8.27 (d, J = 2.30 Hz, $1 \mathrm{H}), 8.17(\mathrm{~d}, \mathrm{~J}=8.98 \mathrm{~Hz}, 1 \mathrm{H}), 8.17(\mathrm{~d}, \mathrm{~J}=8.49 \mathrm{~Hz}, 1 \mathrm{H})$ and $7.89(\mathrm{dd}, \mathrm{J}=9.00$ and $2.41 \mathrm{~Hz}, 1 \mathrm{H})$. ${ }^{13}$ C NMR (125 MHz, DMSO): $\delta$ 166.6, 149.6, 145.7, 137.5, 133.4, 132.3, 131.6, 130.0, 127.2 and 122.2 .

\section{7-Chloro-2-quinaldic Acid (1c)}

${ }^{1} \mathrm{H}$ NMR (500 MHz, DMSO): $\delta 13.59$ (s, 1H), $8.62(\mathrm{~d}, \mathrm{~J}=8.38 \mathrm{~Hz}, 1 \mathrm{H}), 8.23$ (d, J = $2.00 \mathrm{~Hz}$, $1 \mathrm{H}), 8.12(\mathrm{~m}, 2 \mathrm{H}), 7.80(\mathrm{dd}, \mathrm{J}=8.72$ and $2.10 \mathrm{~Hz}, 1 \mathrm{H}) .{ }^{13} \mathrm{C}$ NMR (125 MHz, DMSO): $\delta$ 166.6, 150.3, 147.6, 138.2, 135.5, 130.5, 129.6, 128.7, 127.9 and 121.7. HRMS: Calc'd for $\mathrm{C}_{10} \mathrm{H}_{6} \mathrm{ClNO}_{2}$ 207.00871, found 207.0082.

\section{8-Chloro-2-quinaldic Acid (1d)}

${ }^{1} \mathrm{H}$ NMR (500 MHz, DMSO): $\delta 13.63$ (s, 1H), 8.64 (d, J = $\left.8.58 \mathrm{~Hz}, 1 \mathrm{H}\right), 8.19$ (d, J = $8.54 \mathrm{~Hz}$, $1 \mathrm{H}), 8.08(\mathrm{dd}, \mathrm{J}=8.34$ and $1.24 \mathrm{~Hz}, 1 \mathrm{H}), 8.05(\mathrm{dd}, \mathrm{J}=7.46$ and $1.24 \mathrm{~Hz}, 1 \mathrm{H})$ and $7.71(\mathrm{t}, \mathrm{J}=$ 7.87Hz, 1H). ${ }^{13} \mathrm{C}$ NMR (125 MHz, DMSO): $\delta$ 166.6, 150.0, 143.4, 138.9, 133.64, 131.0, 130.7, 129.2, 128.0 and 122.3. HRMS: Calc'd for $\mathrm{C}_{10} \mathrm{H}_{6} \mathrm{ClNO}_{2}$ 207.00871, found 207.00835.

\section{6-Fluoro-2-quinaldic Acid (1e $)^{8}$}

${ }^{1} \mathrm{H}$ NMR (500 MHz, DMSO): $\delta 13.49(\mathrm{~s}, 1 \mathrm{H}), 8.53(\mathrm{~d}, \mathrm{~J}=8.54 \mathrm{~Hz}, 1 \mathrm{H}), 8.22(\mathrm{dd}, \mathrm{J}=9.41$ and $5.46 \mathrm{~Hz}, 1 \mathrm{H}), 8.14(\mathrm{~d}, \mathrm{~J}=8.58 \mathrm{~Hz}, 1 \mathrm{H}), 7.91(\mathrm{dd}, \mathrm{J}=9.39$ and $2.95 \mathrm{~Hz}, 1 \mathrm{H})$ and $7.79(\mathrm{dt}, \mathrm{J}=$ 8.90 and $2.93 \mathrm{~Hz}, 1 \mathrm{H}) .{ }^{13} \mathrm{C}$ NMR (125 MHz, DMSO): $\delta$ 166.7, 161.2 (d, J = $\left.248 \mathrm{~Hz}\right), 148.7$ (d, J 
$=3.38 \mathrm{~Hz}), 144.5,137.6(\mathrm{~d}, \mathrm{~J}=5.71 \mathrm{~Hz}), 133.2(\mathrm{~d}, \mathrm{~J}=9.63 \mathrm{~Hz}), 130.2(\mathrm{~d}, \mathrm{~J}=11.05 \mathrm{~Hz}), 122.0$, $121.3\left(\mathrm{~d}, \mathrm{~J}=26.45 \mathrm{~Hz}\right.$ ) and111.6 (d, J = 22.09). ${ }^{19} \mathrm{~F}$ NMR (470 MHz, DMSO): $\delta$-111.49.

\section{7-Fluoro-2-quinaldic Acid (1f) ${ }^{8}$}

${ }^{1} \mathrm{H}$ NMR (500 MHz, DMSO): $\delta 13.55(\mathrm{~s}, 1 \mathrm{H}), 8.60(\mathrm{~d}, \mathrm{~J}=8.39 \mathrm{~Hz}, 1 \mathrm{H}), 8.20(\mathrm{t}, \mathrm{J}=7.47 \mathrm{~Hz}$, $1 \mathrm{H}), 8.10(\mathrm{~d}, \mathrm{~J}=8.37 \mathrm{~Hz}, 1 \mathrm{H}), 7.30(\mathrm{~d}, \mathrm{~J}=9.34 \mathrm{~Hz}, 1 \mathrm{H})$ and $7.69(\mathrm{t}, \mathrm{J}=7.76 \mathrm{~Hz}, 1 \mathrm{H}) .{ }^{13} \mathrm{C} \mathrm{NMR}$ (125 MHz, DMSO): $\delta$ 166.7, $163.3(\mathrm{~d}, \mathrm{~J}=249 \mathrm{~Hz}), 150.2,148.2(\mathrm{~d}, \mathrm{~J}=13.0 \mathrm{~Hz}), 138.3,131.2$ $(\mathrm{d}, \mathrm{J}=10.2 \mathrm{~Hz}), 126.6,120.8,119.4(\mathrm{~d}, \mathrm{~J}=25.7 \mathrm{~Hz})$ and $113.4(\mathrm{~d}, \mathrm{~J}=20.1 \mathrm{~Hz})$.

\section{6-Bromo-2-quinaldic Acid (1g)}

${ }^{1} \mathrm{H}$ NMR (500 MHz, DMSO): $\delta 13.56(\mathrm{~s}, 1 \mathrm{H}), 8.52(\mathrm{~d}, \mathrm{~J}=8.68 \mathrm{~Hz}, 1 \mathrm{H}), 8.40(\mathrm{~d}, \mathrm{~J}=2.20 \mathrm{~Hz}$, $1 \mathrm{H}), 8.15(\mathrm{~d}, \mathrm{~J}=8.60 \mathrm{~Hz}, 1 \mathrm{H}), 8.08(\mathrm{~d}, \mathrm{~J}=8.96,1 \mathrm{H})$ and $7.97(\mathrm{dd}, \mathrm{J}=8.97$ and $2.35,1 \mathrm{H}) .{ }^{13} \mathrm{C}$ NMR (125 MHz, DMSO): $\delta$ 166.61, 149.6, 145.9, 137.4, 134.1, 132.3, 130.5, 130.45, 122.2 and 122.19. Spectra matches commercially available compound. ${ }^{9}$

\section{7-Bromo-2-quinaldic Acid (1h)}

${ }^{1} \mathrm{H}$ NMR (500 MHz, DMSO): $\delta 13.57(\mathrm{~s}, 1 \mathrm{H}), 8.59(\mathrm{~d}, \mathrm{~J}=8.47 \mathrm{~Hz}, 1 \mathrm{H}), 8.36(\mathrm{~d}, \mathrm{~J}=1.83 \mathrm{~Hz}$, $1 \mathrm{H})), 8.41(\mathrm{~d}, \mathrm{~J}=8.56 \mathrm{~Hz}, 1 \mathrm{H}), 8.06(\mathrm{~d}, \mathrm{~J}=8.74 \mathrm{~Hz}, 1 \mathrm{H})$ and $7.87(\mathrm{dd}, \mathrm{J}=8.79$ and $1.99 \mathrm{~Hz}$, 1H). ${ }^{13} \mathrm{C}$ NMR (125 MHz, DMSO): $\delta 166.6,150.2,147.8,138.4,132.1,131.0,130.5,128.1$, 124.3 and 121.8. Spectra matches commercially available compound. ${ }^{10}$

\section{7-Cyano-2-quinaldic Acid (1i) ${ }^{11}$}

${ }^{1} \mathrm{H}$ NMR (500 MHz, DMSO): $\delta 13.75$ (s, 1H), 8.73 (s, 1H), 8.69 (d, J = $\left.8.59 \mathrm{~Hz}, 1 \mathrm{H}\right), 8.29$ (d, J = $8.51 \mathrm{~Hz}, 1 \mathrm{H}), 8.26(\mathrm{~d}, \mathrm{~J}=8.55 \mathrm{~Hz}, 1 \mathrm{H})$ and $8.04(\mathrm{dd}, \mathrm{J}=8.47$ and $1.40,1 \mathrm{H}) .{ }^{13} \mathrm{C}$ NMR $(125$ MHz, DMSO): $\delta$ 166.4, 151.0, 146.1, 138.5, 136.2, 131.3, 130.4, 129.4, 123.7, 118.8 and 113.4. HRMS: Calc'd for $\mathrm{C}_{11} \mathrm{H}_{6} \mathrm{~N}_{2} \mathrm{O}_{2}$ 198.04293, found 198.0432.

\section{2,7-Quinolinedicarboxylic acid, 7-methyl ester (1j)}

${ }^{1} \mathrm{H}$ NMR (500 MHz, DMSO): $\delta 13.59$ (s, 1H), $8.67(\mathrm{~s}, 1 \mathrm{H}), 8.64(\mathrm{~d}, \mathrm{~J}=8.62 \mathrm{~Hz}, 1 \mathrm{H}), 8.21(\mathrm{~d}, \mathrm{~J}=$ $8.63 \mathrm{~Hz}, 1 \mathrm{H}), 8.20(\mathrm{~d}, \mathrm{~J}=8.49 \mathrm{~Hz}, 1 \mathrm{H}), 8.16(\mathrm{dd}, \mathrm{J}=8.52$ and $1.58 \mathrm{~Hz}, 1 \mathrm{H})$ and $3.96(\mathrm{~s}, 3 \mathrm{H}) .{ }^{13} \mathrm{C}$ NMR (125 MHz, DMSO): $\delta$ 166.5, 166.2, 150.4, 146.4, 138.2, 132.0, 131.63, 131.59, 129.3, 127.6, 123.1 and 53.1. HRMS: Calc'd for $\mathrm{C}_{12} \mathrm{H}_{9} \mathrm{NO}_{4} 231.05316$, found 231.05418. 


\section{6-Methoxy-2-quinaldic Acid (1k)}

${ }^{1} \mathrm{H}$ NMR (500 MHz, DMSO): $\delta 13.25(\mathrm{~s}, 1 \mathrm{H}) 8.41(\mathrm{~d}, \mathrm{~J}=8.50 \mathrm{~Hz}, 1 \mathrm{H}), 8.08(\mathrm{~d}, \mathrm{~J}=8.52 \mathrm{~Hz}$, $1 \mathrm{H}), 8.06(\mathrm{~d}, \mathrm{~J}=9.19 \mathrm{~Hz}, 1 \mathrm{H}), 7.51(\mathrm{dd}, \mathrm{J}=9.14$ and $2.90 \mathrm{~Hz}, 1 \mathrm{H}), 7.47(\mathrm{~d}, \mathrm{~J}=2.84 \mathrm{~Hz}, 1 \mathrm{H})$ and 3.94 (s, 3H). ${ }^{13} \mathrm{C}$ NMR (125 MHz, DMSO): $\delta 166.9,159.2,146.5,143.3,136.5,131.7,130.8$, 123.8, 121.6, 105.9 and 56.2. HRMS: Calc'd for $\mathrm{C}_{11} \mathrm{H}_{9} \mathrm{NO}_{3} 203.05824$, found 203.05863.

\section{7-Methoxy-2-quinaldic Acid (11) ${ }^{12}$}

${ }^{1} \mathrm{H}$ NMR (500 MHz, DMSO): $\delta 13.34$ (s, 1H), 8.47 (d, J = $\left.8.35 \mathrm{~Hz}, 1 \mathrm{H}\right), 7.99$ (m, 2H), 7.53 (d, J $=2.40 \mathrm{~Hz}, 1 \mathrm{H}), 7.39(\mathrm{dd}, \mathrm{J}=9.00$ and $2.53 \mathrm{~Hz}, 1 \mathrm{H})$ and $3.96(\mathrm{~s}, 3 \mathrm{H}) .{ }^{13} \mathrm{C} \mathrm{NMR}(125 \mathrm{MHz}$, DMSO): $\delta 166.9,161.3,149.14,149.09,137.7,129.6,124.7,122.0,119.1,108.0$ and 56.1.

\section{6-Hydroxy-2-quinaldic Acid (1m)}

${ }^{1} \mathrm{H}$ NMR (500 MHz, DMSO): $\delta 10.43(\mathrm{~s}, 1 \mathrm{H}), 8.31(\mathrm{~d}, \mathrm{~J}=8.52 \mathrm{~Hz}, 1 \mathrm{H}), 8.01(\mathrm{~d}, \mathrm{~J}=9.09 \mathrm{~Hz}$, $1 \mathrm{H}), 8.00(\mathrm{~d}, \mathrm{~J}=8.54 \mathrm{~Hz}, 1 \mathrm{H}), 7.43(\mathrm{dd}, \mathrm{J}=9.10$ and $2.66 \mathrm{~Hz}, 1 \mathrm{H})$ and $7.23(\mathrm{~d}, \mathrm{~J}=2.66 \mathrm{~Hz}$, 1H). ${ }^{13} \mathrm{C}$ NMR (125 MHz, DMSO): $\delta$ 167.0, 157.8, 145.6, 142.4, 135.8, 131.9, 131.1, 123.7, 121.3 and 108.57. HRMS: Calc'd for $\mathrm{C}_{10} \mathrm{H}_{7} \mathrm{NO}_{3}$ 189.04259, found 189.04252.

\section{7-(N,N-Dimethyl)-quinaldic Acid Methyl Ester (1n)}

${ }^{1} \mathrm{H}$ NMR (500 MHz, DMSO): $\delta 8.32$ (d, J = 8.26 Hz, 1H), 7.87 (d, J = 9.23 Hz, 1H), 7.77 (d, J = $8.23 \mathrm{~Hz}, 1 \mathrm{H}), 7.44(\mathrm{dd}, \mathrm{J}=9.24$ and $2.02 \mathrm{~Hz}, 1 \mathrm{H}), 7.08(\mathrm{~d}, \mathrm{~J}=2.07 \mathrm{~Hz}, 1 \mathrm{H}), 3.93(\mathrm{~s}, 3 \mathrm{H})$ and 3.09 (s, 6H). ${ }^{13} \mathrm{C}$ NMR (125 MHz, DMSO): $\delta 165.9,152.1,149.0,147.3,137.6,128.9,122.1$, 119.3, 116.9, 105.6, 52.9 and 40.4. HRMS: Calc'd for $\mathrm{C}_{12} \mathrm{H}_{12} \mathrm{~N}_{2} \mathrm{O}_{2} 230.10553$, found 230.10498.

\section{6,7-Dimethoxy-quinaldic Acid (10)}

${ }^{1} \mathrm{H}$ NMR (500 MHz, DMSO): $\delta$ 8.33, (d, J = 8.38 Hz, 1H), $7.97(\mathrm{~d}, \mathrm{~J}=8.35,1 \mathrm{H}), 7.49(\mathrm{~s}, 1 \mathrm{H})$, $7.44(\mathrm{~s}, 1 \mathrm{H}), 3.97(\mathrm{~s}, 3 \mathrm{H})$ and $3.96(\mathrm{~s}, 3 \mathrm{H}) .{ }^{13} \mathrm{C}$ NMR (125 MHz, DMSO): $\delta$ 167.0, 153.4, 151.5, 146.3, 144.3, 135.7, 125.6, 119.6, 108.4, 105.7, 56.32 and 56.31. HRMS (ESI-Neg): Calc'd for $\mathrm{C}_{12} \mathrm{H}_{10} \mathrm{NO}_{4} 232.0615$, found 232.0609 .

\section{6,8-Dibromo-2-quinaldic Acid (1p)}

${ }^{1} \mathrm{H}$ NMR (500 MHz, DMSO): $\delta 13.71$ (s, 1H), 8.58 (d, J = $\left.8.55 \mathrm{~Hz}, 1 \mathrm{H}\right), 8.46$ (s, 1H), 8.43 (s, $1 \mathrm{H})$ and $8.21(\mathrm{~d}, \mathrm{~J}=8.55 \mathrm{~Hz}, 1 \mathrm{H}) .{ }^{13} \mathrm{C} \mathrm{NMR}(125 \mathrm{MHz}, \mathrm{DMSO}): \delta 168.4,150.7,143.2,138.3$, 136.6, 131.3, 130.7, 126.8, 123.2 and 121.6. HRMS: Calc'd for $\mathrm{C}_{10} \mathrm{H}_{5} \mathrm{Br}_{2} \mathrm{NO}_{2}$ 328.86870, found 328.86910 . 




\section{Figure S1.}

The widely accepted chemical mechanism of dihydrodipicolinate synthase ${ }^{13}$ (TOP) and the suggested mechanism for NahE-catalyzed quinaldic acid formation (BOTTOM). 


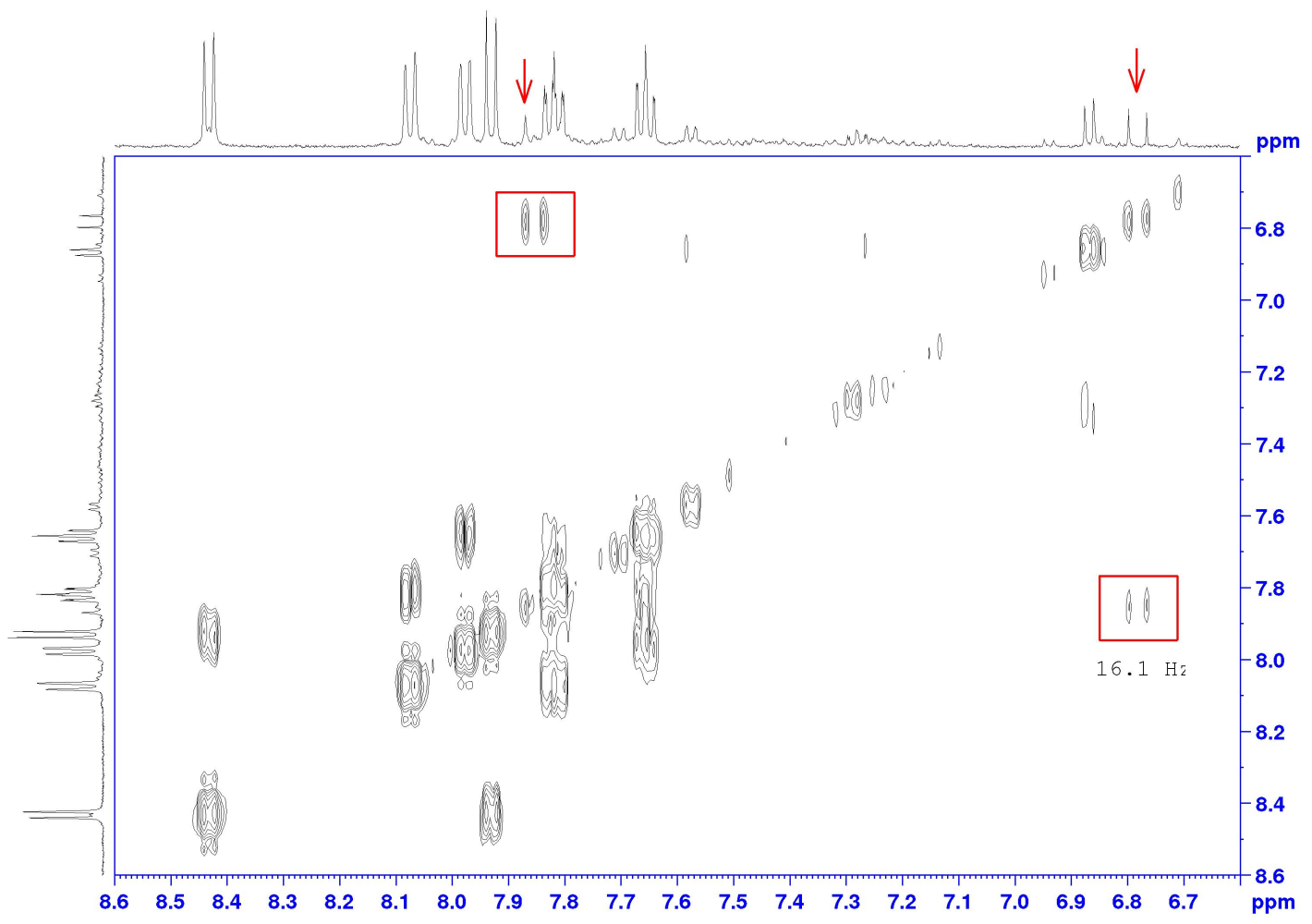

\section{Figure S2.}

COSY NMR spectra 10 minutes after start of reaction showing the coupling constant of the transalkene doublets at 6.77 and 7.85 . 

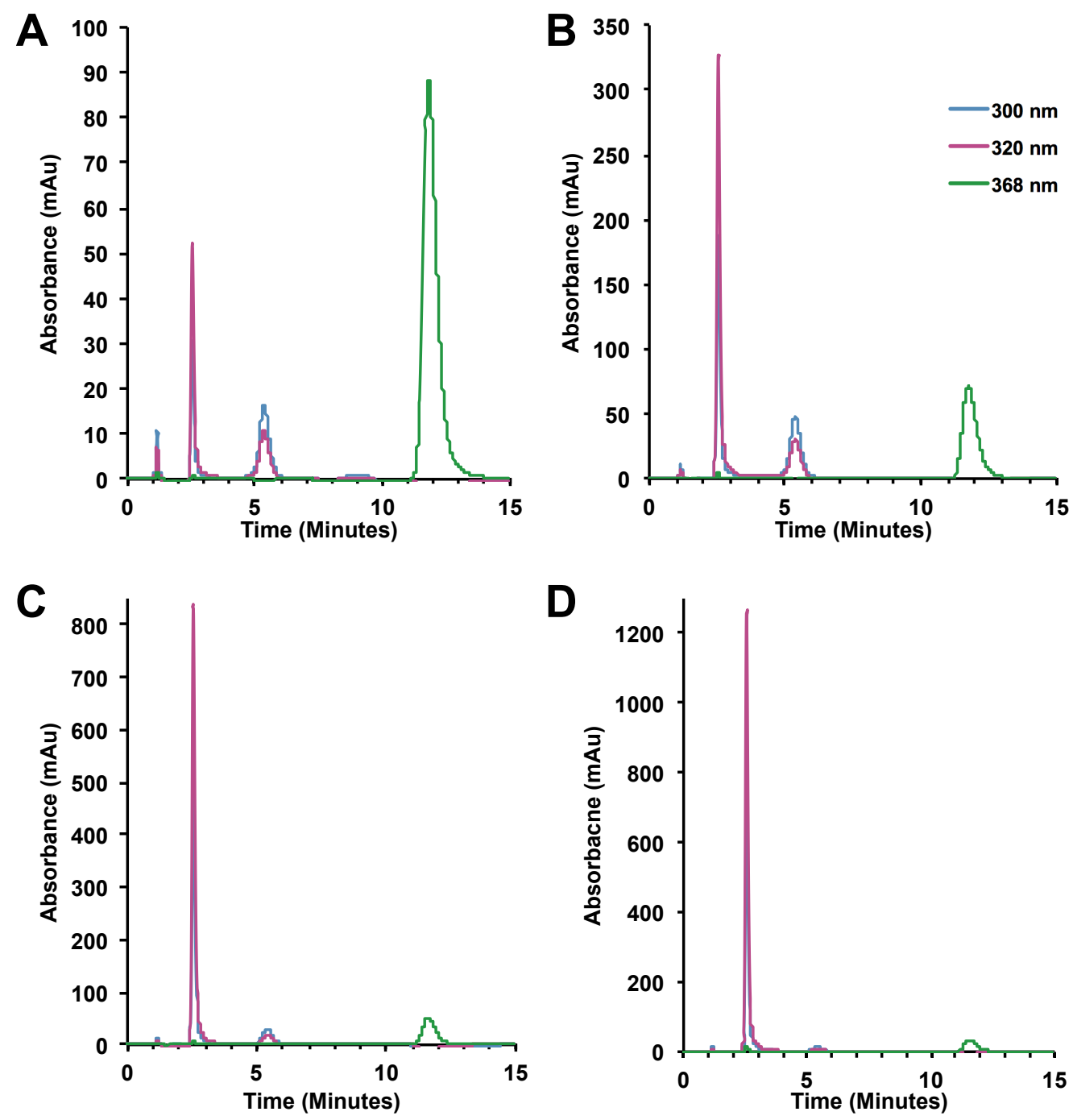

\section{Figure S3.}

HPLC chromatogram of the NahE-catalyzed reaction of pyruvate and 2-AB, after A) 5 min, B) $40 \mathrm{~min}, \mathrm{C}) 140 \mathrm{~min}$, and D) $300 \mathrm{~min}$. The solvent front elutes at retention time $=1.1 \mathrm{~min}$, and the starting material, $2-\mathrm{AB}$, at $11.75 \mathrm{~min}$. 

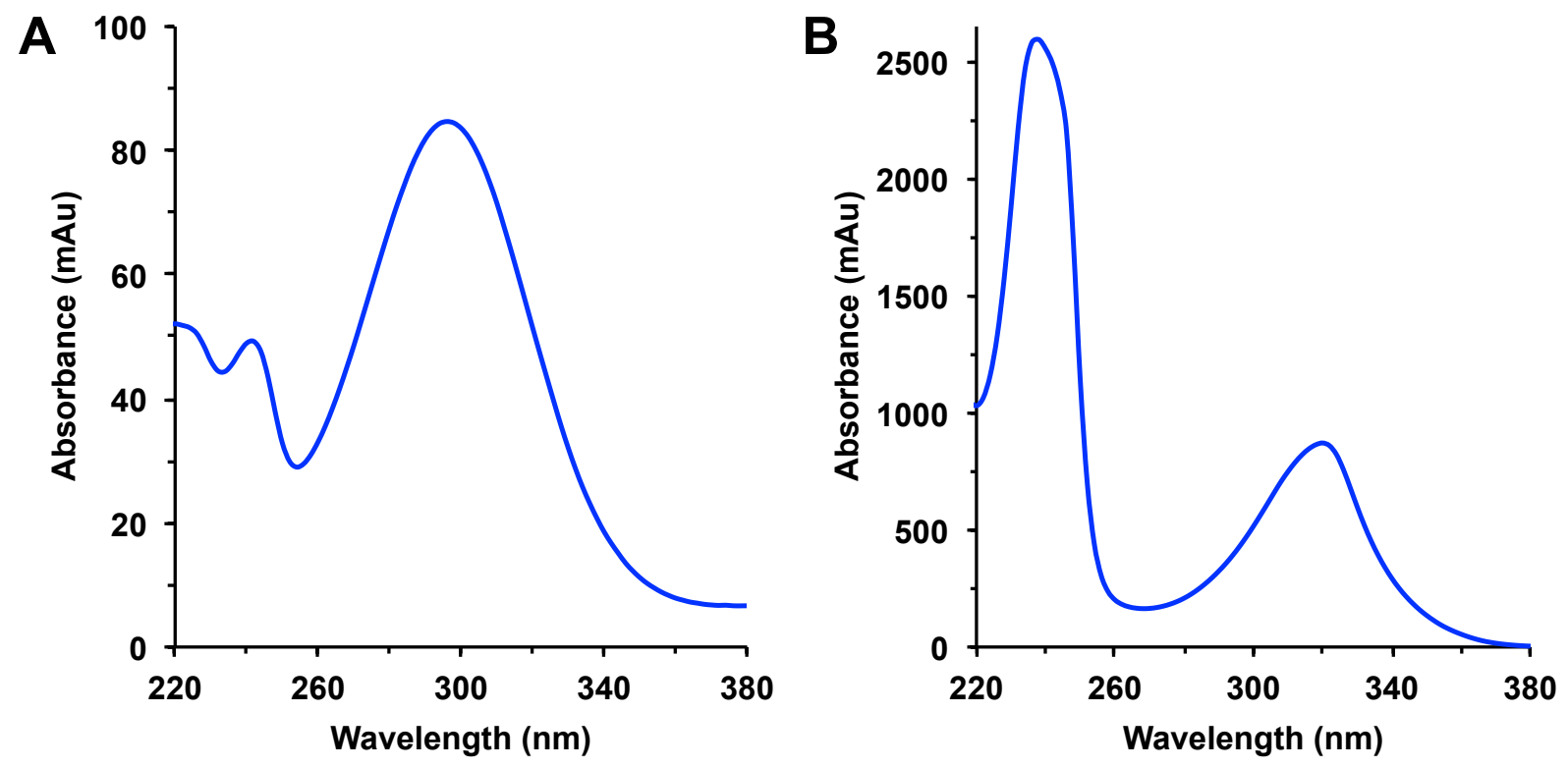

\section{Figure S4.}

$\mathrm{UV}$-visible spectrum recorded for $\mathrm{A}$ ) the peak at retention time $=5.25 \mathrm{~min}$ in Figure $\mathrm{S} 3$, corresponding to 2-aminobenzylidenepyruvic acid, and B) the peak at retention time $=2.52 \mathrm{~min}$ in Figure S4, corresponding to quinaldic acid. 


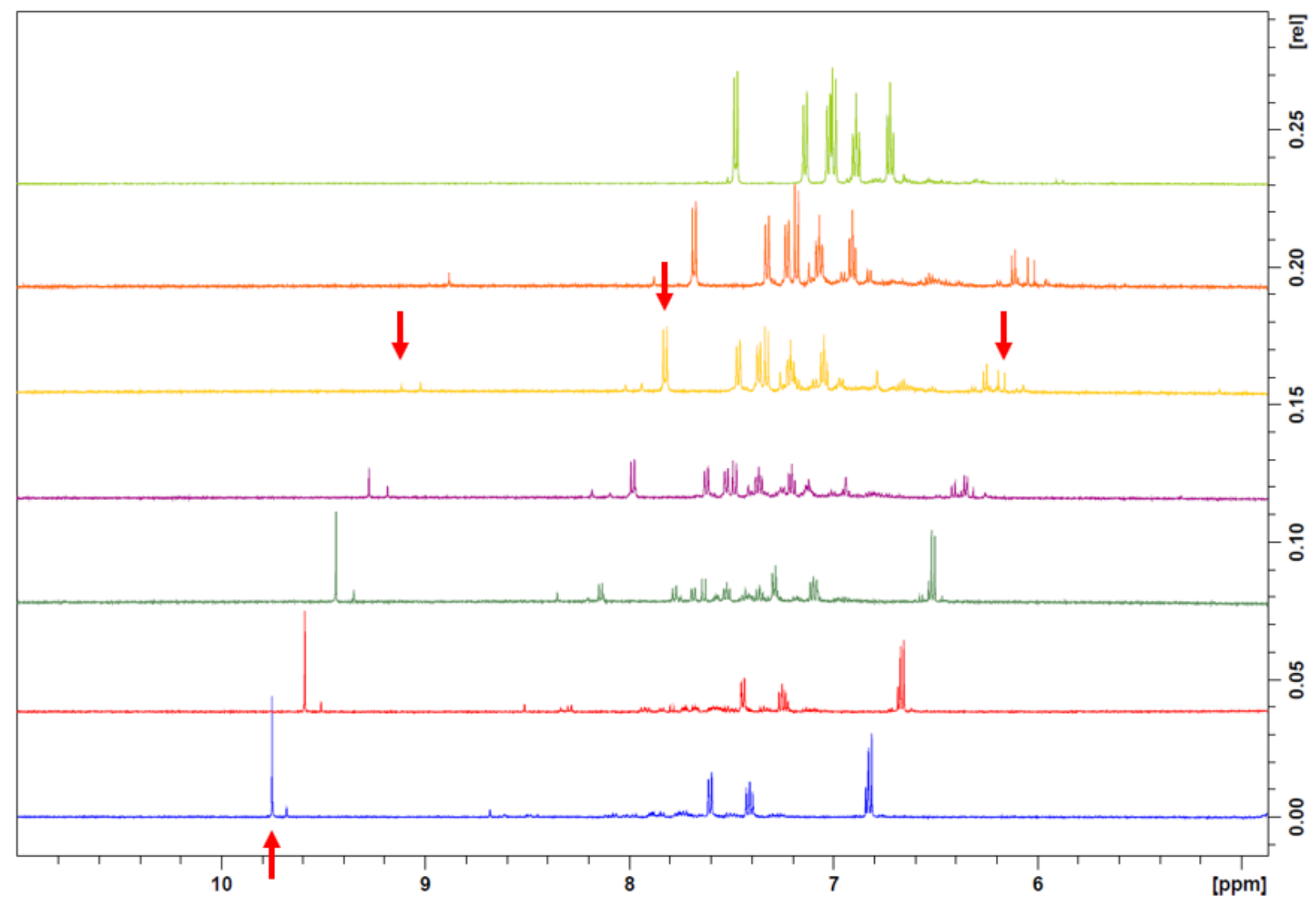

\section{Figure S5.}

${ }^{1} \mathrm{H}$ NMR of enzymatic conversion of 2-AB to 2-QA over time. Enzyme incubation time: (Bottom to Top) 0.083 minutes (blue), 0.25 minutes (red), 0.75 minutes (dark green), 2.33 minutes (purple), 4.33 minutes (yellow), 10 minutes (orange) and 1440 minutes (light green). The red arrows indicate the peaks used to follow the course of the reaction, as described above (p. S3). 




Figure S6.

NMR time course of the NahE-catalyzed reaction indicating relative amounts of 2-AB, trans-oaminobenzylidenepyruvate, and quinaldic acid. 


\section{NMR spectra}

${ }^{1}$ H NMR: 4-Chloro-2-nitrobenzoic acid $N$-methoxy- $N$-methylamide<smiles>CON(C)C(=O)c1ccc(Cl)cc1[N+](=O)[O-]</smiles>

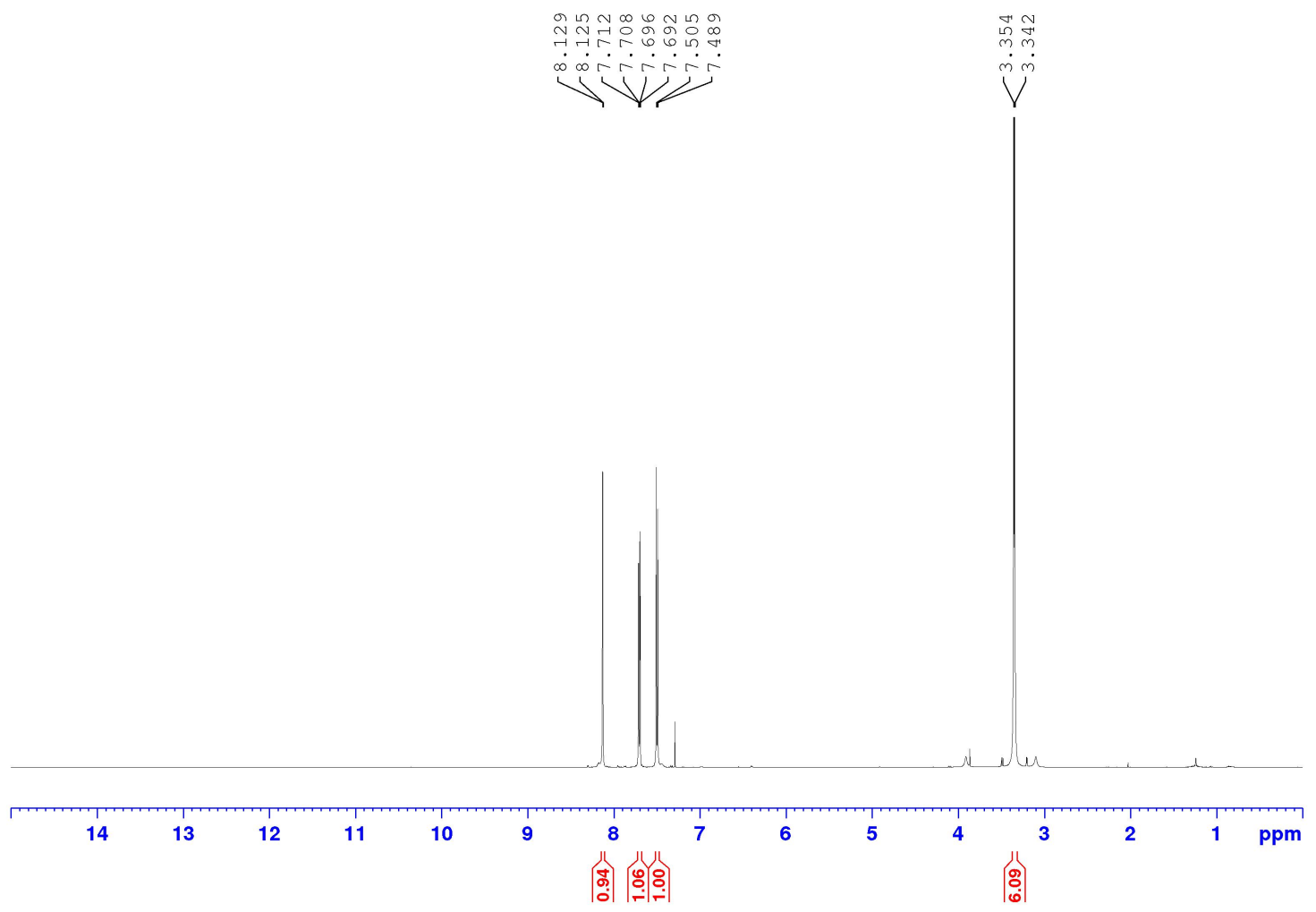


${ }^{13} \mathrm{C}$ NMR: 4-Chloro-2-nitrobenzoic acid $N$-methoxy- $N$-methylamide<smiles>CON(C)C(=O)c1ccc(Cl)cc1[N+](=O)[O-]</smiles>

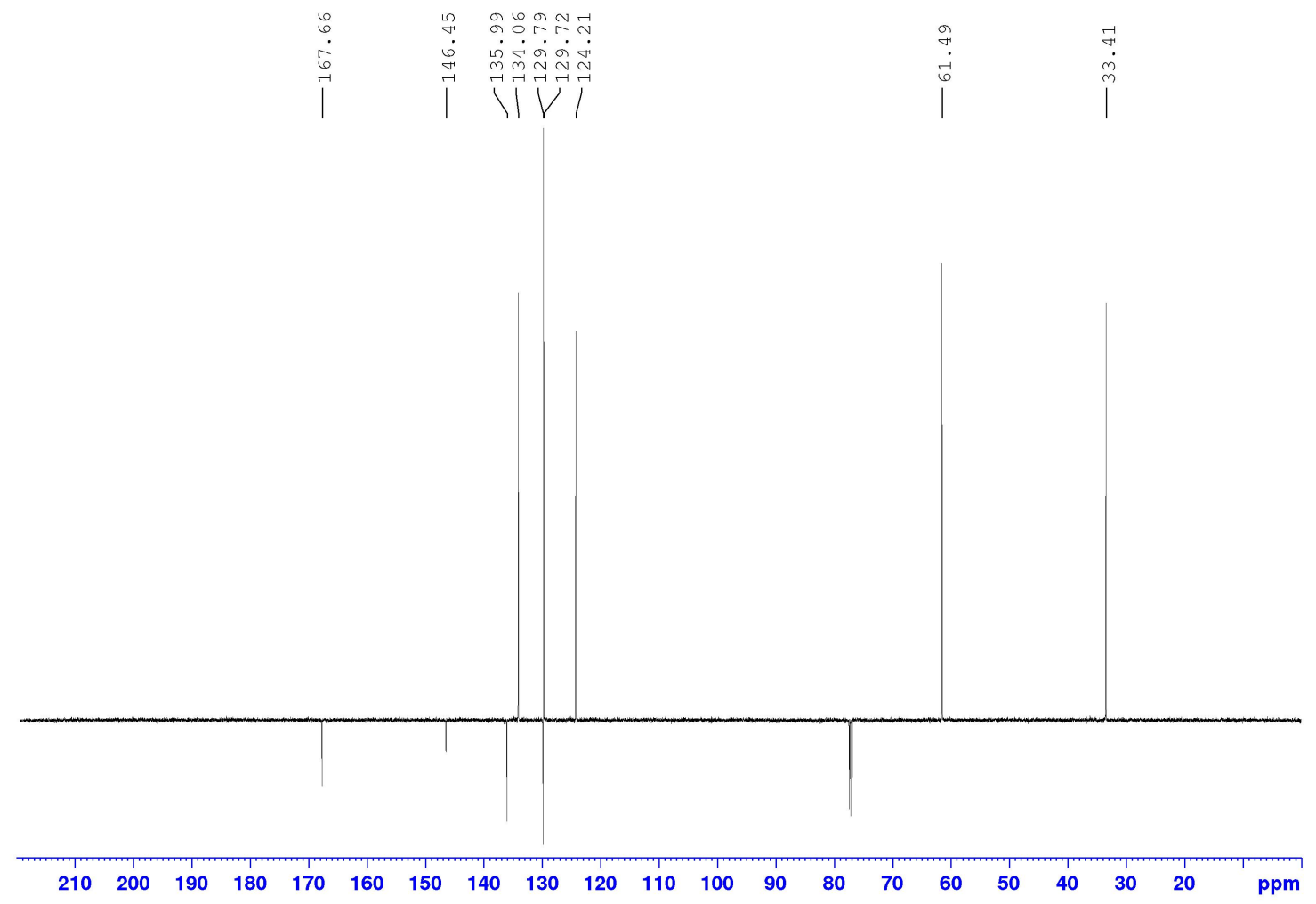


${ }^{1}$ H NMR: 4-Chloro-2-nitrobenzaldehyde<smiles>O=Cc1ccc(Cl)cc1[N+](=O)[O-]</smiles>

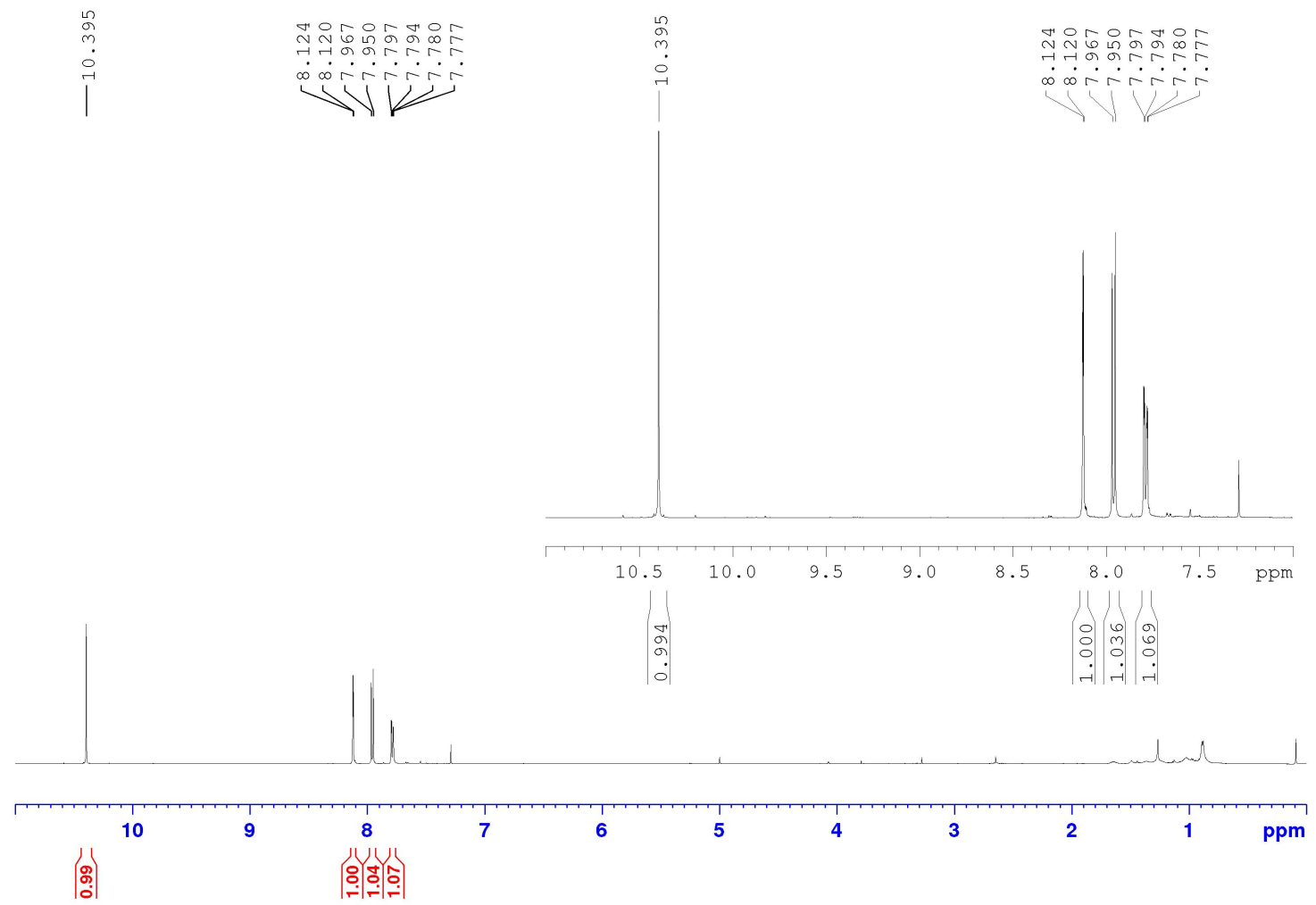


${ }^{1}$ H NMR: 3-Chloro-2-nitrobenzoic acid N-methoxy-N-methylamide<smiles>CON(C)C(=O)c1cccc(Cl)c1[N+](=O)[O-]</smiles>

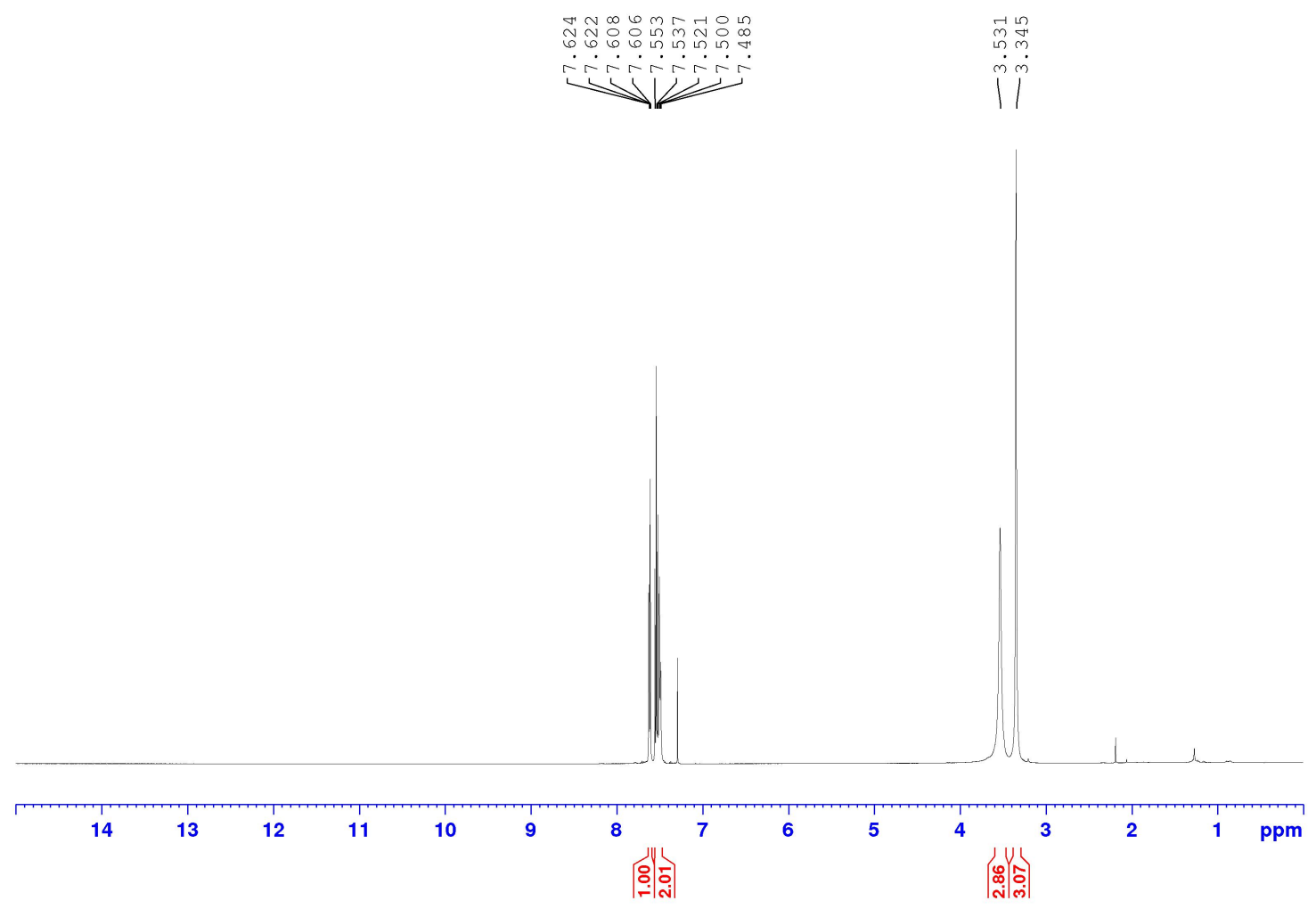


${ }^{13}$ C NMR: 3-Chloro-2-nitrobenzoic acid N-methoxy-N-methylamide<smiles>CON(C)C(=O)c1cccc(Cl)c1[N+](=O)[O-]</smiles>

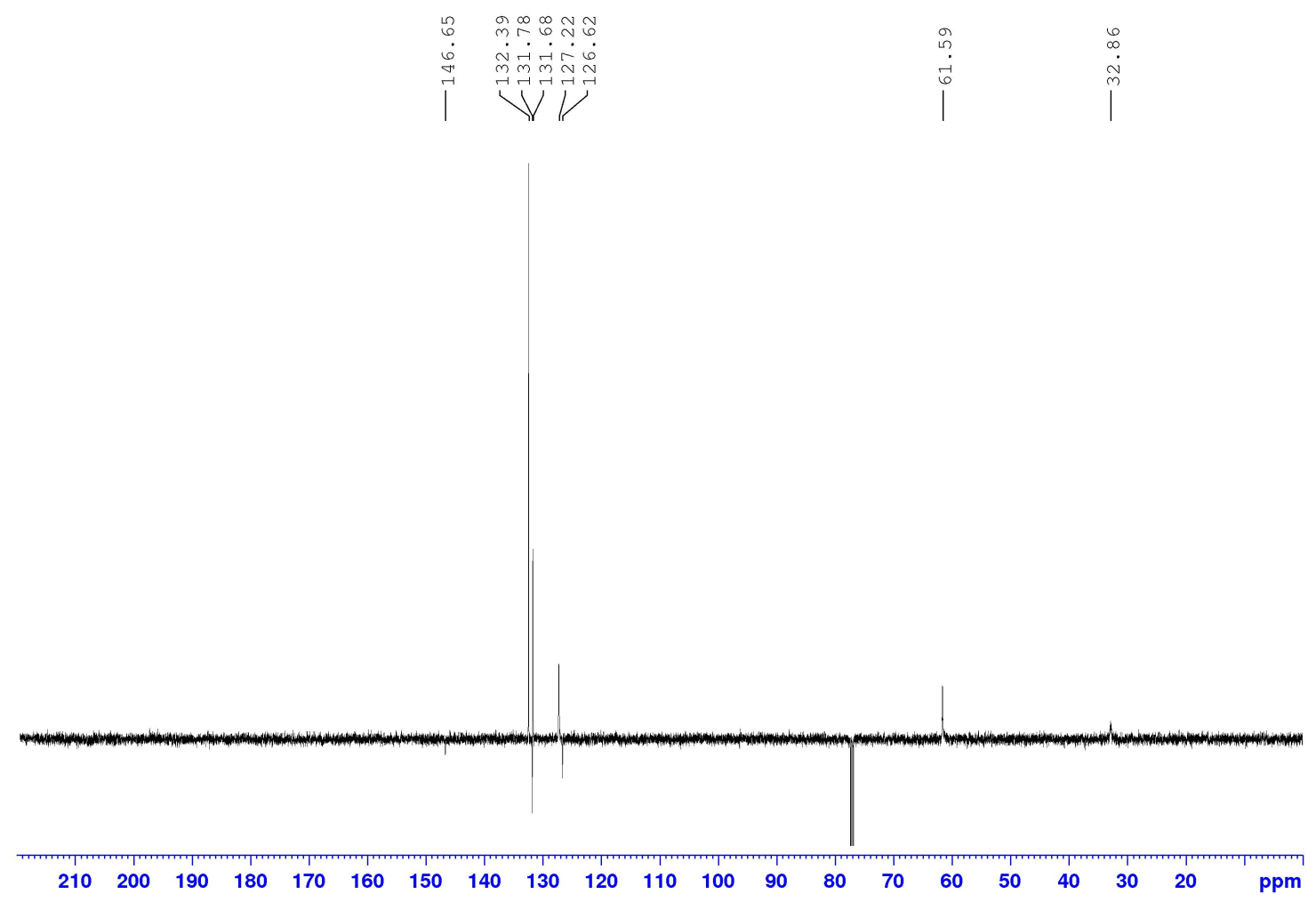


${ }^{1}$ H NMR: 3-Chloro-2-nitrobenzaldehyde<smiles>O=Cc1cccc(Cl)c1[N+](=O)[O-]</smiles>

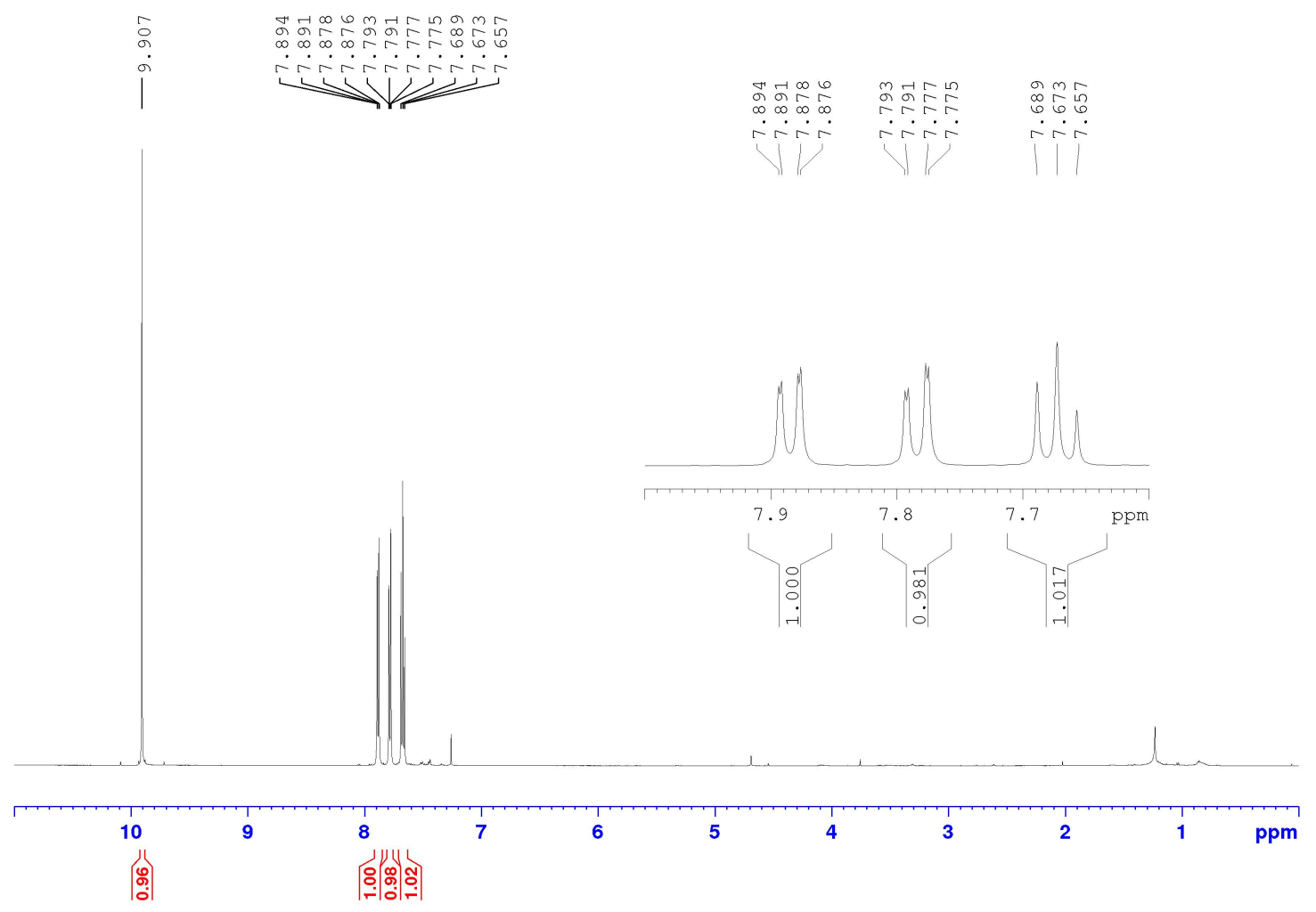


${ }^{13}$ C NMR: 3-Chloro-2-nitrobenzaldehyde<smiles>O=Cc1cccc(Cl)c1[N+](=O)[O-]</smiles>

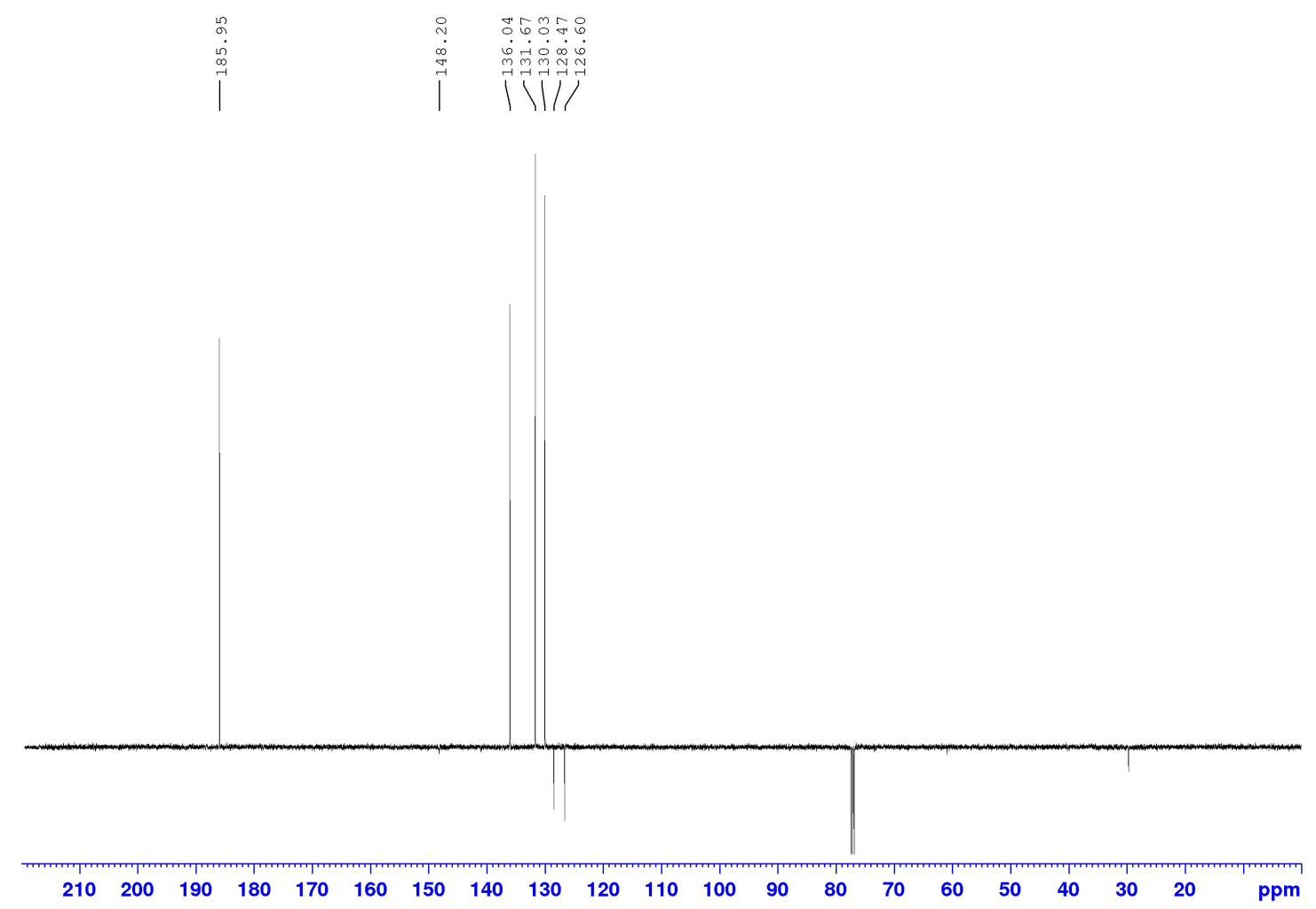


${ }^{1}$ H NMR: 3-Nitro-4-[(2-N,N-dimethylamino)ethenyl]benzonitrile<smiles>CN(C)/C=C/c1ccc(C#N)cc1[N+](=O)[O-]</smiles>




${ }^{13} \mathrm{C}$ NMR: 3-Nitro-4-[(2-N,N-dimethylamino)ethenyl]benzonitrile<smiles>CN(C)/C=C/c1ccc(C#N)cc1[N+](=O)[O-]</smiles>

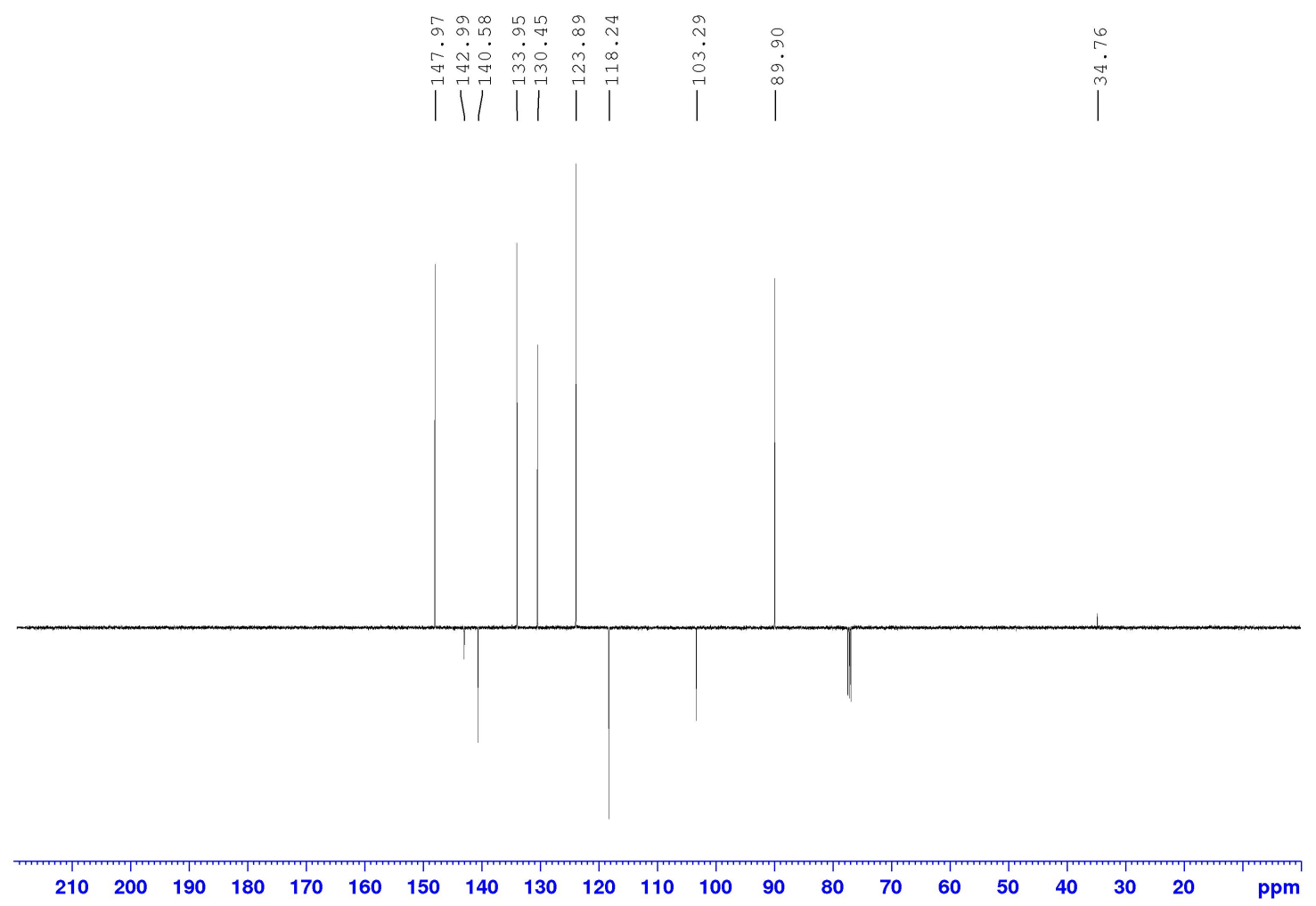


${ }^{1}$ H NMR: 4-Cyano-2-nitrobenzaldehyde<smiles>N#Cc1ccc(C=O)c([N+](=O)[O-])c1</smiles>

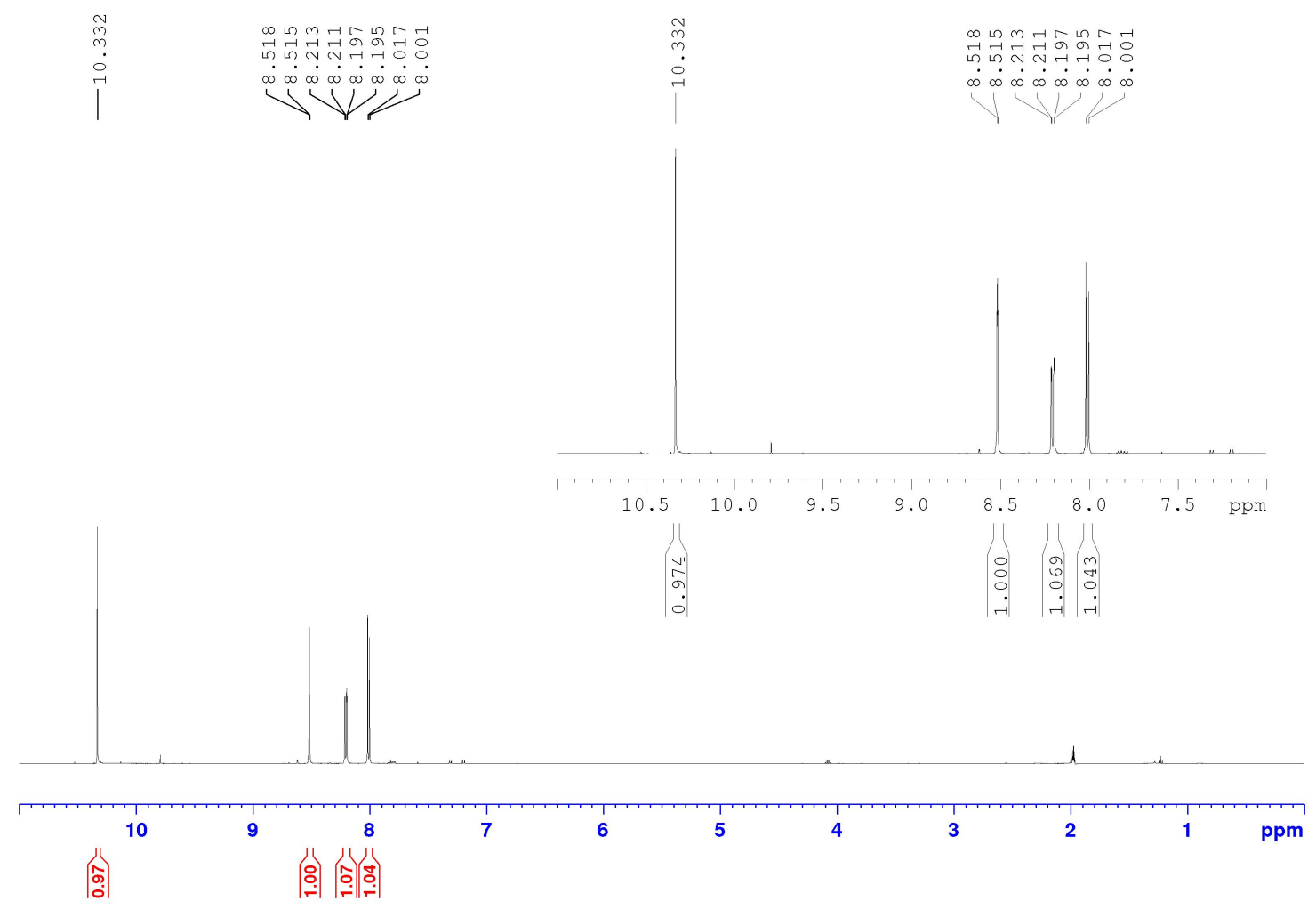


${ }^{13}$ C NMR: 4-Cyano-2-nitrobenzaldehyde<smiles>N#Cc1ccc(C=O)c([N+](=O)[O-])c1</smiles>

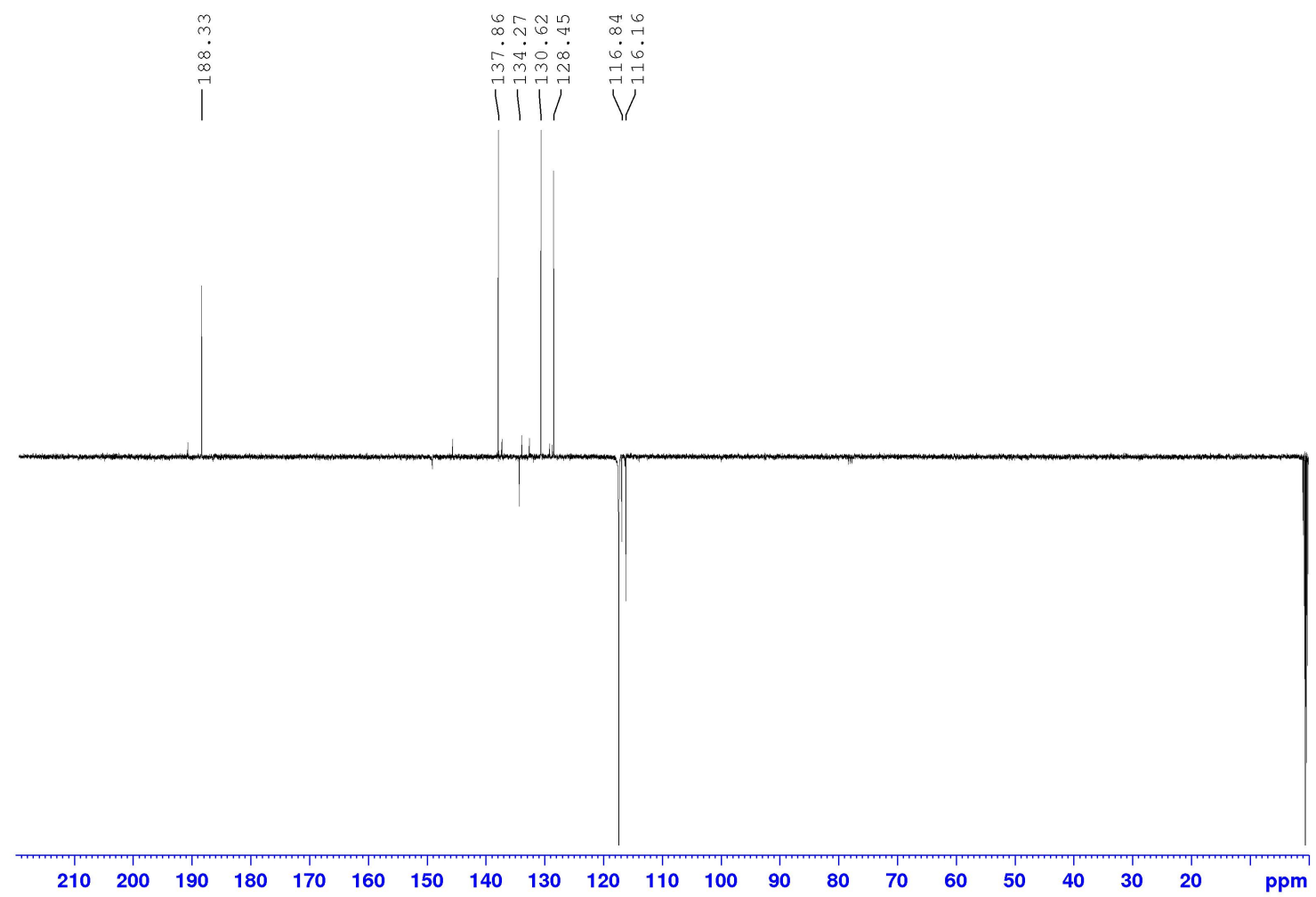


${ }^{1}$ H NMR: Quinaldic Acid<smiles>O=C(O)c1ccc2ccccc2n1</smiles>
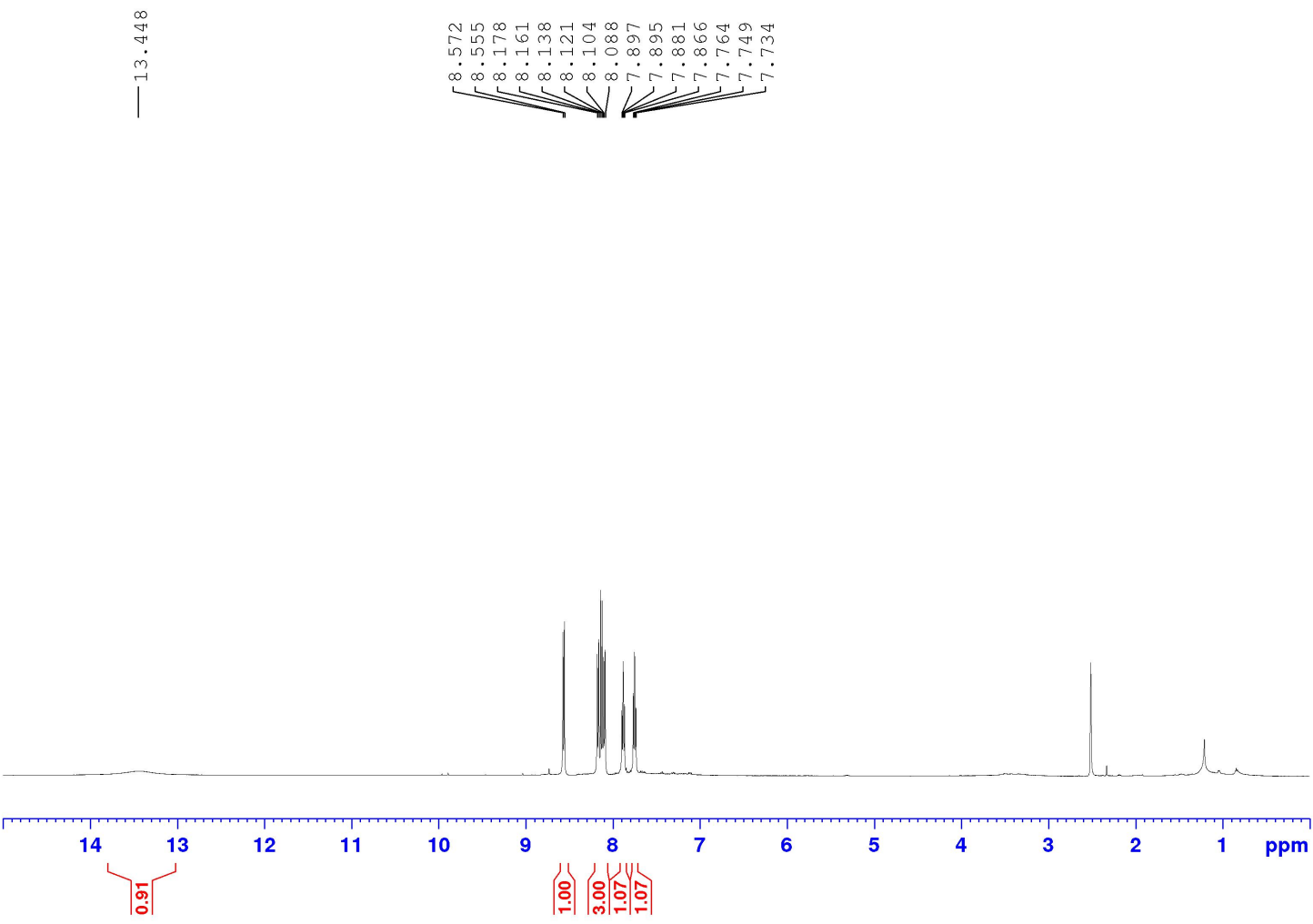
${ }^{13}$ C NMR: Quinaldic Acid<smiles>O=C(O)c1ccc2ccccc2n1</smiles>
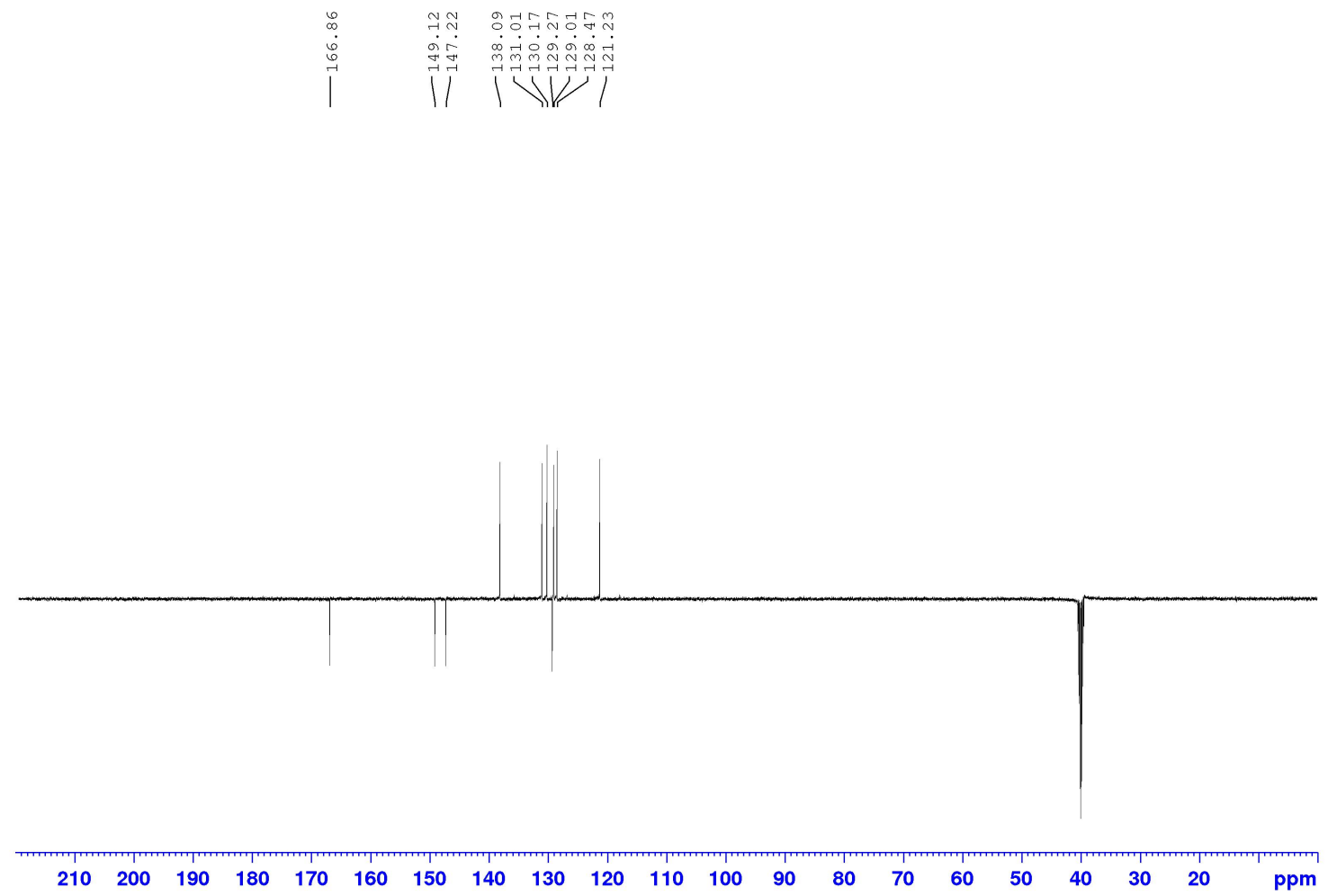
${ }^{1}$ H NMR: 5-Chloro-2-quinaldic Acid (1a)<smiles>O=C(O)c1ccc2c(Cl)cccc2n1</smiles>

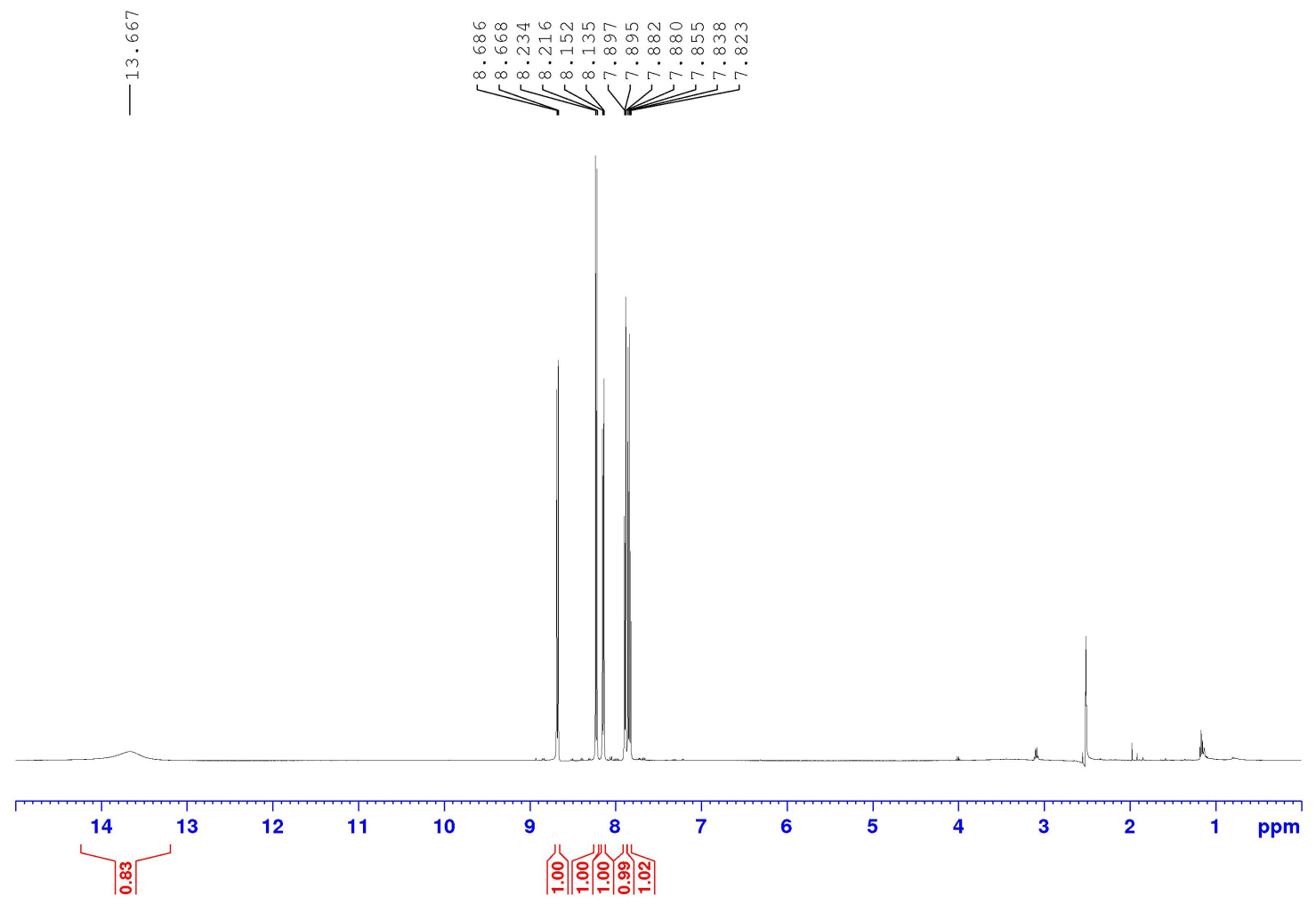


${ }^{13}$ C NMR: 5-Chloro-2-quinaldic Acid (1a)<smiles>O=C(O)c1ccc2c(Cl)cccc2n1</smiles>

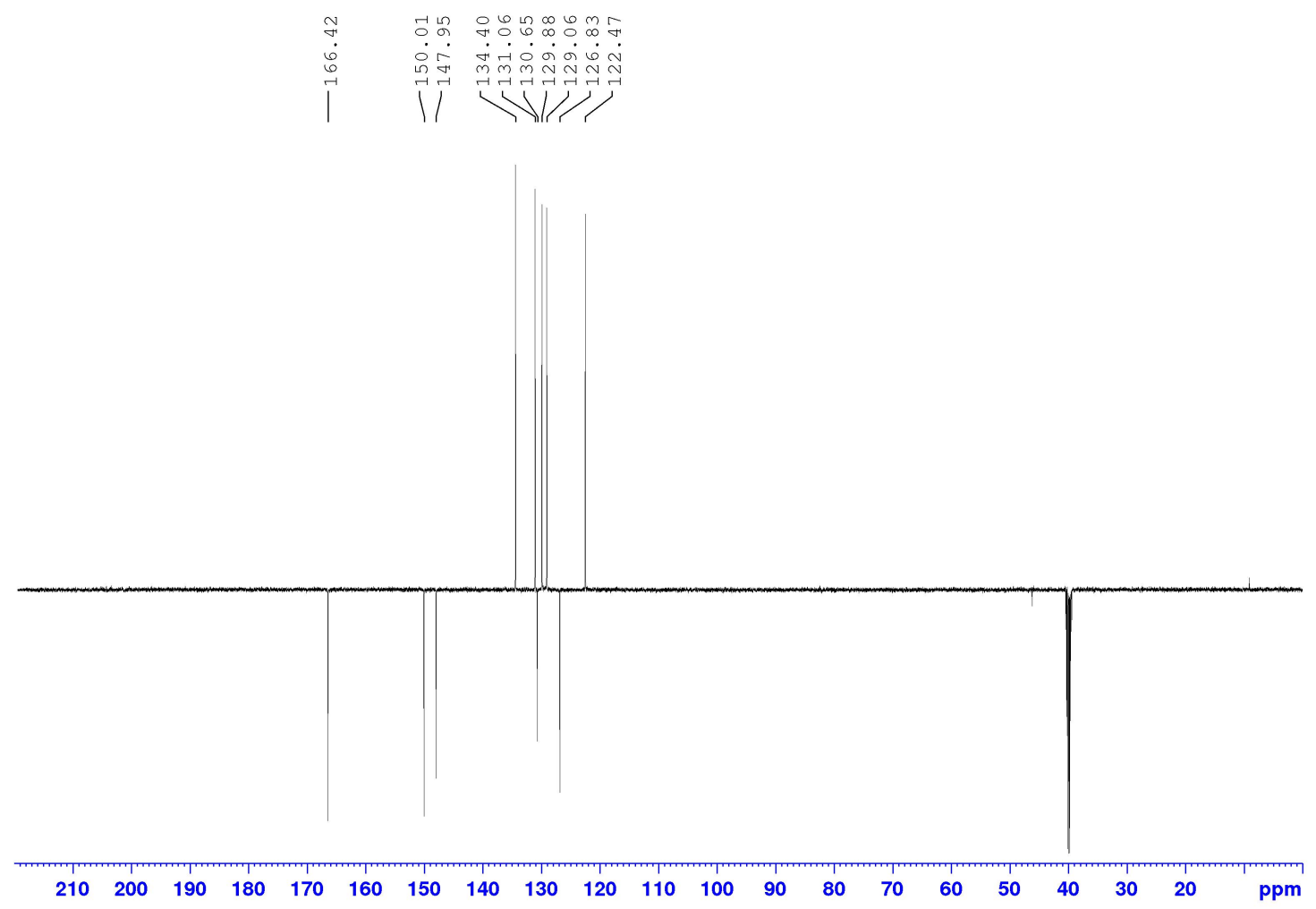


${ }^{1}$ H NMR: 6-Chloro-2-quinaldic Acid (1b)<smiles>O=C(O)c1ccc2cc(Cl)ccc2n1</smiles>
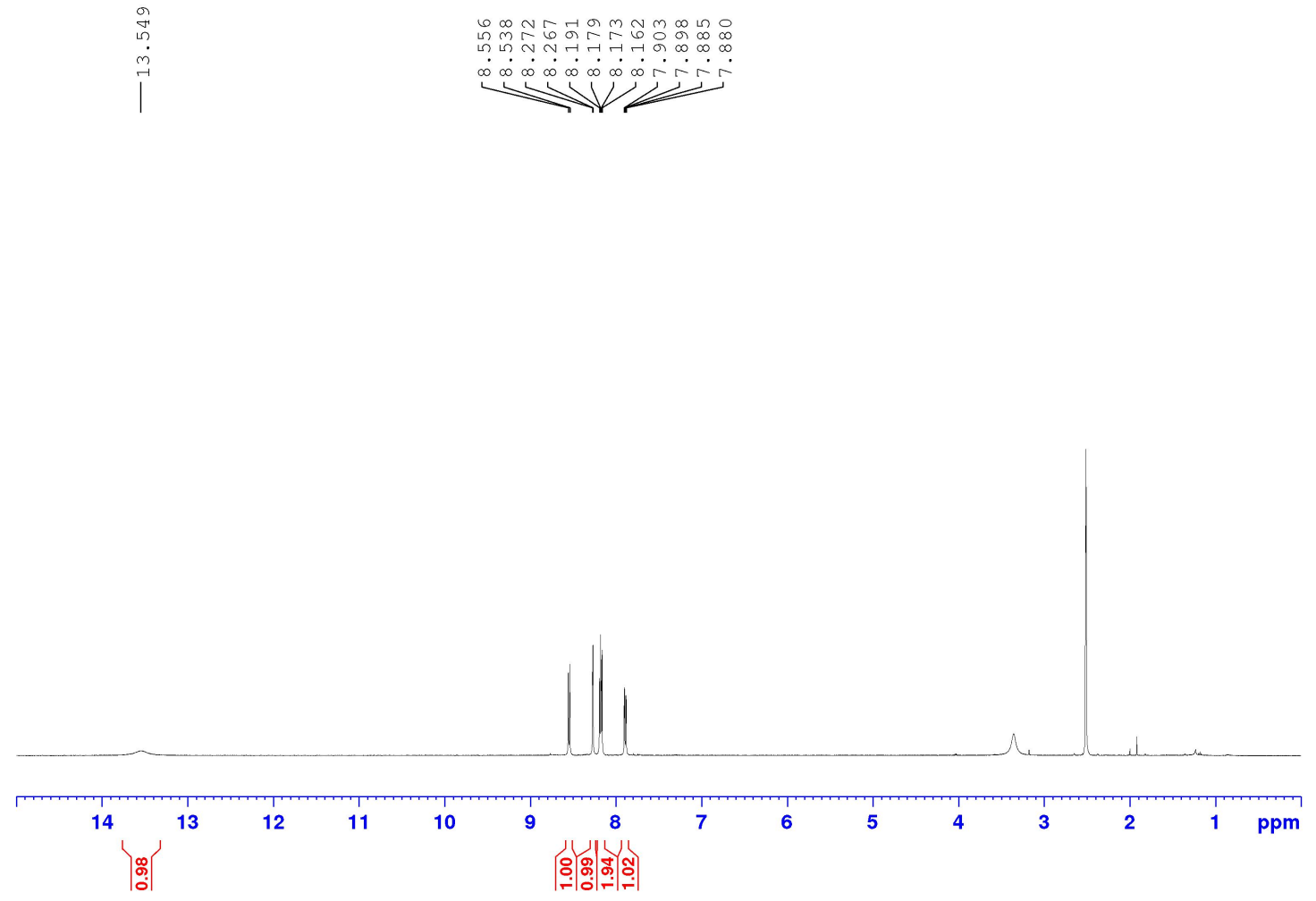
${ }^{13}$ C NMR: 6-Chloro-2-quinaldic Acid (1b)<smiles>O=C(O)c1ccc2cc(Cl)ccc2n1</smiles>

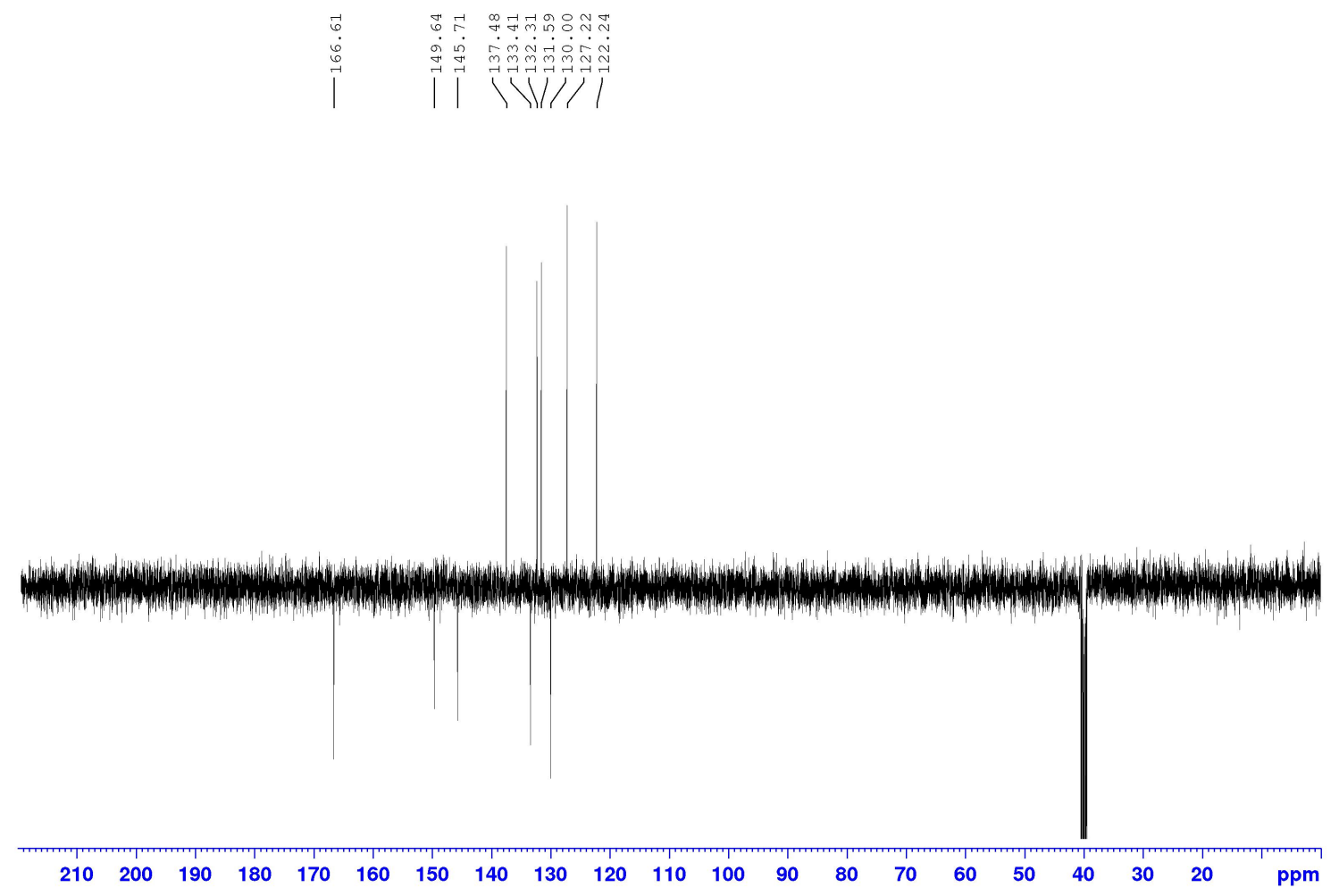


${ }^{1}$ H NMR: 7-Chloro-2-quinaldic Acid (1c)<smiles>O=C(O)c1ccc2ccc(Cl)cc2n1</smiles>

${ }^{13}$ C NMR: 7-Chloro-2-quinaldic Acid (1c)<smiles>O=C(O)c1ccc2ccc(Cl)cc2n1</smiles>
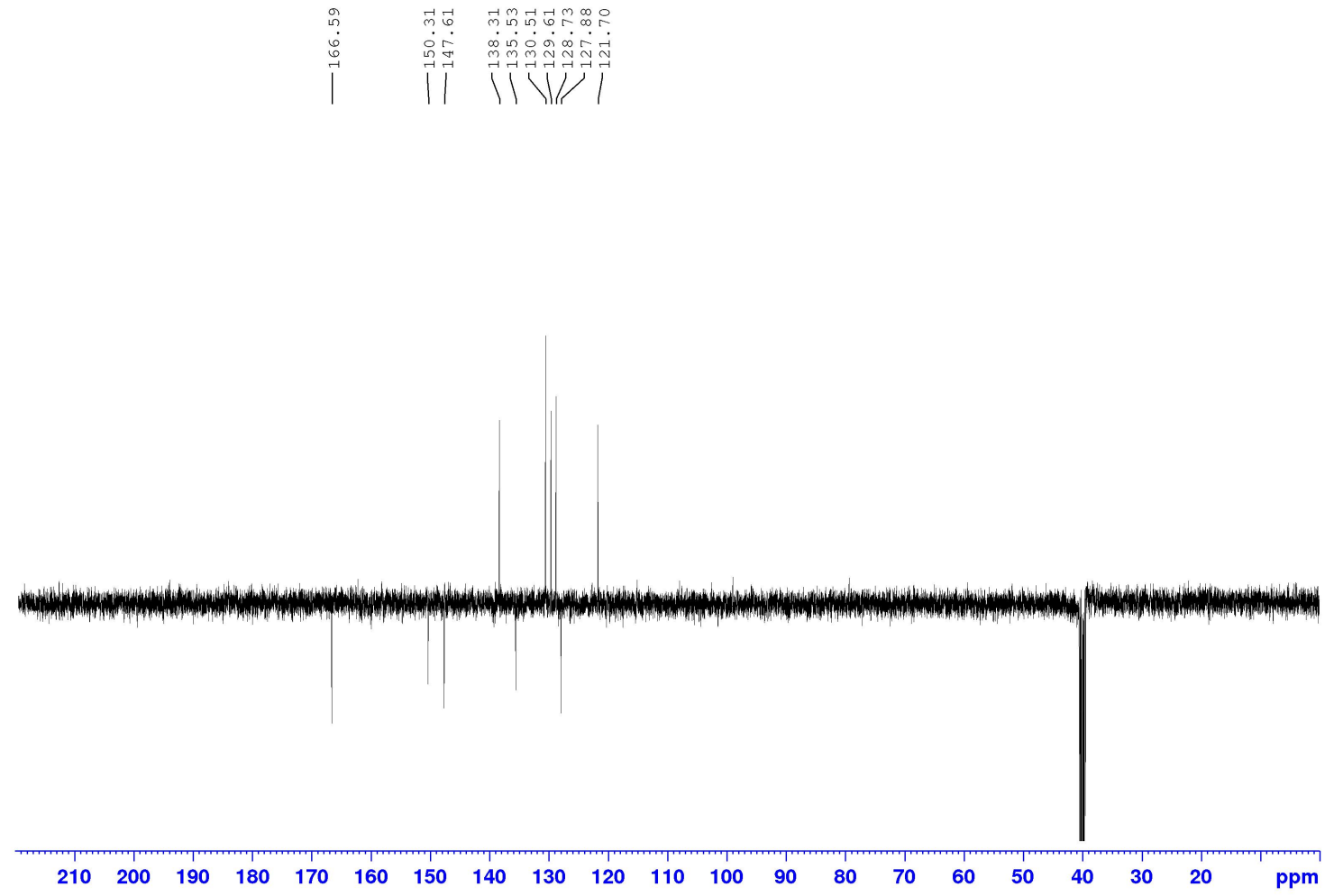
${ }^{1}$ H NMR: 8-Chloro-2-quinaldic Acid (1d)<smiles>O=C(O)c1ccc2cccc(Cl)c2n1</smiles>




${ }^{13}$ C NMR: 8-Chloro-2-quinaldic Acid (1d)<smiles>O=C(O)c1ccc2cccc(Cl)c2n1</smiles>




${ }^{1}$ H NMR: 6-Fluoro-2-quinaldic Acid (1e)<smiles>O=C(O)c1ccc2cc(F)ccc2n1</smiles>

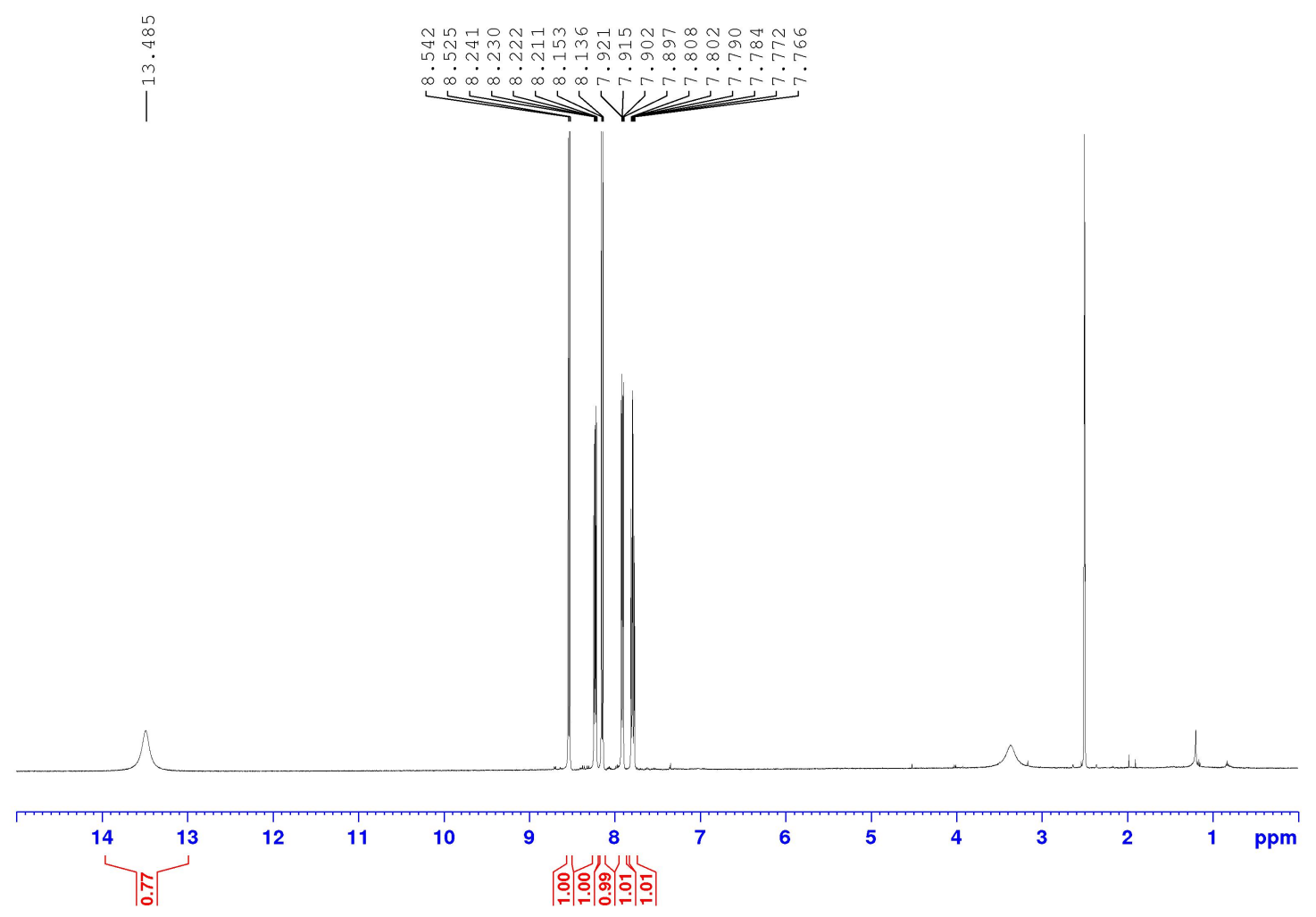


${ }^{13}$ C NMR: 6-Fluoro-2-quinaldic Acid (1e)<smiles>O=C(O)c1ccc2cc(F)ccc2n1</smiles>

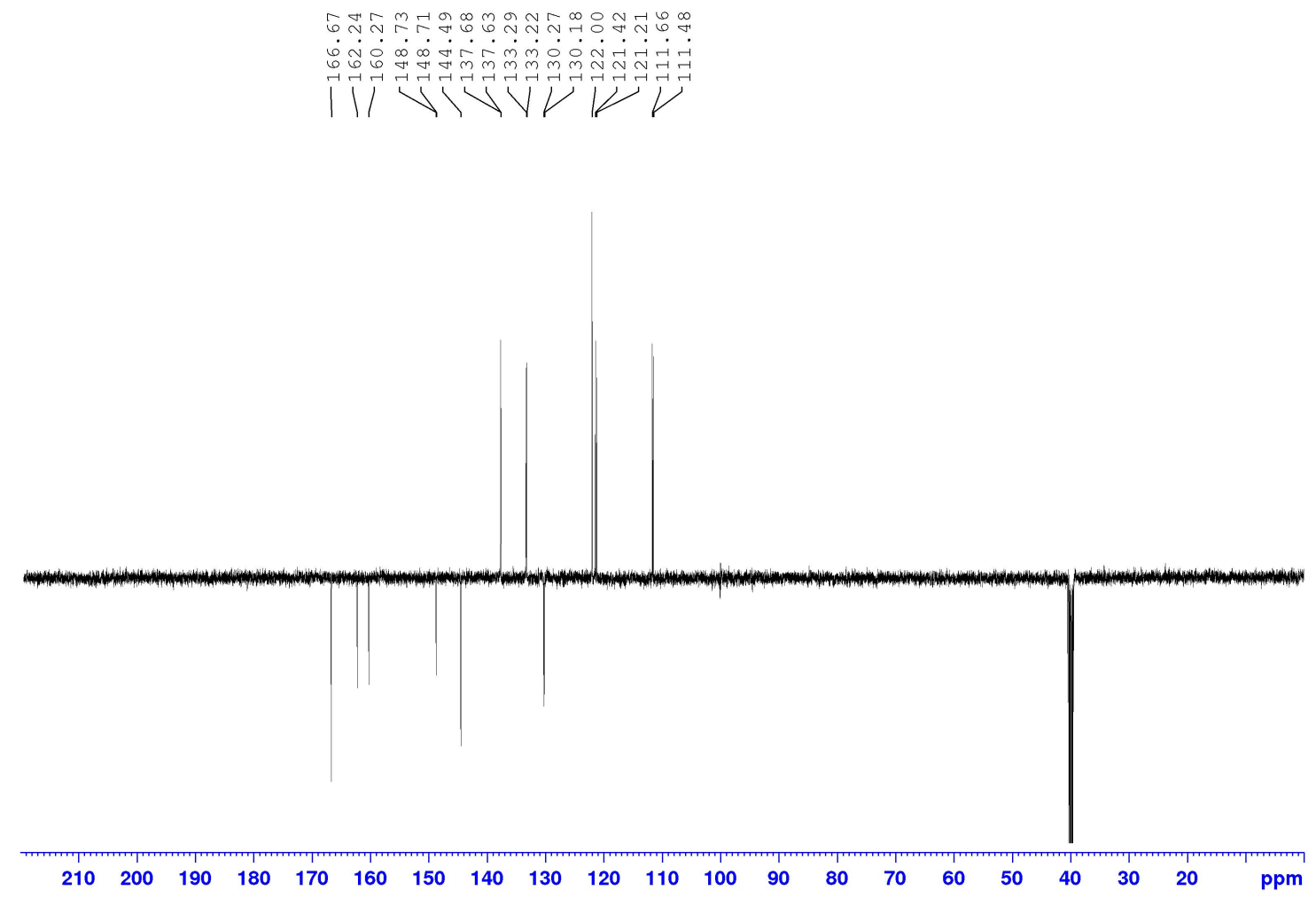


${ }^{19}$ F NMR \{Proton Coupled\}: 6-Fluoro-2-quinaldic Acid (1e)<smiles>O=C(O)c1ccc2cc(F)ccc2n1</smiles>

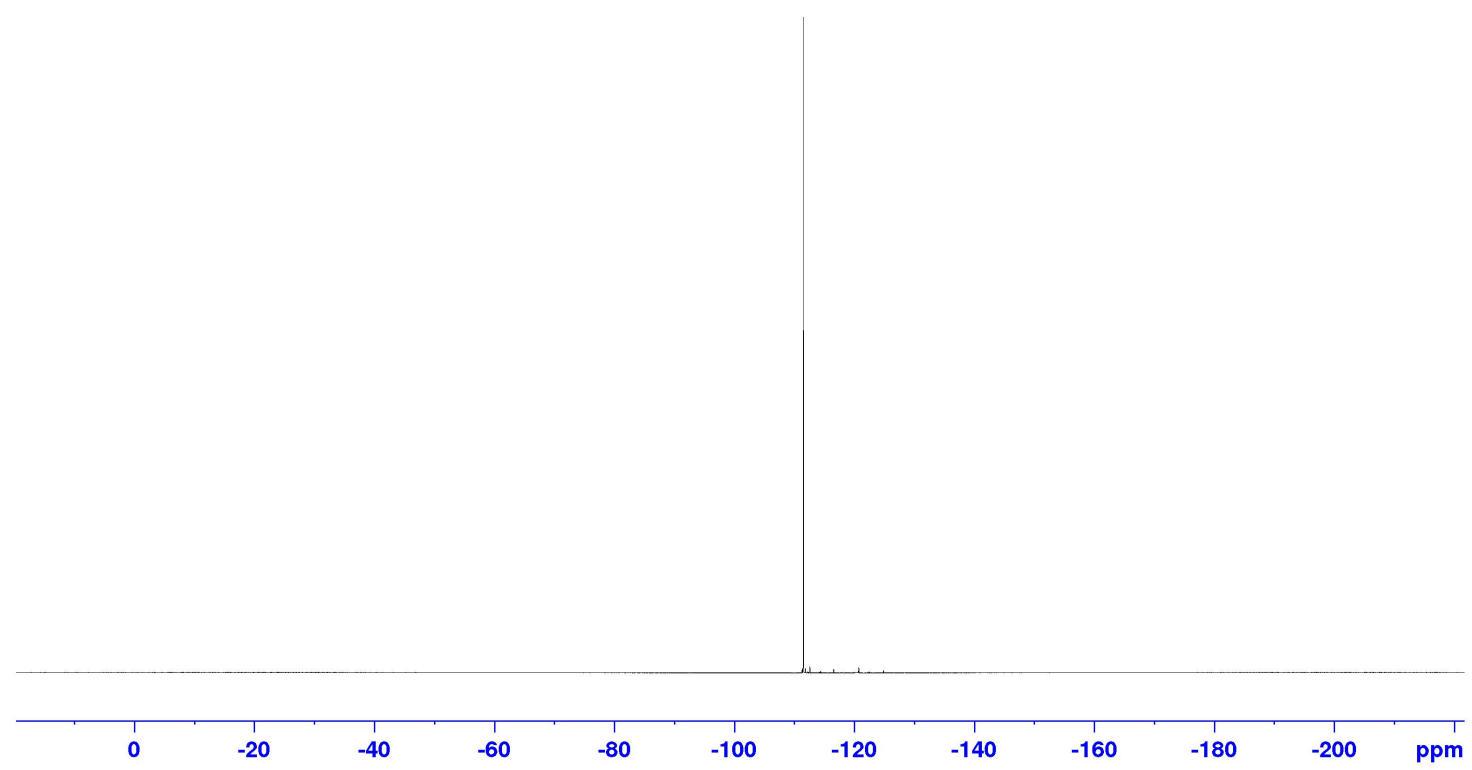


${ }^{19}$ F NMR \{Proton De-coupled\}: 6-Fluoro-2-quinaldic Acid (1e)<smiles>O=C(O)c1ccc2cc(F)ccc2n1</smiles>

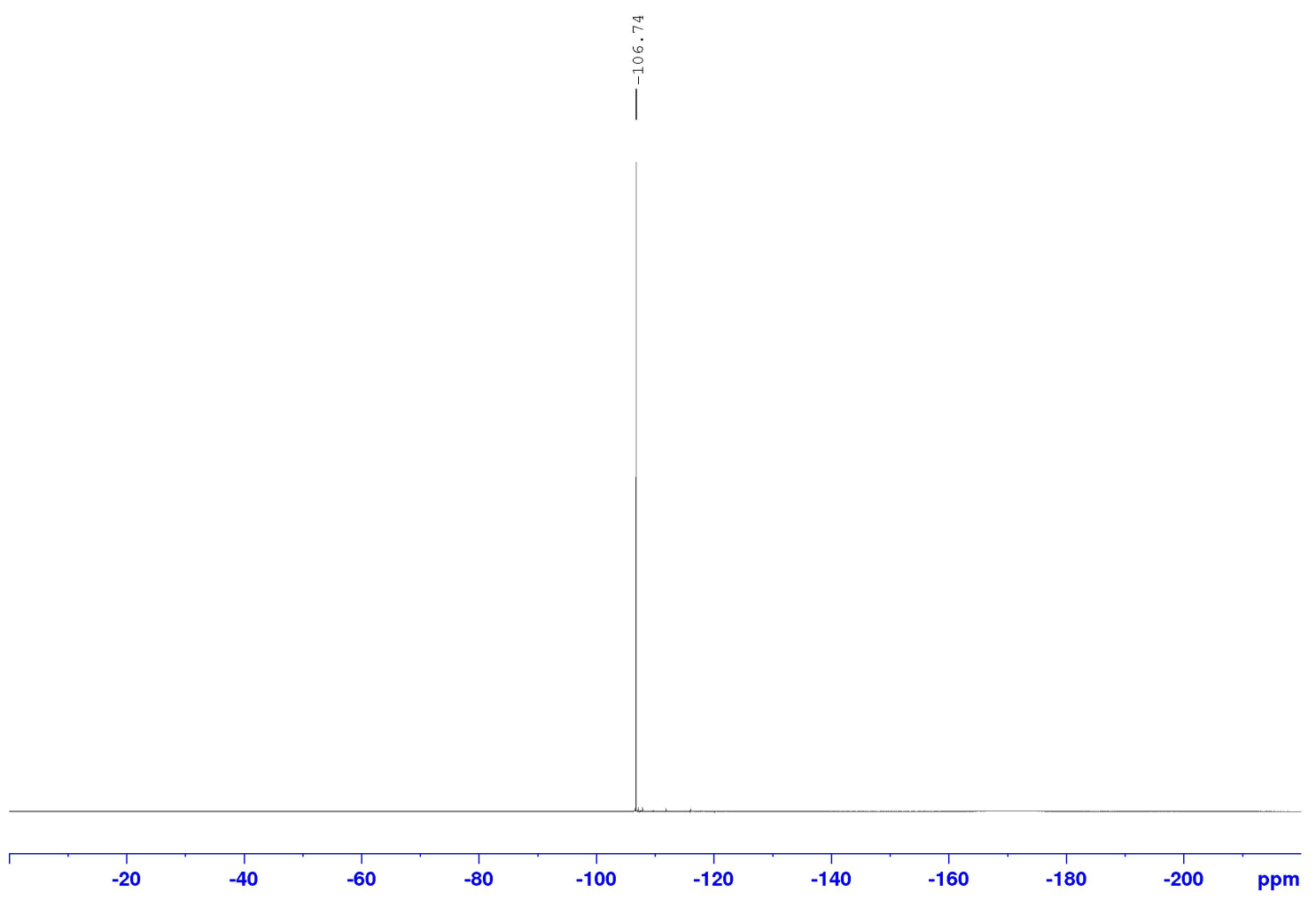


${ }^{1}$ H NMR: 7-Fluoro-2-quinaldic Acid (1f)<smiles>O=C(O)c1ccc2ccc(F)cc2n1</smiles>

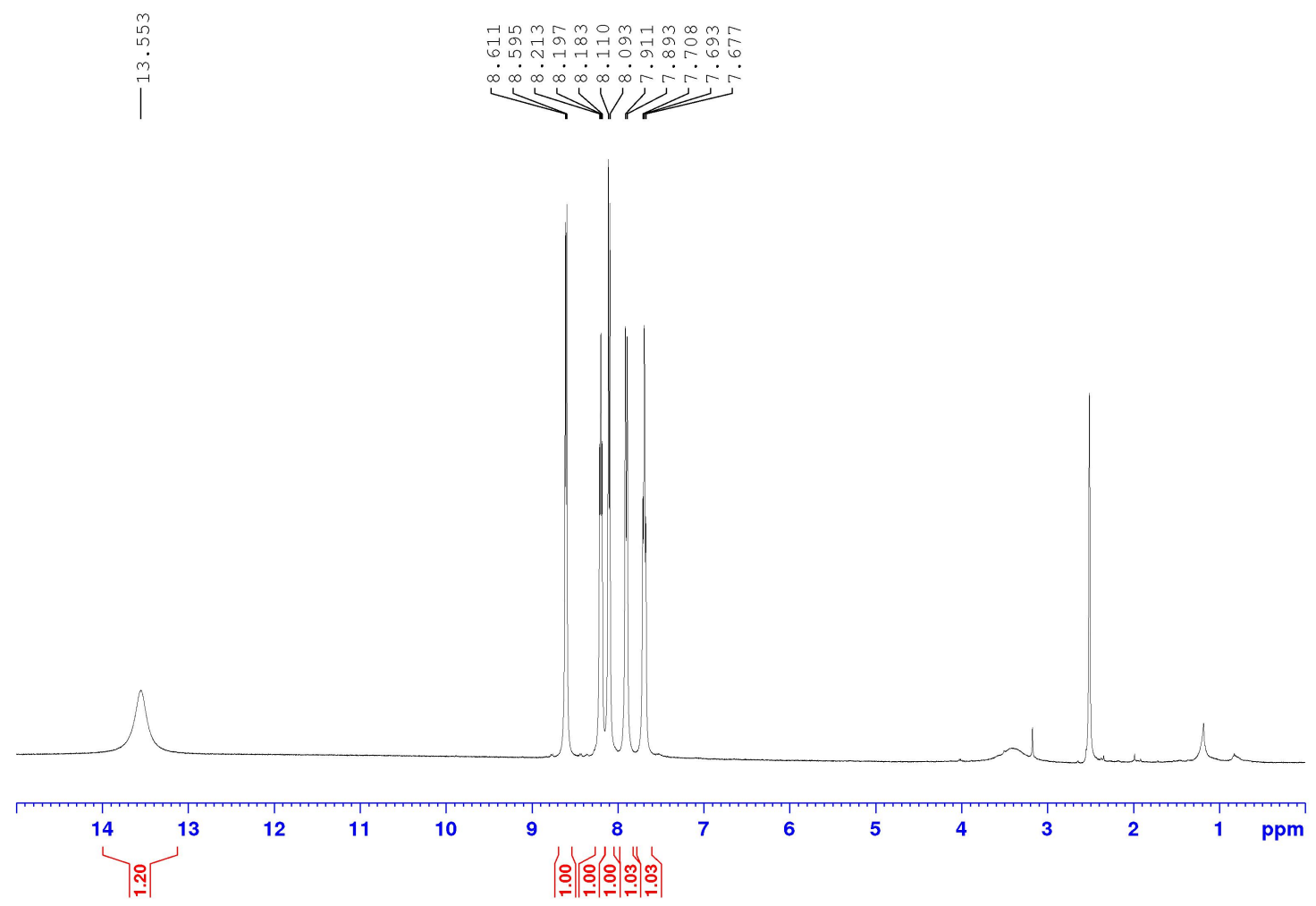


${ }^{13}$ C NMR: 7-Fluoro-2-quinaldic Acid (1f)<smiles>O=C(O)c1ccc2ccc(F)cc2n1</smiles>

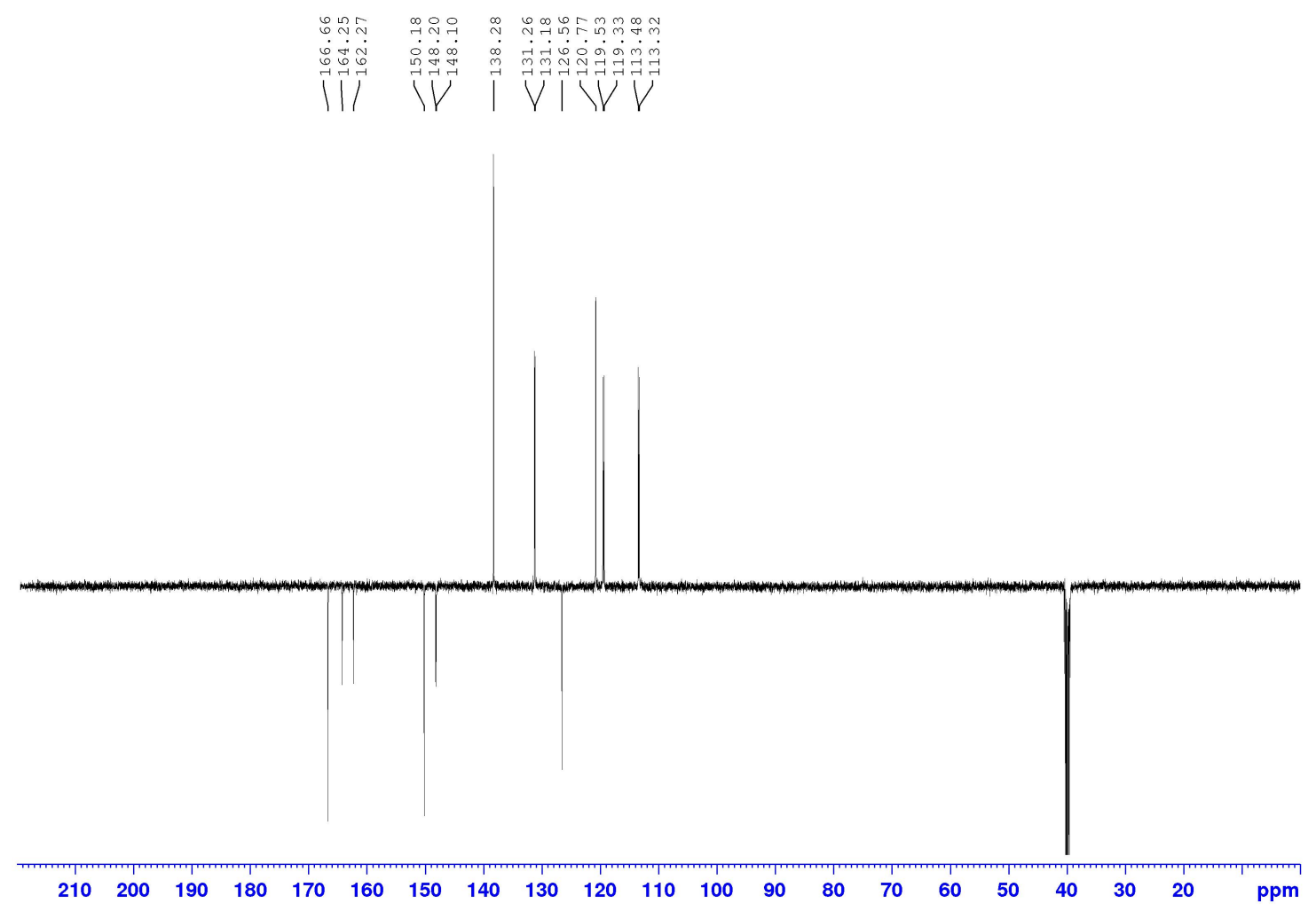


${ }^{1}$ H NMR: 6-Bromo-2-quinaldic Acid (1g)<smiles>O=C(O)c1ccc2cc(Br)ccc2n1</smiles>




${ }^{13}$ C NMR: 6-Bromo-2-quinaldic Acid (1g)<smiles>O=C(O)c1ccc2cc(Br)ccc2n1</smiles>

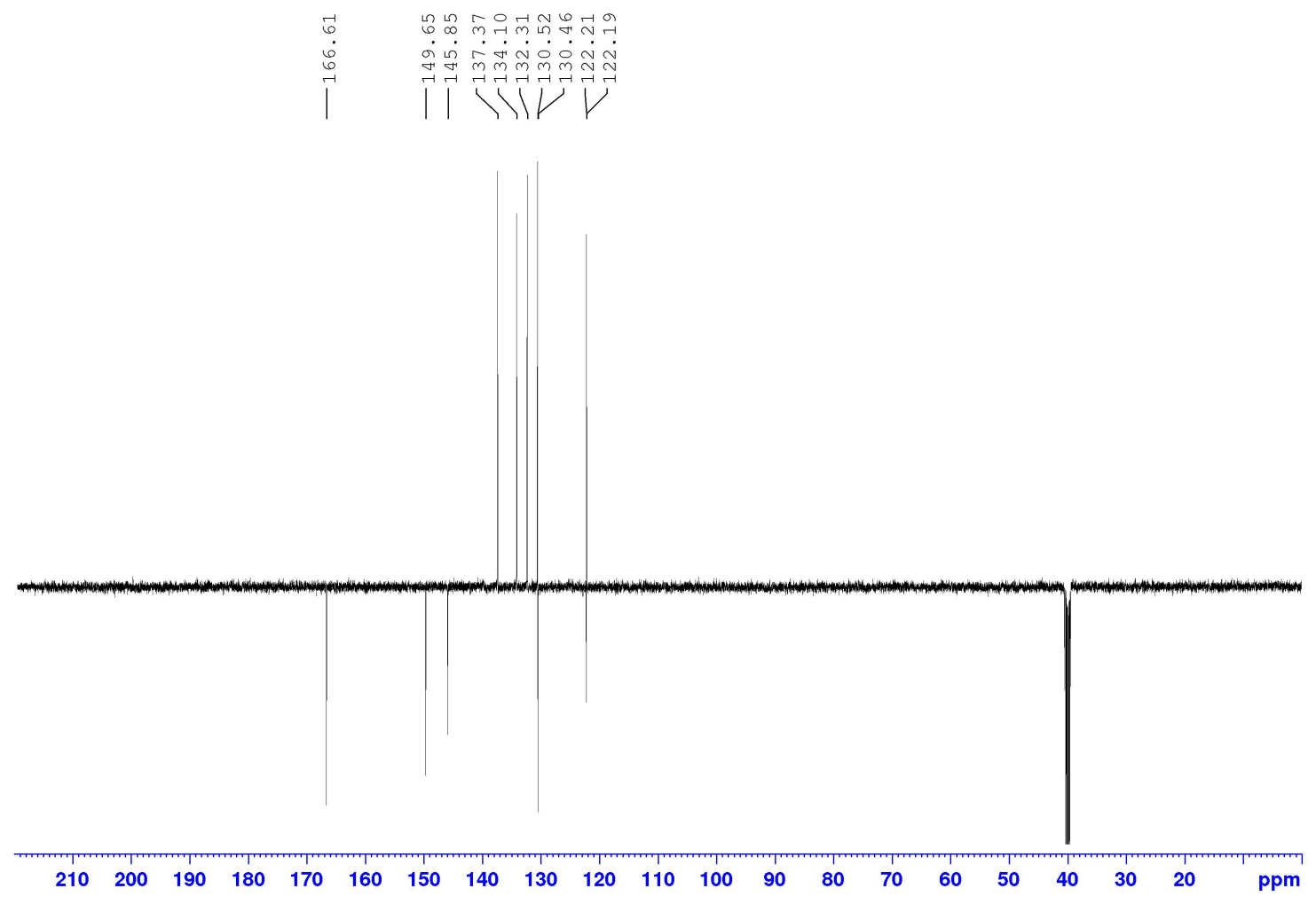


${ }^{1}$ H NMR: 7-Bromo-2-quinaldic Acid (1h)<smiles>O=C(O)c1ccc2ccc(Br)cc2n1</smiles>

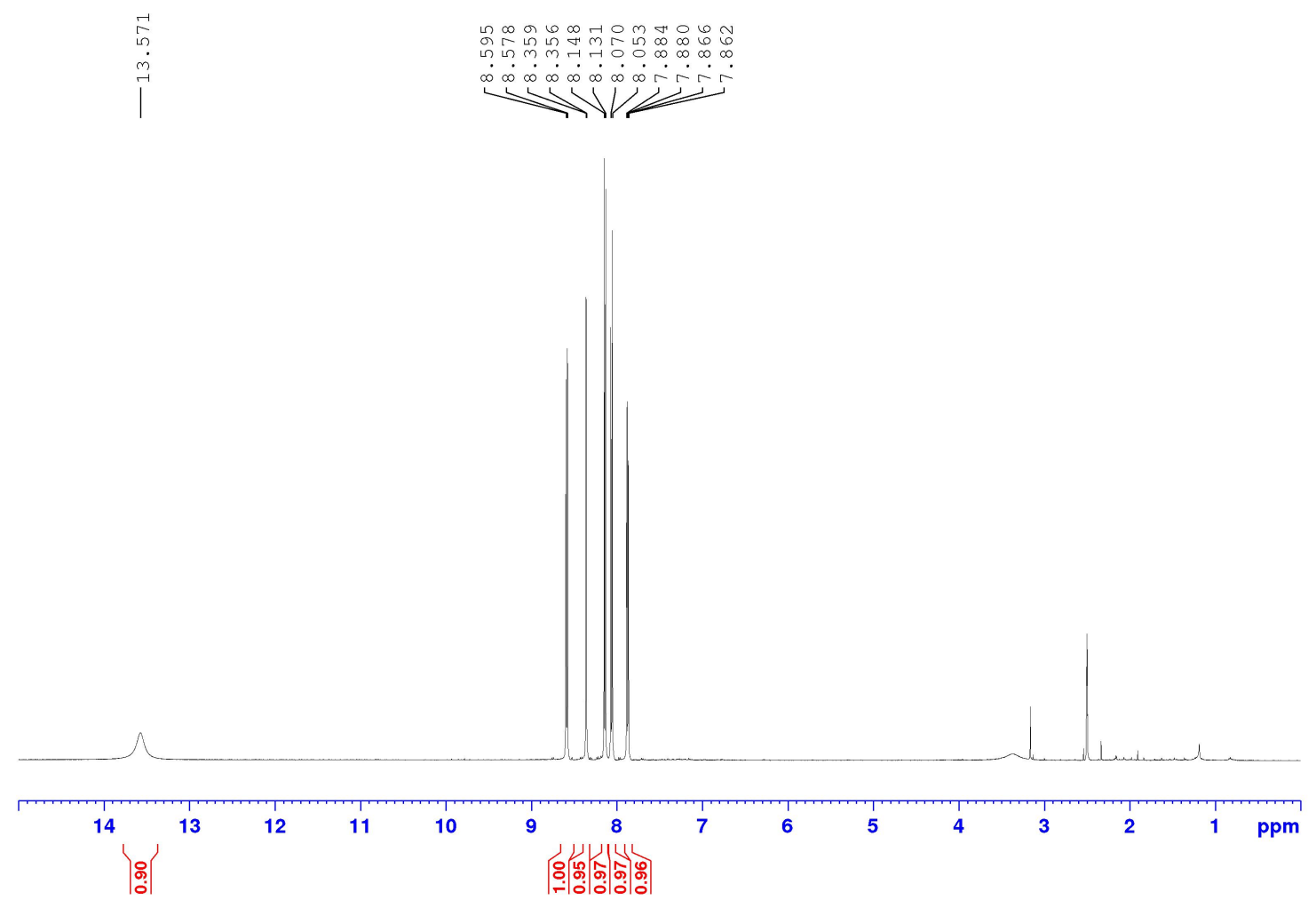


${ }^{13}$ C NMR: 7-Bromo-2-quinaldic Acid (1h)<smiles>O=C(O)c1ccc2ccc(Br)cc2n1</smiles>
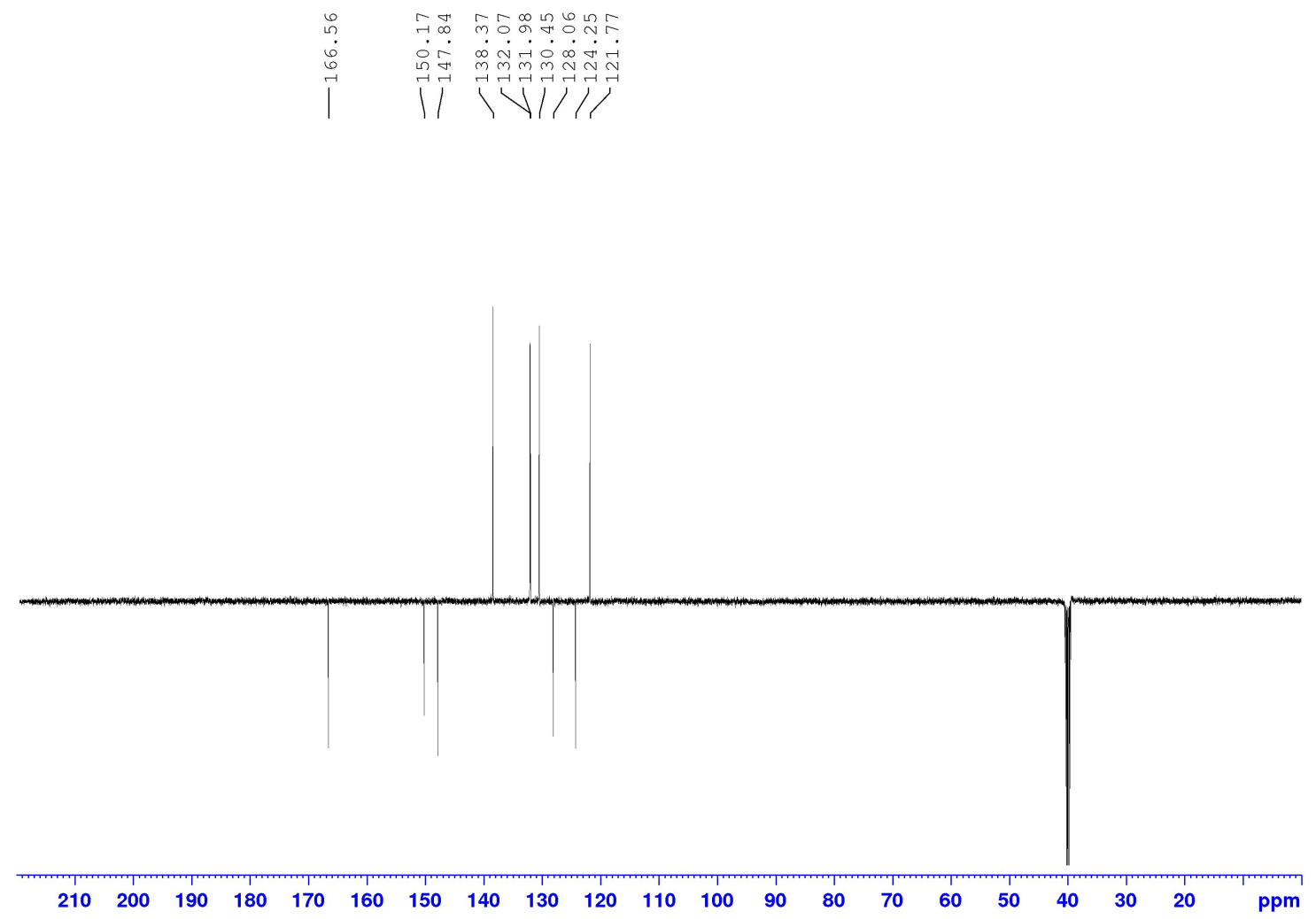
${ }^{1}$ H NMR: 7-Cyano-2-quinaldic Acid (1i)<smiles>N#Cc1ccc2ccc(C(=O)O)nc2c1</smiles>

${ }^{13}$ C NMR: 7-Cyano-2-quinaldic Acid (1i)<smiles>N#Cc1ccc2ccc(C(=O)O)nc2c1</smiles>

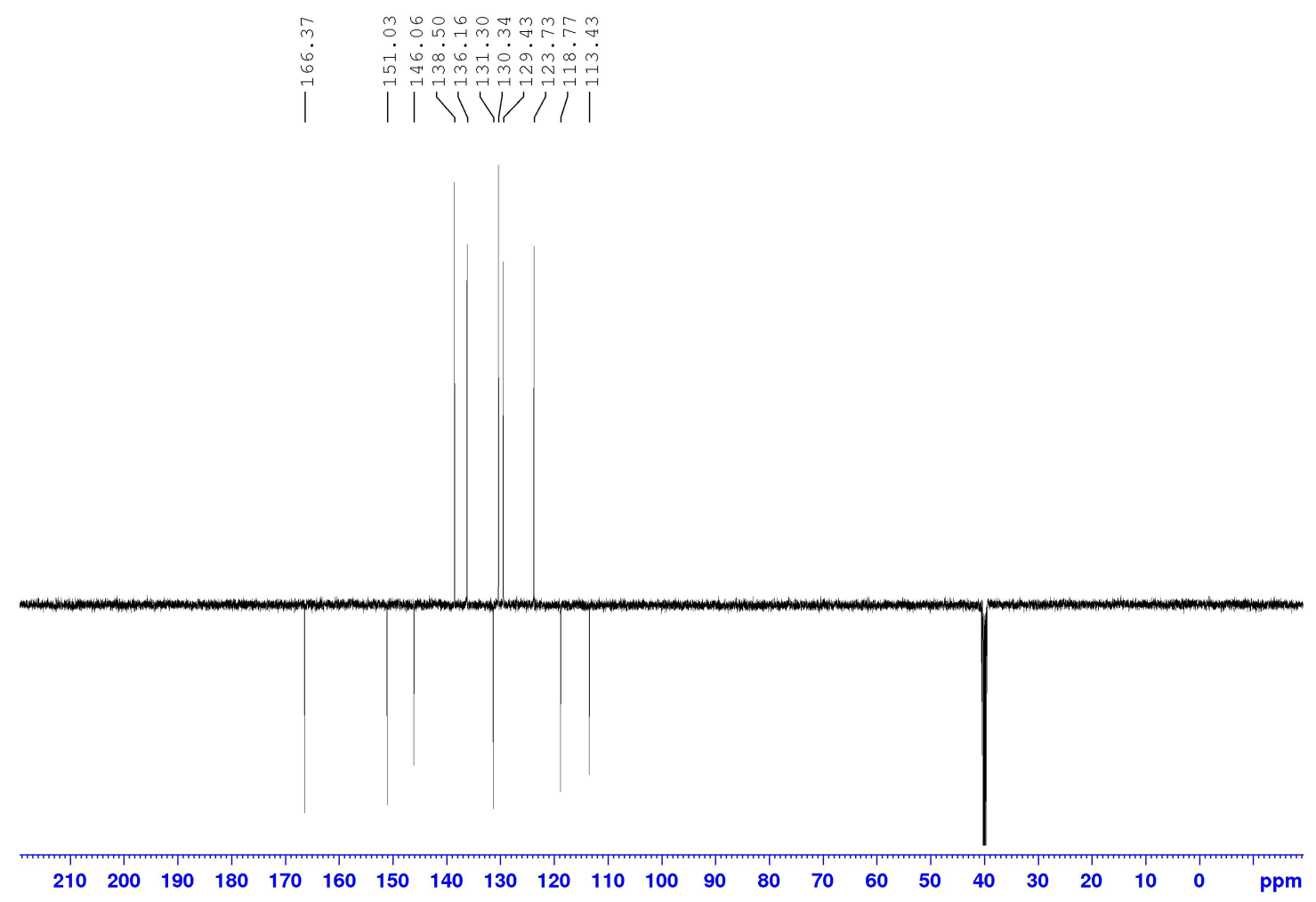


${ }^{1}$ H NMR: 2,7-Quinolinedicarboxylic acid, 7-methyl ester (1j)<smiles>CC(=O)c1ccc2ccc(C(=O)O)nc2c1</smiles>




${ }^{13}$ C NMR: 2,7-Quinolinedicarboxylic acid, 7-methyl ester (1j)<smiles>CC(=O)c1ccc2ccc(C(=O)O)nc2c1</smiles>
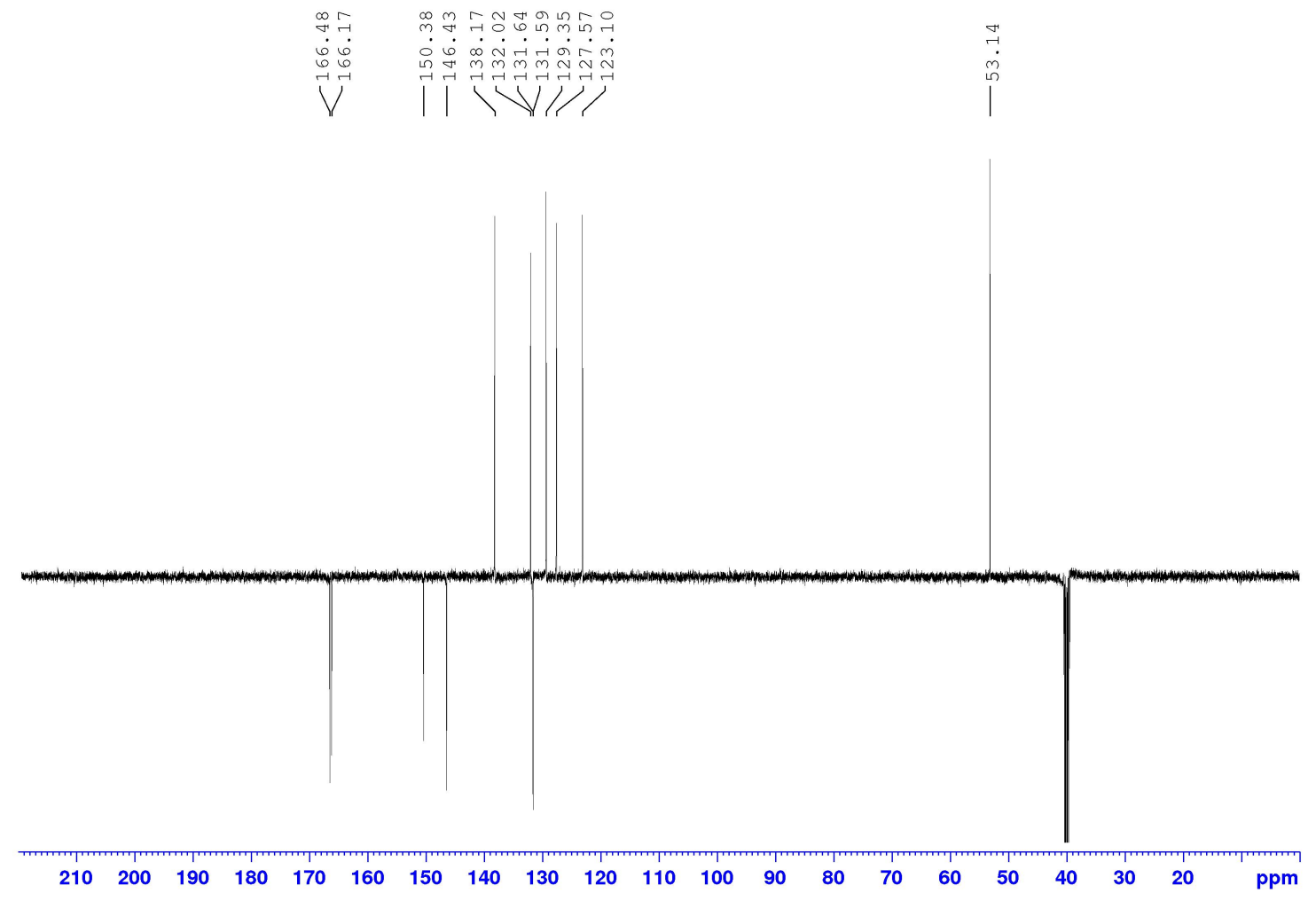
${ }^{1}$ H NMR: 6-Methoxy-2-quinaldic Acid (1k)<smiles>COc1ccc2nc(C(=O)O)ccc2c1</smiles>
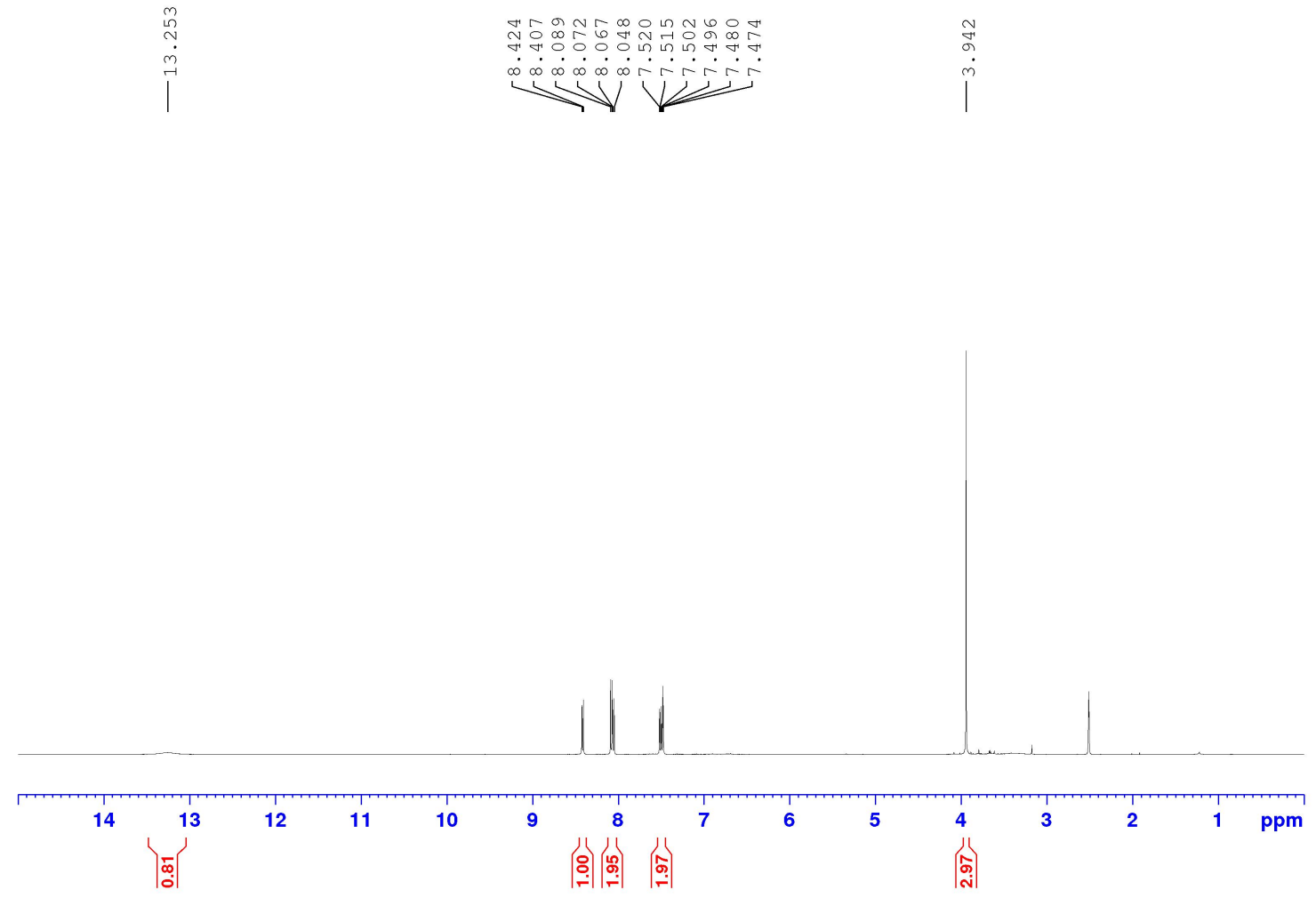
${ }^{13}$ C NMR: 6-Methoxy-2-quinaldic Acid (1k)<smiles>COc1ccc2nc(C(=O)O)ccc2c1</smiles>

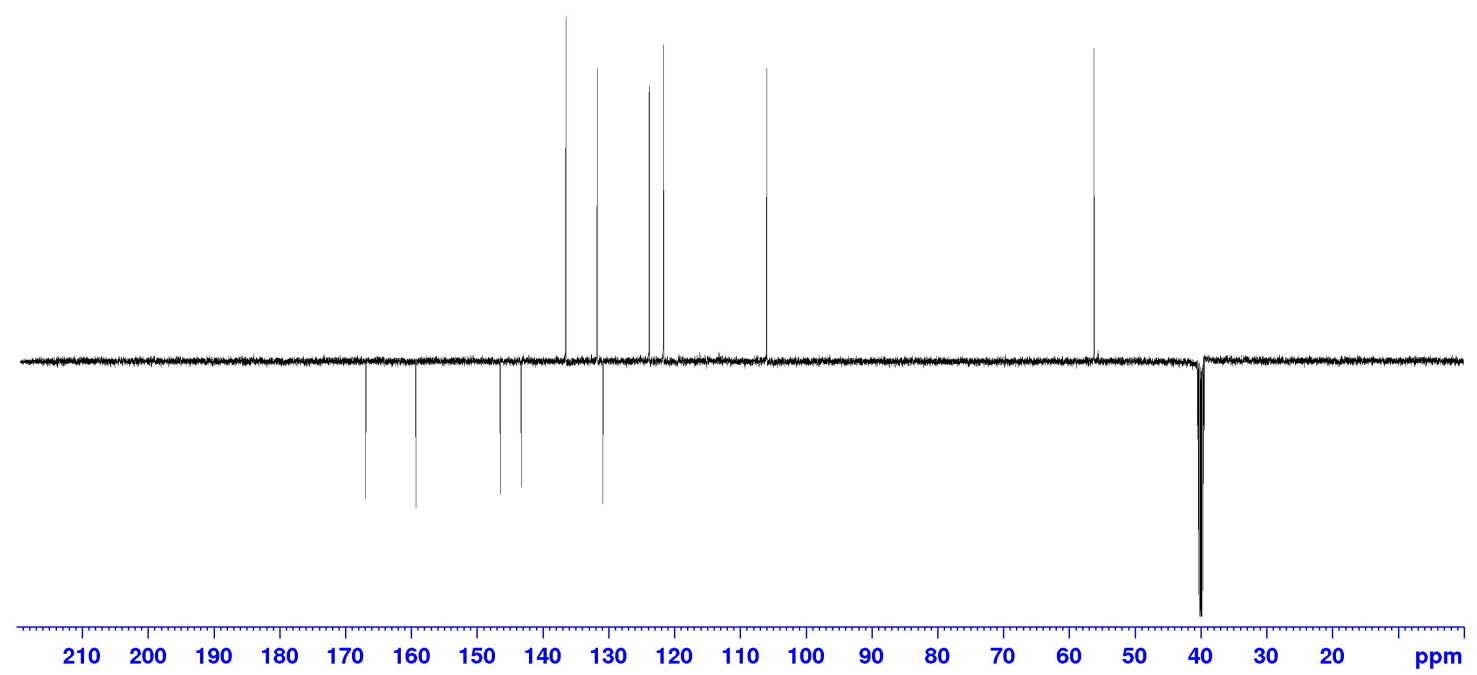


${ }^{1}$ H NMR: 7-Methoxy-2-quinaldic Acid (11)<smiles>COc1ccc2ccc(C(=O)O)nc2c1</smiles>

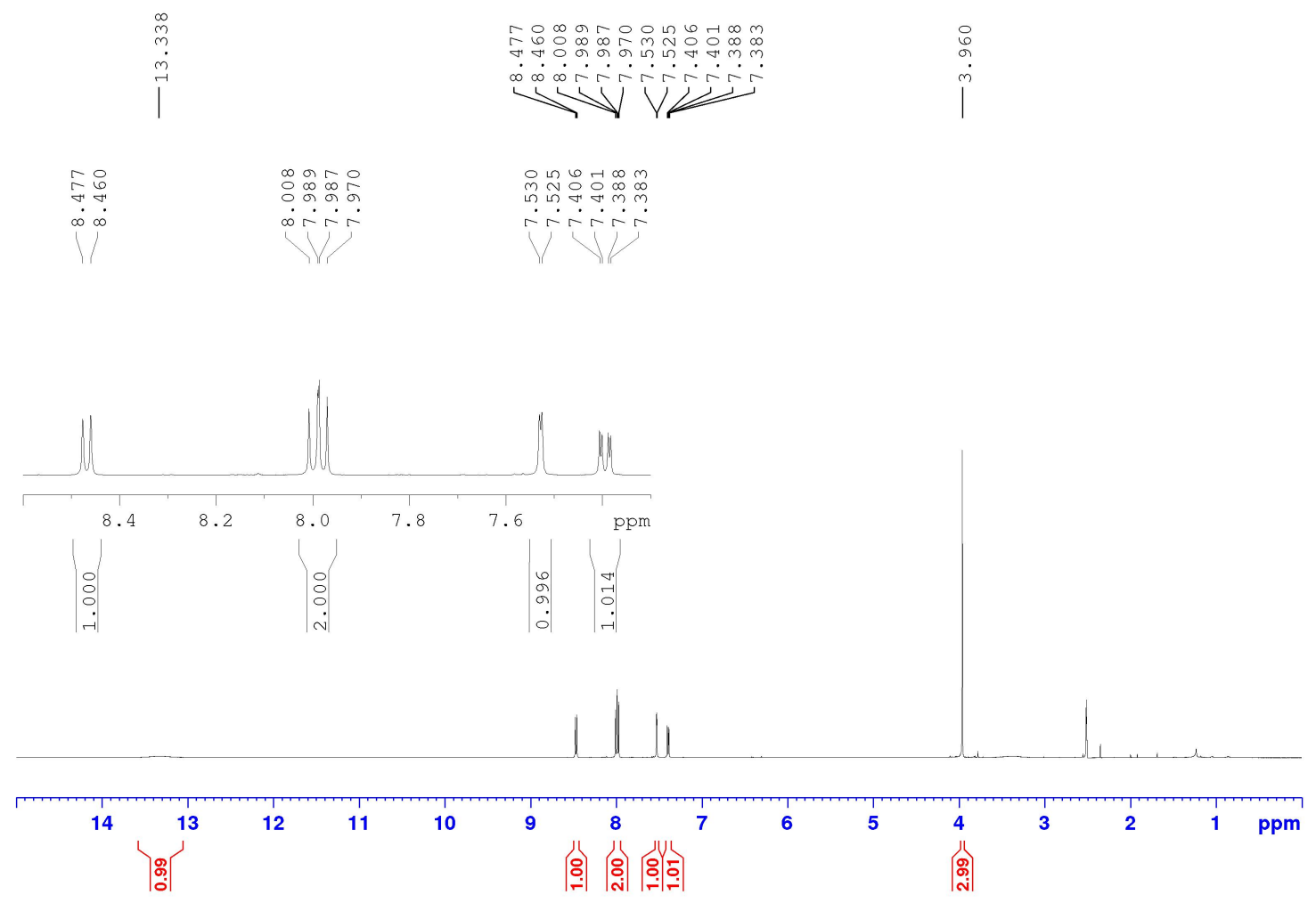


${ }^{13}$ C NMR: 7-Methoxy-2-quinaldic Acid (11)<smiles>COc1ccc2ccc(C(=O)O)nc2c1</smiles>
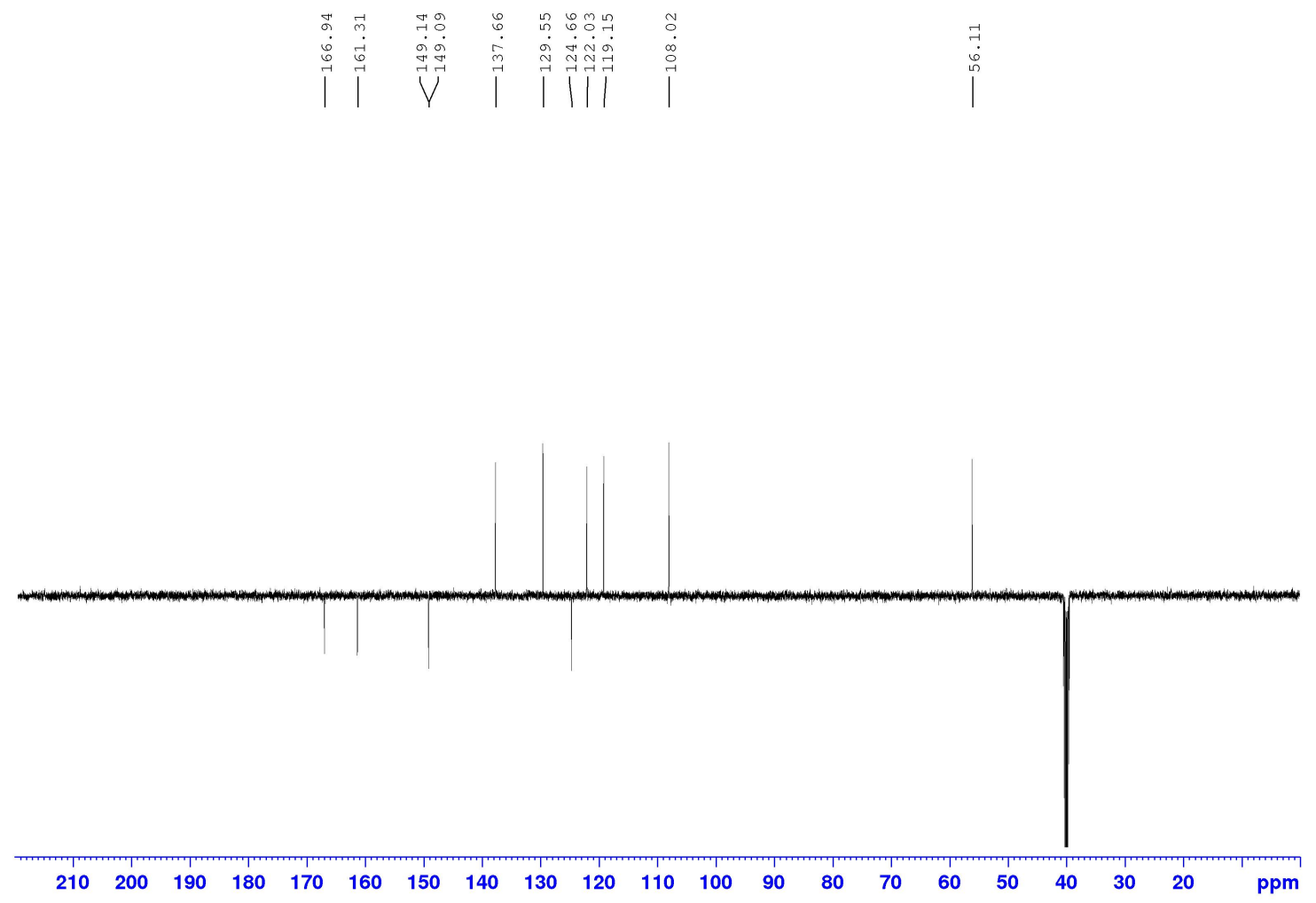
${ }^{1}$ H NMR: 6-Hydroxy-2-quinaldic Acid (1m)<smiles>O=C(O)c1ccc2cc(O)ccc2n1</smiles>
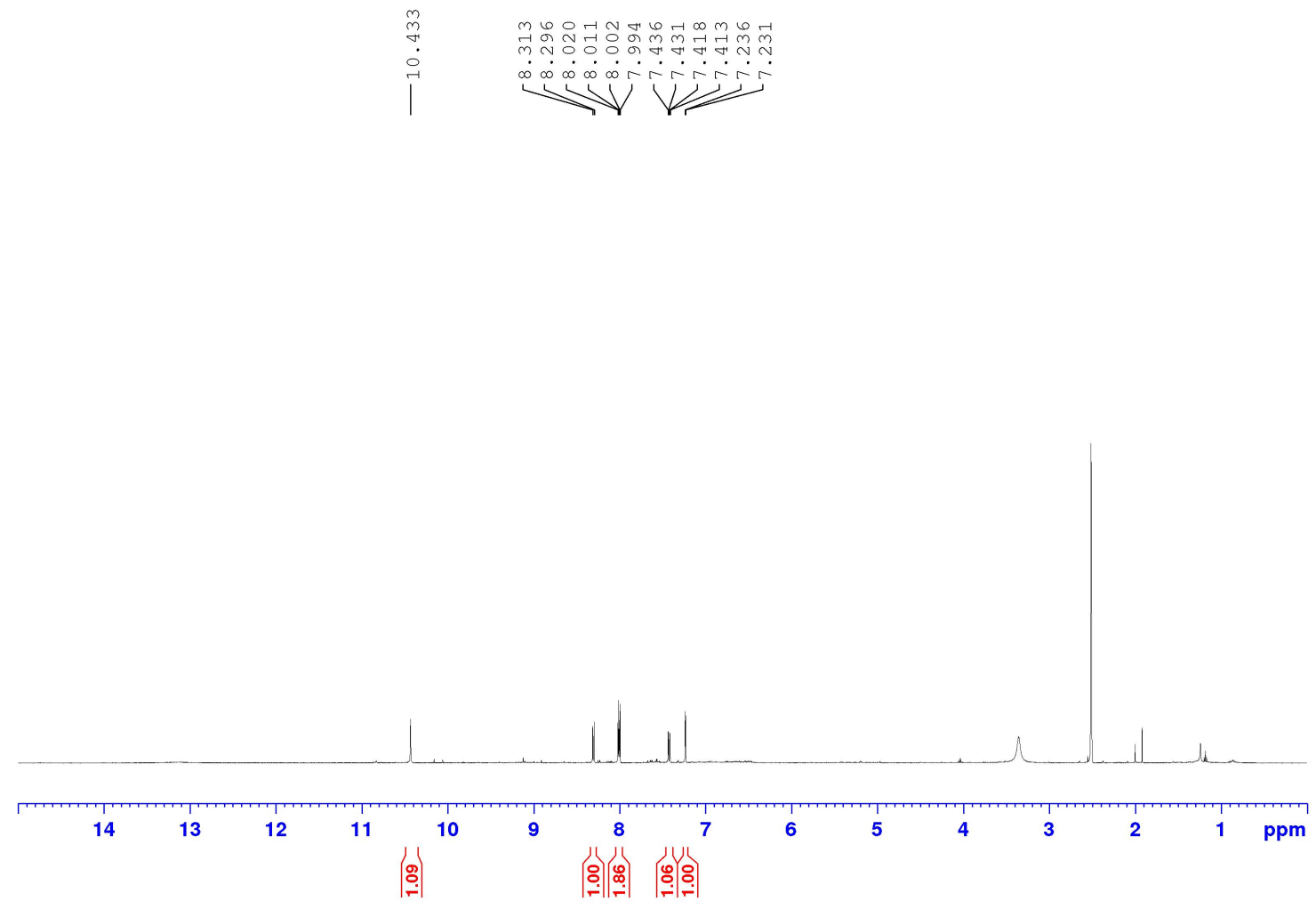
${ }^{13}$ C NMR: 6-Hydroxy-2-quinaldic Acid (1 m)<smiles>O=C(O)c1ccc2cc(O)ccc2n1</smiles>

$$
\text { | }
$$

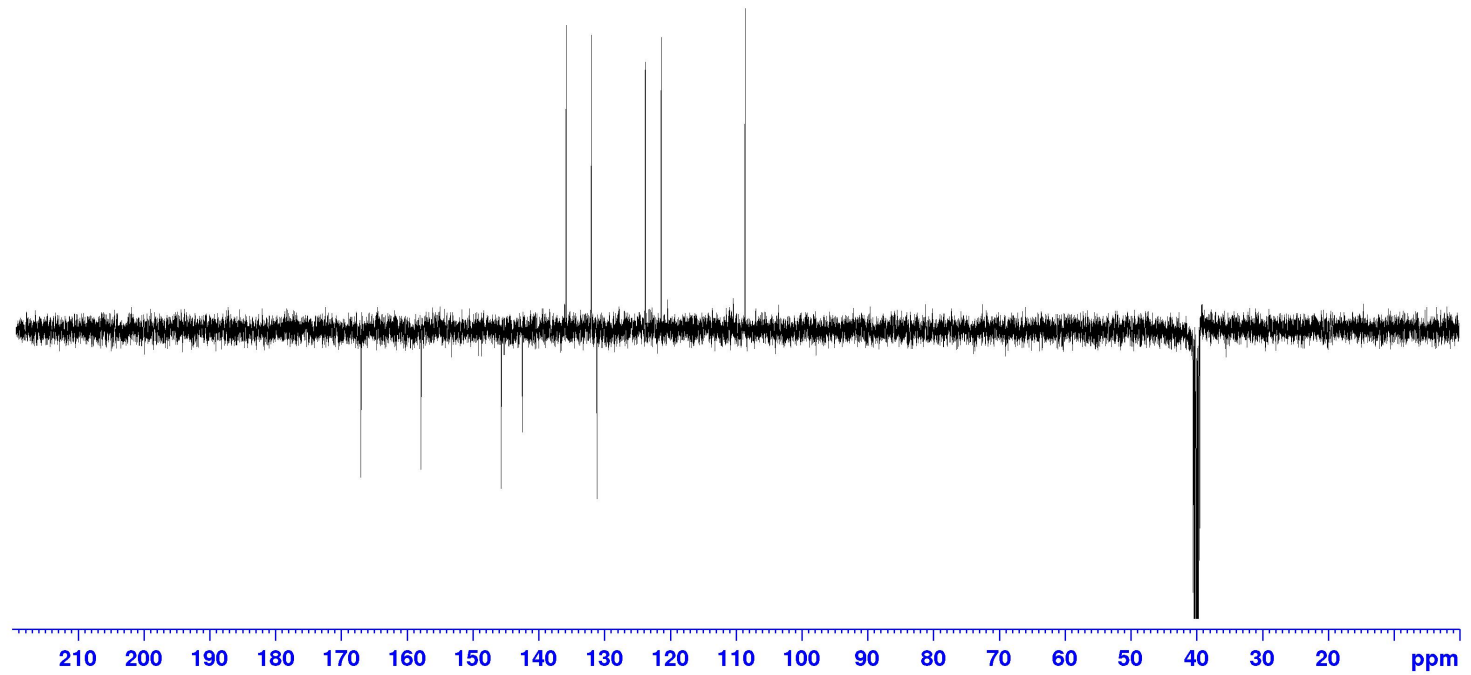


${ }^{1}$ H NMR: 7-(N,N-Dimethyl)-quinaldic Acid (1n) Methyl Ester<smiles>COC(=O)c1ccc2ccc(N(C)C)cc2n1</smiles>

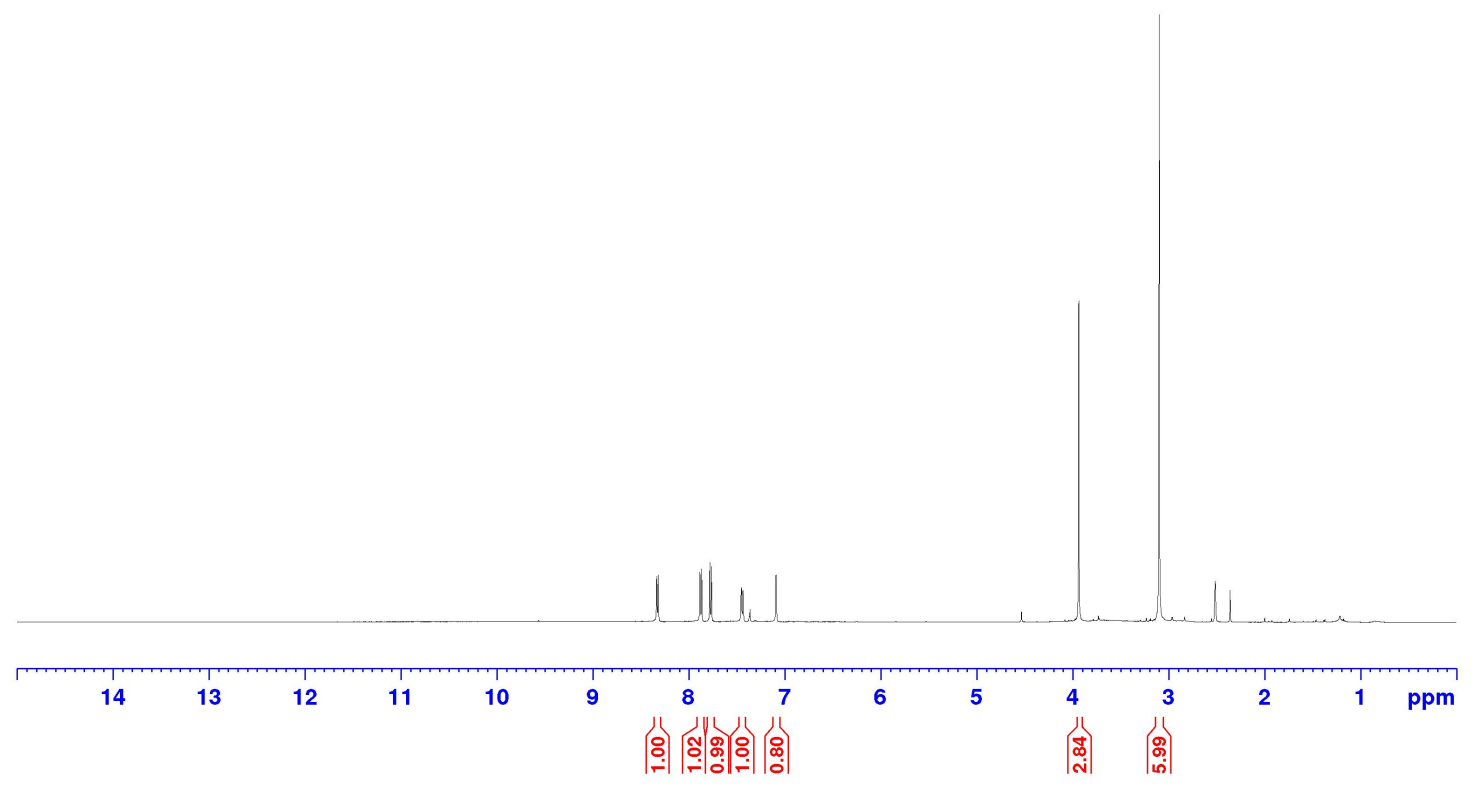


${ }^{13}$ C NMR: 7-(N,N-Dimethyl)-quinaldic Acid Methyl Ester (1n)<smiles>CC(=O)c1ccc2ccc(N(C)C)cc2n1</smiles>

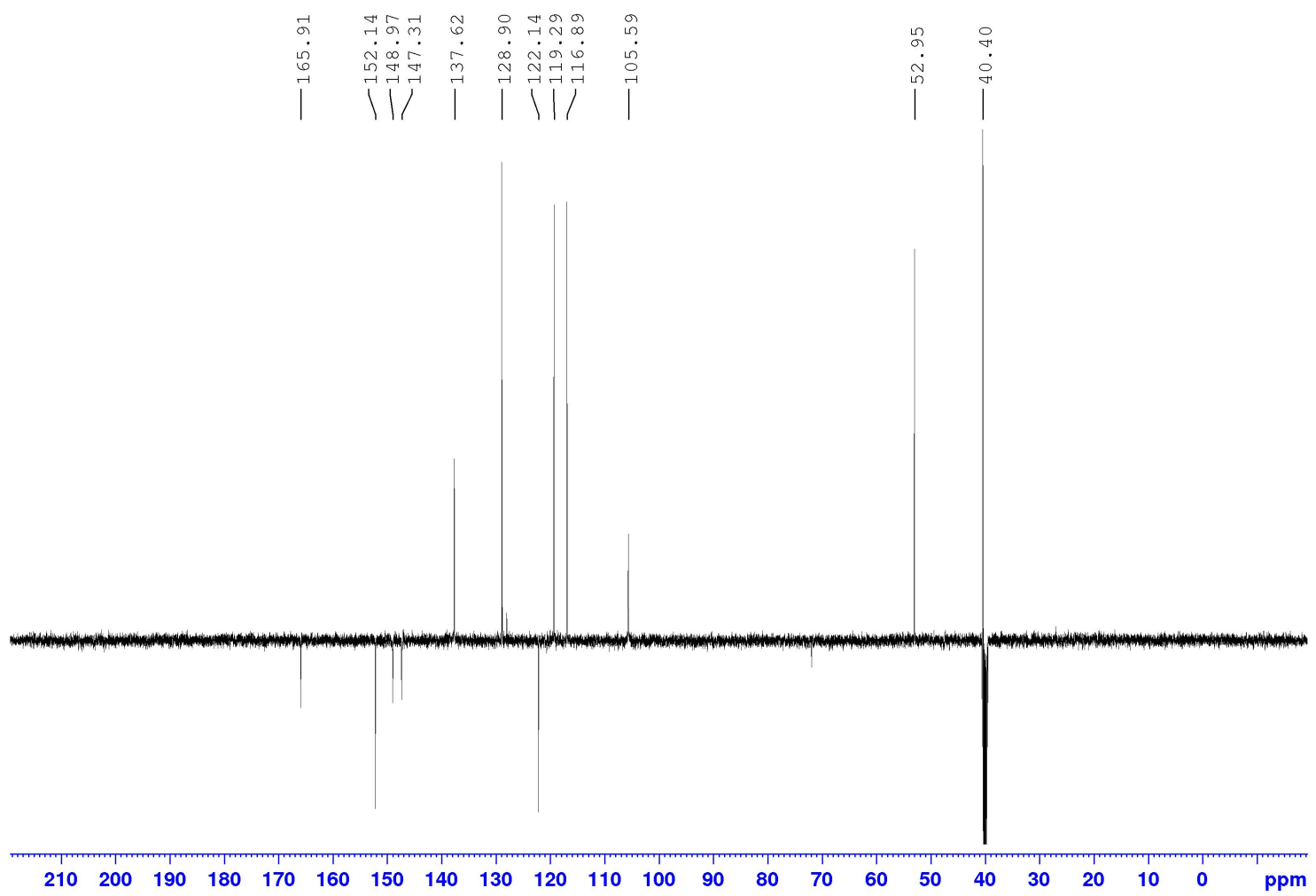


${ }^{1}$ H NMR: 6,7-Dimethoxy-quinaldic Acid (10)<smiles>COc1cc2ccc(C(=O)O)nc2cc1OC</smiles>

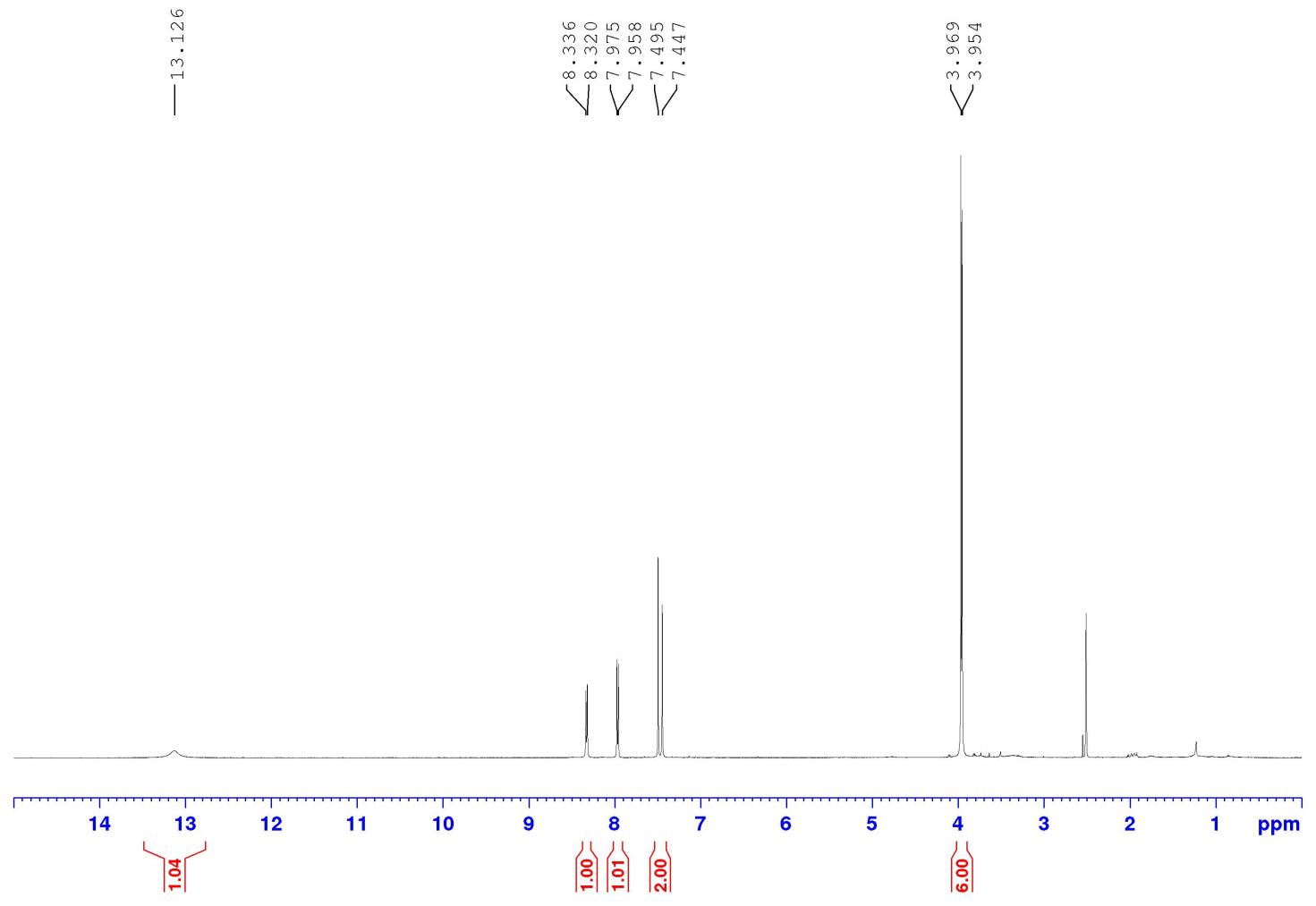


${ }^{13}$ C NMR: 6,7-Dimethoxy-quinaldic Acid (1o)<smiles>COc1cc2ccc(C(=O)O)nc2cc1OC</smiles>

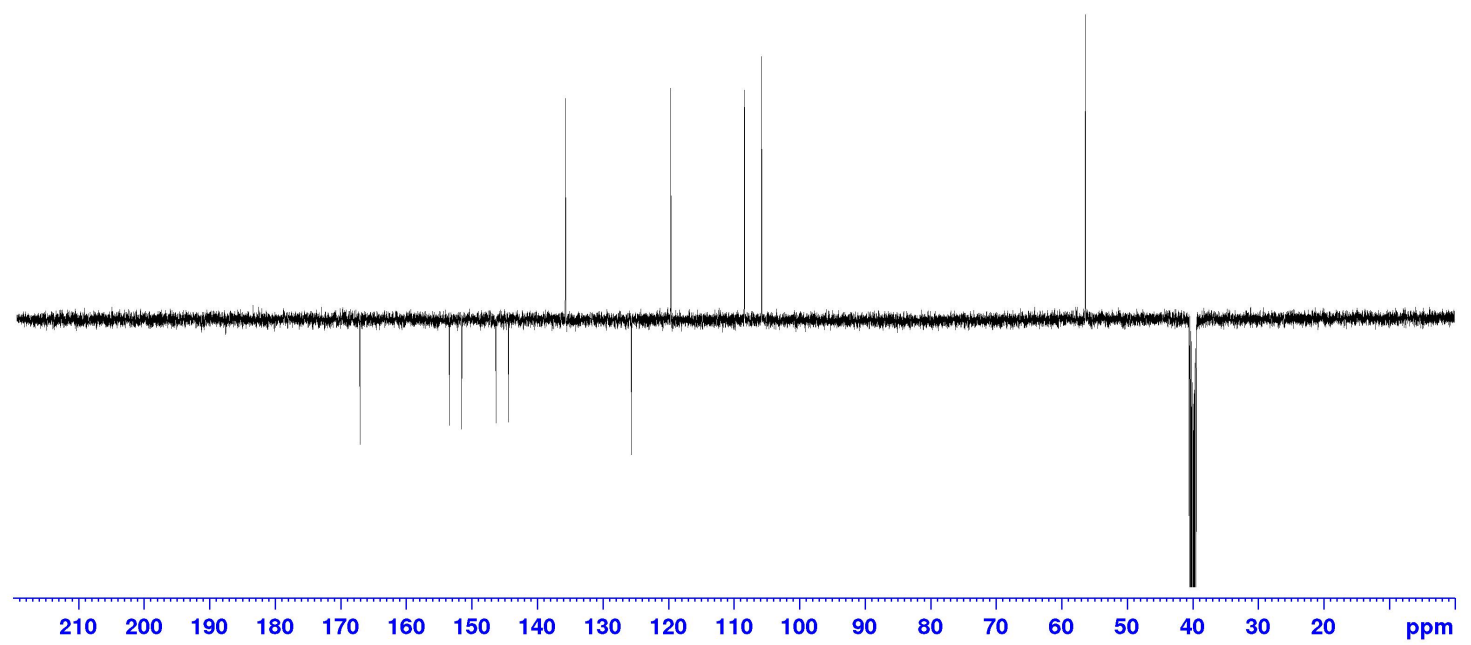


${ }^{1}$ H NMR: 6,8-Dibromo-2-quinaldic Acid (1p)<smiles>O=C(O)c1ccc2cc(Br)cc(Br)c2n1</smiles>

${ }^{13}$ C NMR: 6,8-Dibromo-2-quinaldic Acid (1p)<smiles>O=C(O)c1ccc2cc(Br)cc(Br)c2n1</smiles>
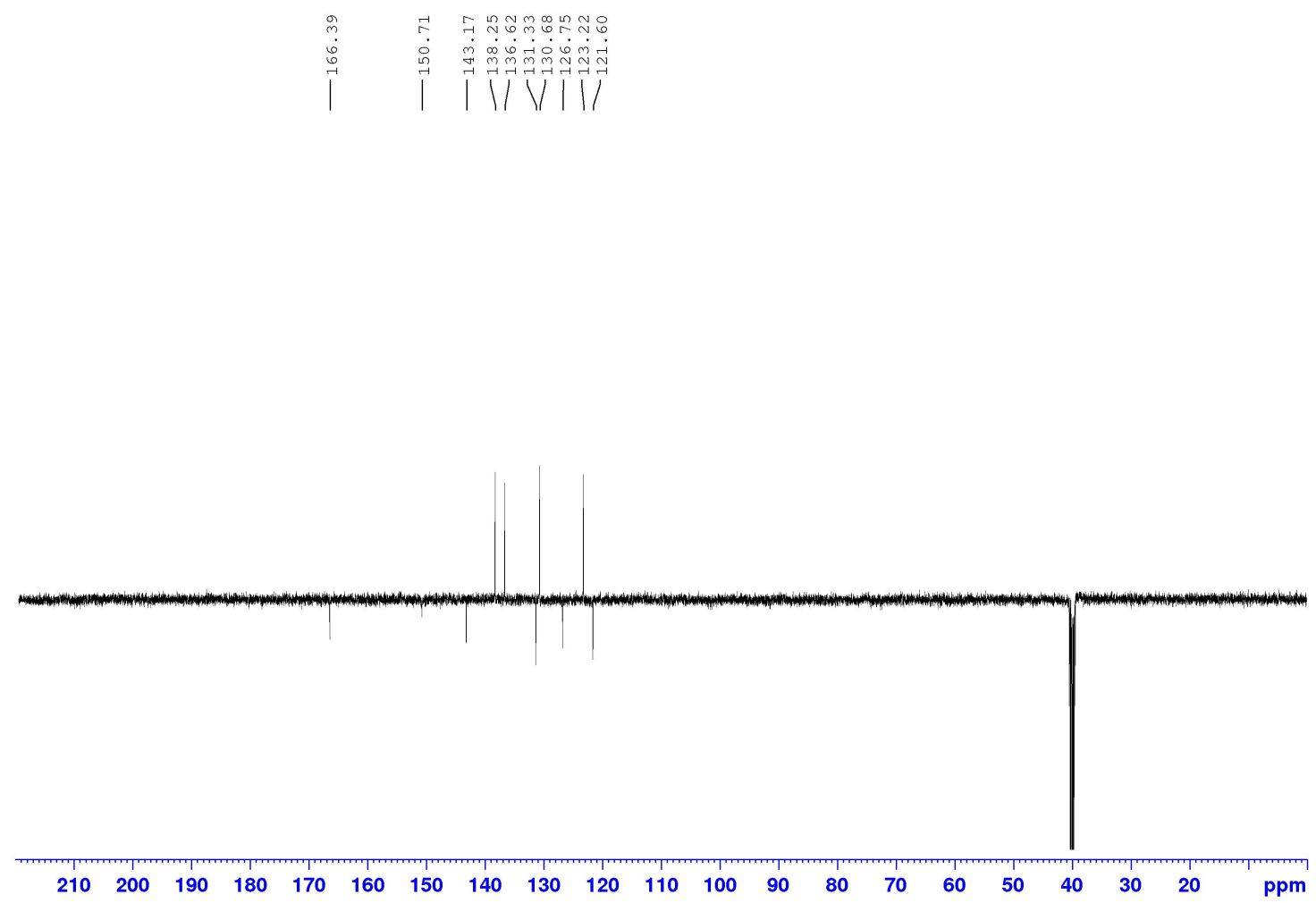
${ }^{1} \mathrm{H}$ NMR of Reaction Mixture: 2-AB to 2-QA after 0.083-minute NahE incubation

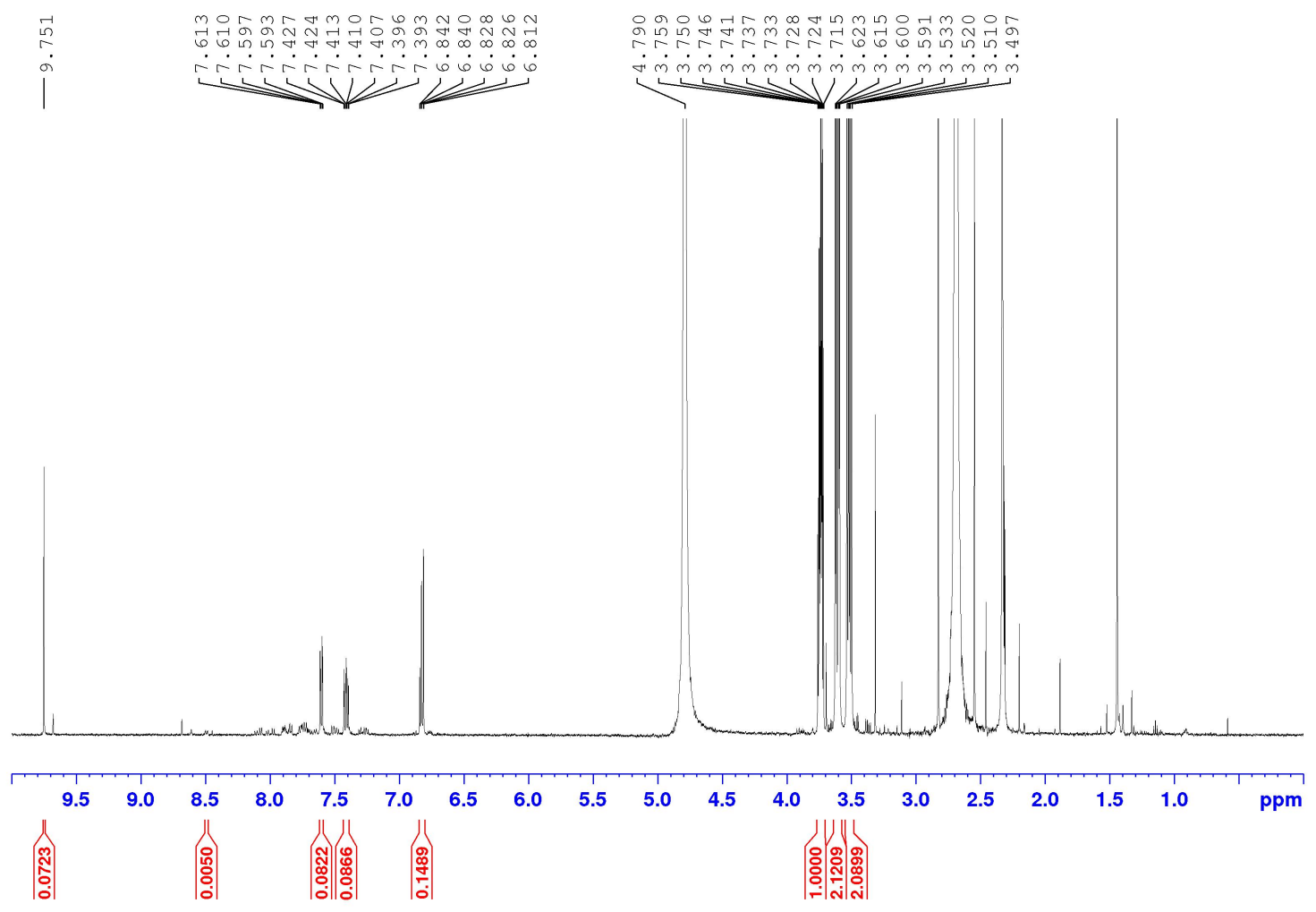


${ }^{1} \mathrm{H}$ NMR of Reaction Mixture: 2-AB to 2-QA after 0.25-minute NahE incubation

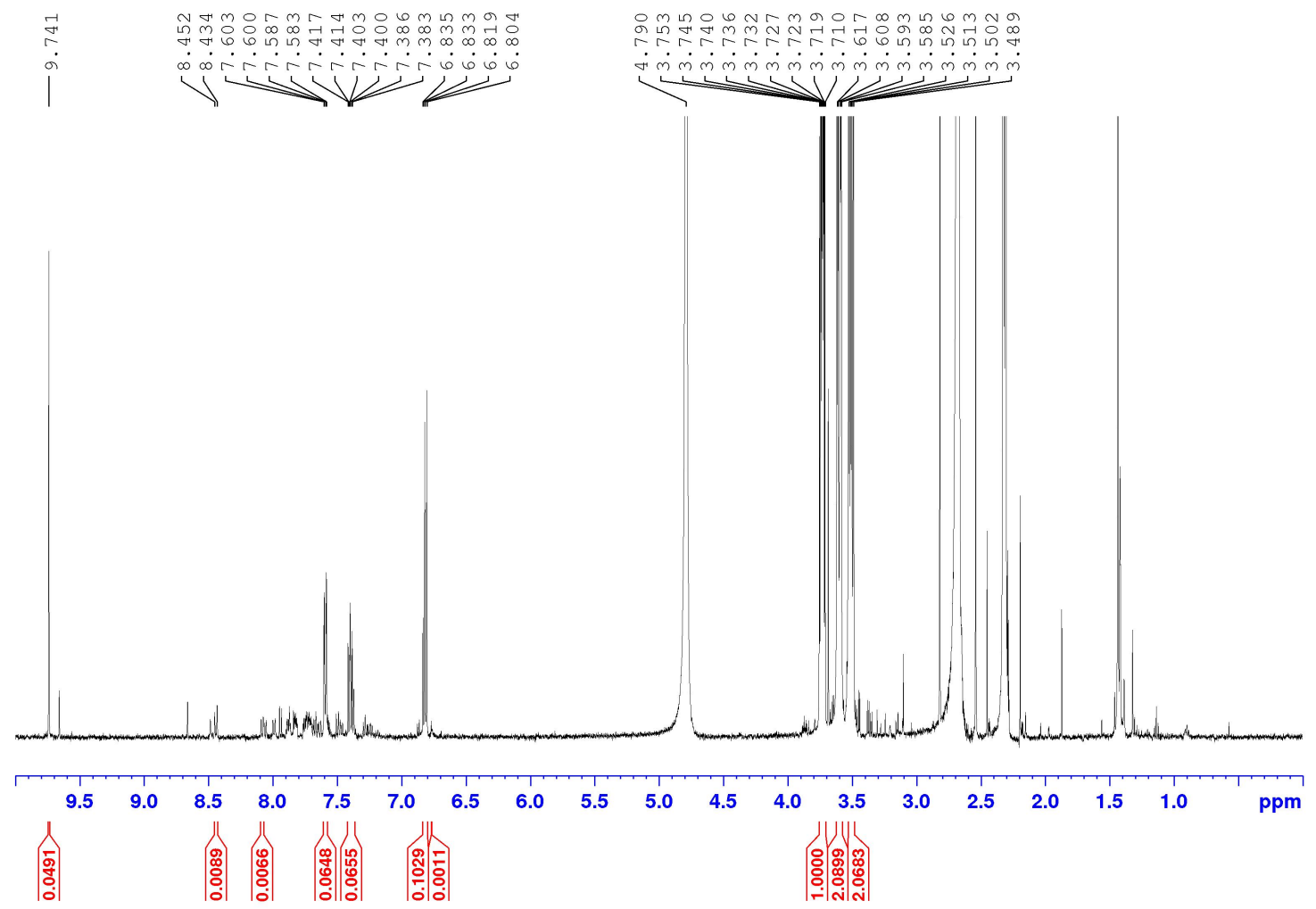




\section{${ }^{1} \mathrm{H}$ NMR of Reaction Mixture: 2-AB to 2-QA after 0.75-minute NahE incubation}

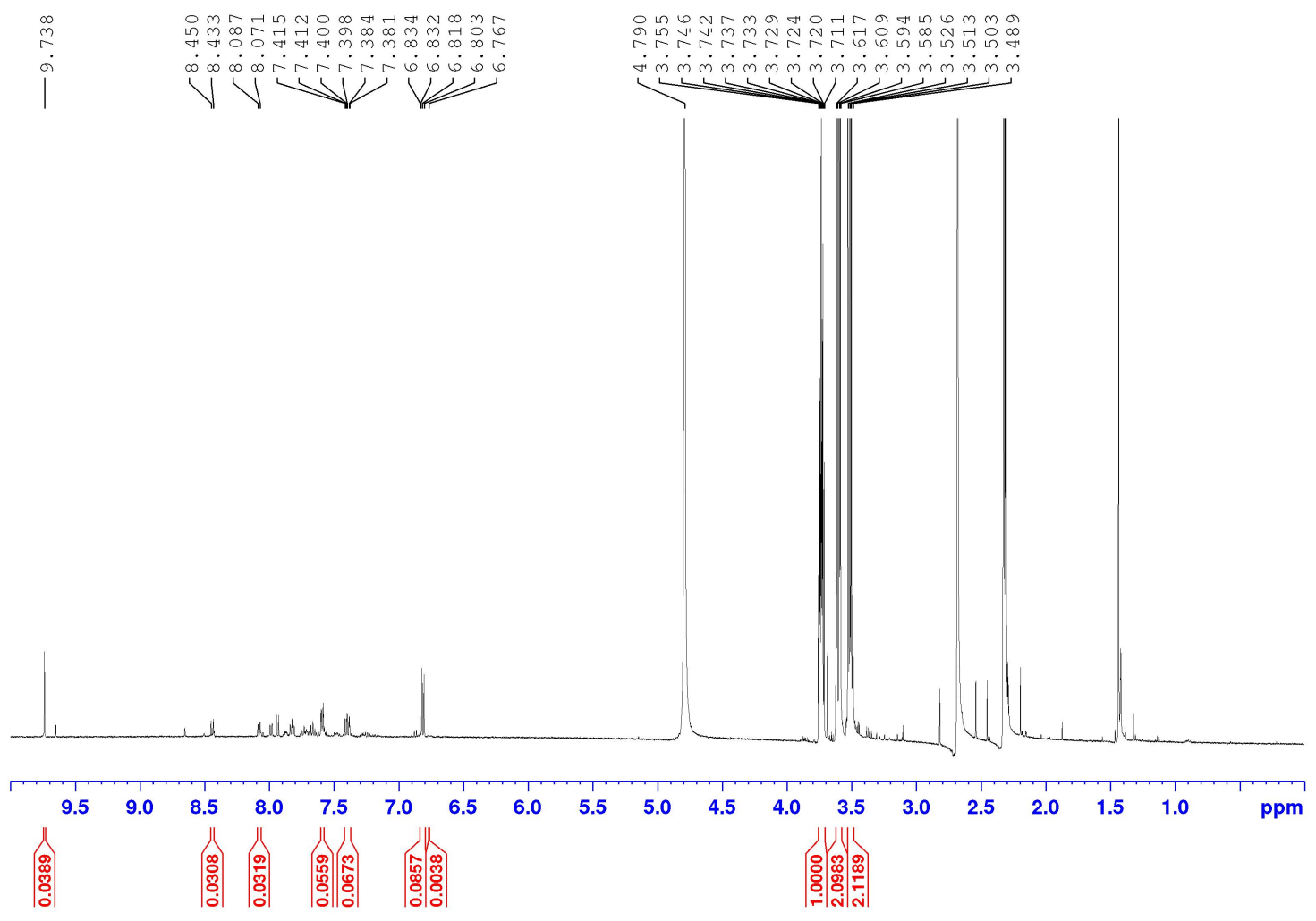


${ }^{1}$ H NMR of Reaction Mixture: 2-AB to 2-QA after 2.33-minute NahE incubation

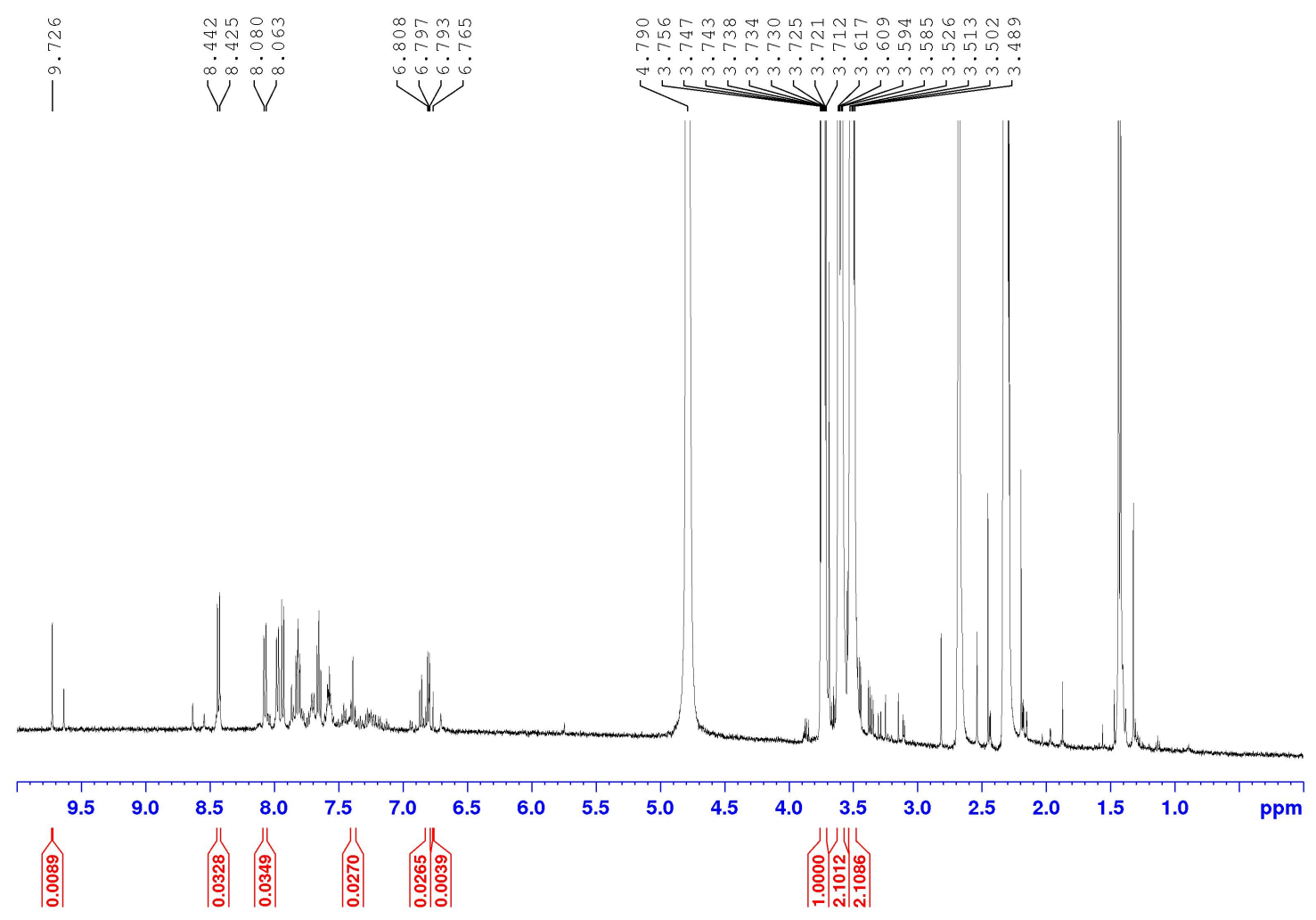


${ }^{1} \mathrm{H}$ NMR of Reaction Mixture: 2-AB to 2-QA after 4.33-minute NahE incubation




${ }^{1} \mathrm{H}$ NMR of Reaction Mixture: 2-AB to 2-QA after 10-minute NahE incubation

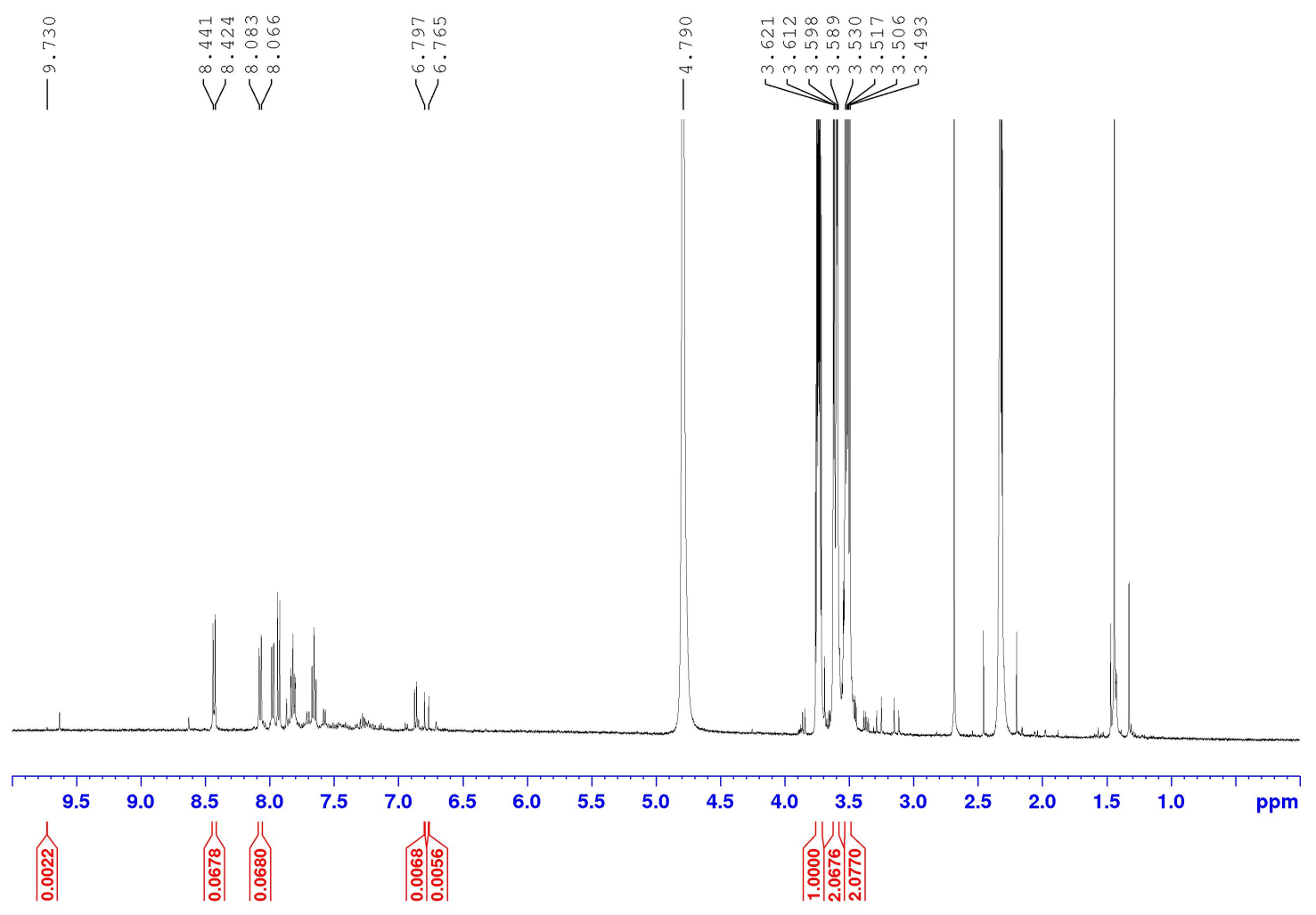


${ }^{1} \mathrm{H}$ NMR of Reaction Mixture: 2-AB to 2-QA after 1440-minute NahE incubation

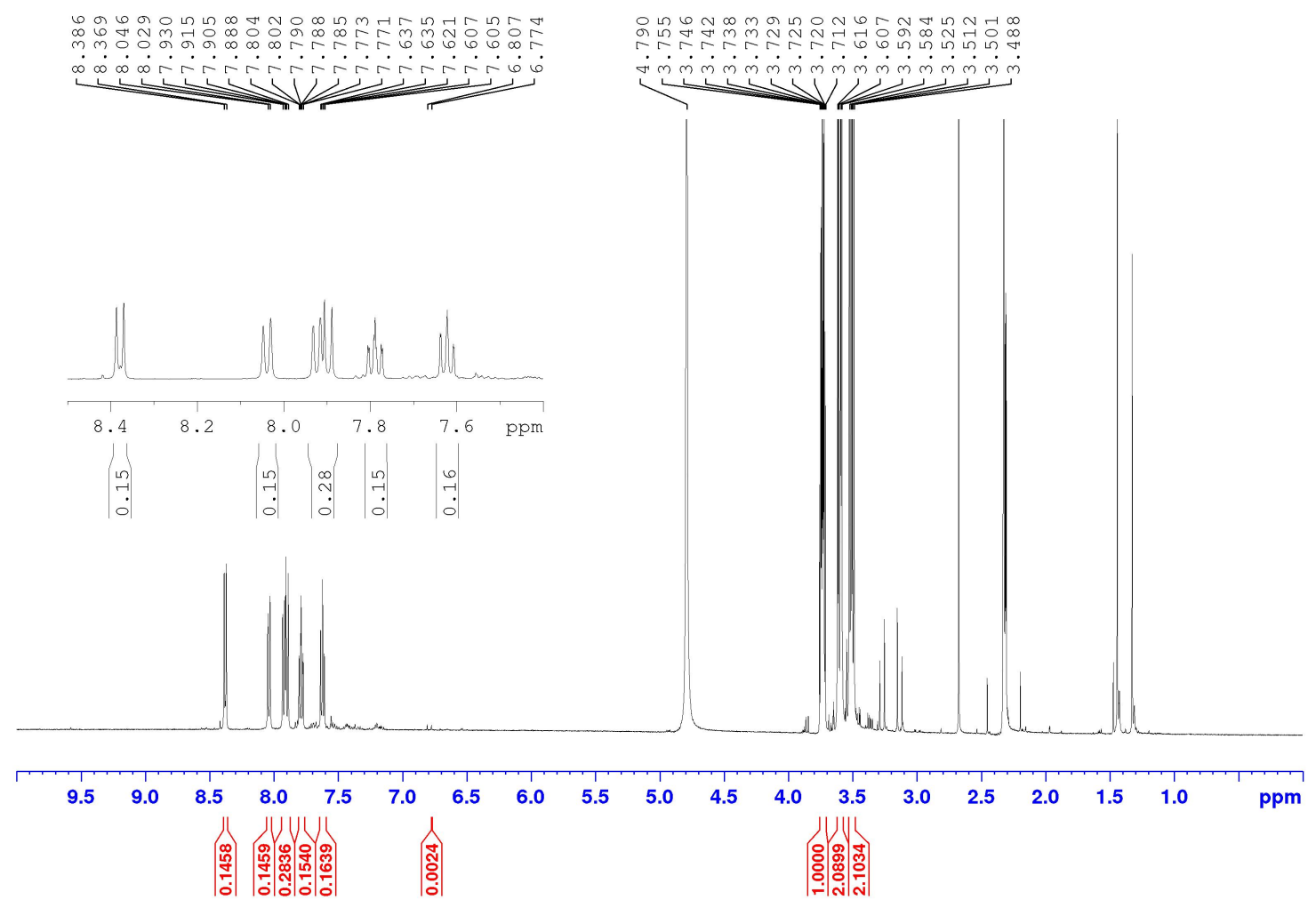




\section{References:}

(1) Howard, J. K.; Müller, M.; Berry, A.; Nelson, A. An Enantio- and Diastereoselective Chemoenzymatic Synthesis of $\alpha$-Fluoro $\beta$-Hydroxy Carboxylic Esters. Angew. Chemie Int. Ed. 2016, 55 (23), 6767-6770.

(2) Roberts, S. J.; Morris, J. C.; Dobson, R. C. J.; Baxter, C. L.; Gerrard, J. A. Two Complete Syntheses of (S)-Aspartate Semi-Aldehyde and Demonstration That $\Delta 2$ Tetrahydroisophthalic Acid Is a Non-Competitive Inhibitor of Dihydrodipicolinate Synthase. Arkivoc 2004, 2004 (10), 166-177.

(3) Rajeshwaran, G. G.; Mohanakrishnan, A. K. Synthetic Studies on Indolocarbazoles: A Facile Synthesis of Staurosporinone Analogues. Org. Lett. 2011, 13 (6), 1418-1421.

(4) Ashburn, B. O.; Rathbone, L. K.; Camp, E. H.; Carter, R. G. A Diels-Alder Approach to Biaryls (DAB): Synthesis of the Western Portion of TMC-95. Tetrahedron 2008, 64 (5), 856-865.

(5) Patrick, D. A.; Bakunov, S. A.; Bakunova, S. M.; Kumar, E. V. K. S.; Lombardy, R. J.; Jones, S. K.; Bridges, A. S.; Zhirnov, O.; Hall, J. E.; Wenzler, T.; et al. Synthesis and in Vitro Antiprotozoal Activities of Dicationic 3,5-Diphenylisoxazoles. J. Med. Chem. 2007, 50 (10), 2468-2485.

(6) Diedrich, C. L.; Haase, D.; Saak, W.; Christoffers, J. Regioselectivity of Friedländer Quinoline Syntheses. European J. Org. Chem. 2008, No. 10, 1811-1816.

(7) Filace, F.; Sánchez-Murcia, P. A.; Sucunza, D.; Pérez-Redondo, A.; Álvarez-Búlla, J.; Gago, F.; Burgos, C. Silyl Assistance in the Intramolecular Addition of Pyridyl Radicals onto Pyridines and Quinolines. European J. Org. Chem. 2016, 2016 (10), 1891-1896.

(8) Houghton, D. T.; Arulsamy, N.; Mehn, M. P. Synthesis and Characterization of Iron(II) Quinaldate Complexes. Inorg. Chem. 2010, 49 (3), 879-887.

(9) 6-Bromoquinoline-2-carboxylic acid https://www.ambeed.com/products/65148-10-9.html.

(10) 7-Bromoquinoline-2-carboxylic acid https:/www.ambeed.com/products/1057217-636.html.

(11) Ashimori, Atsuyuki Yoshida, T.; Ono, S.; Eda, M.; Kosaka, K.; Mori, F.; Inoe, Y.; Imada, M.; Ikegawa, R. Preparation of Naphthalene and Quinoline Derivatives as Glycoprotein GP IIb/IIa Antagonists. JP 07179407. 
(12) St. Laurent, D. R.; Serrano-Wu, M. H.; Belema, M.; Ding, M.; Fang, H.; Gao, M.; Goodrich, J. T.; Krause, R. G.; Lemm, J. A.; Liu, M.; et al. HCV NS5A Replication Complex Inhibitors. Part 4.1 Optimization for Genotype 1a Replicon Inhibitory Activity. J. Med. Chem. 2014, 57 (5), 1976-1994.

(13) Dobson, R. C. J.; Griffin, M. D. W.; Roberts, S. J.; Gerrard, J. A. Dihydrodipicolinate synthase (DHDPS) from Escherichia coli displays partial mixed inhibition with respect to its first substrate, pyruvate. Biochimie 2004, 86, 311-315. 